\title{
Report on The Down-Selected
} Nanoprecipitates-Strengthened Advanced Ferritic Alloys for Nuclear Reactor Applications

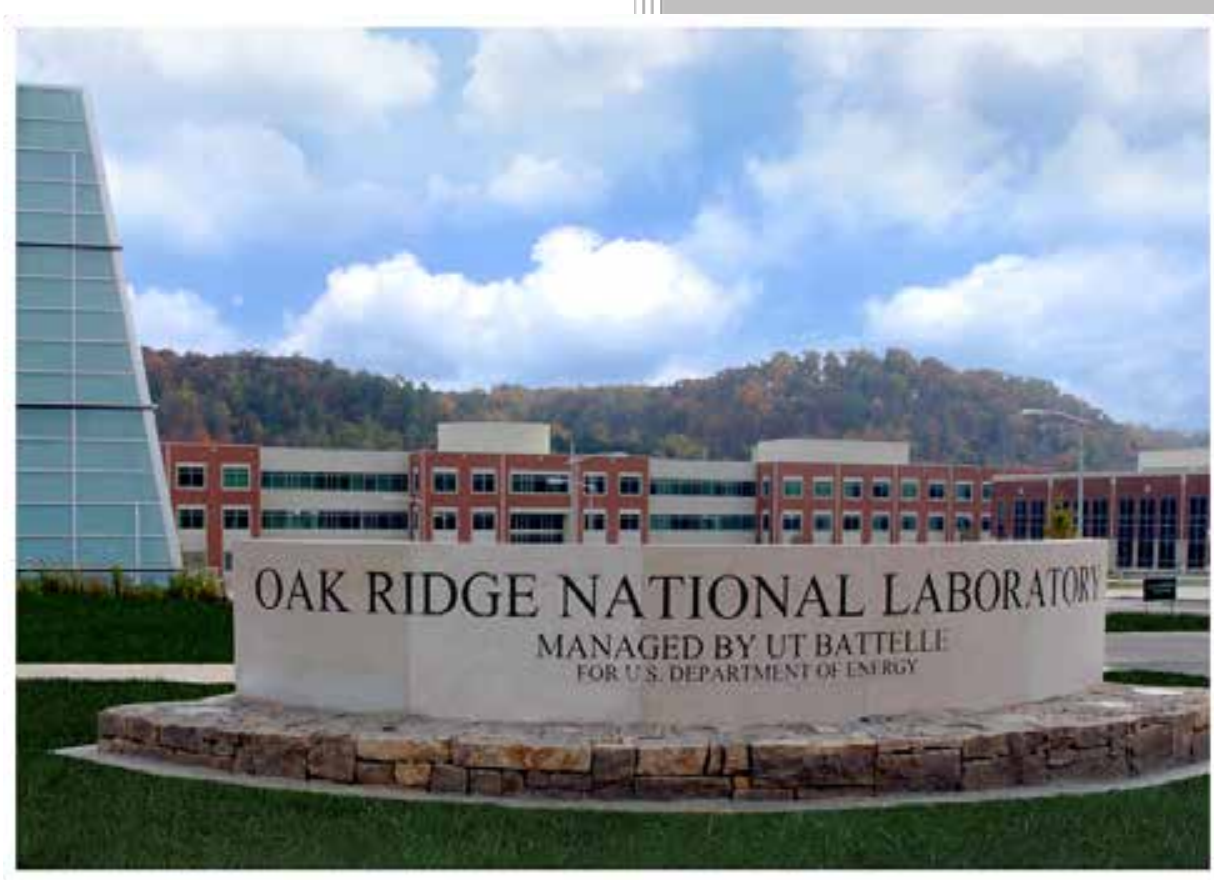

Approved for public release. Distribution is unlimited.
Lizhen Tan

Tianyi Chen

Ying Yang

Oak Ridge National Laboratory

$\mathrm{Li} \mathrm{He}$

Kumar Sridharan

University of Wisconsin-Madison

February 28, 2019 


\title{
DOCUMENT AVAILABILITY
}

Reports produced after January 1, 1996, are generally available free via US Department of Energy (DOE) SciTech Connect.

Website www.osti.gov

Reports produced before January 1,1996, may be purchased by members of the public from the following source:

\author{
National Technical Information Service \\ 5285 Port Royal Road \\ Springfield, VA 22161 \\ Telephone 703-605-6000 (1-800-553-6847) \\ TDD 703-487-4639 \\ Fax 703-605-6900 \\ E-mail info@ntis.gov \\ Website http://classic.ntis.gov/
}

Reports are available to DOE employees, DOE contractors, Energy Technology Data Exchange representatives, and International Nuclear Information System representatives from the following source:

Office of Scientific and Technical Information

PO Box 62

Oak Ridge, TN 37831

Telephone 865-576-8401

Fax 865-576-5728

E-mail reports@osti.gov

Website http://www.osti.gov/contact.html

This report was prepared as an account of work sponsored by an agency of the United States Government. Neither the United States Government nor any agency thereof, nor any of their employees, makes any warranty, express or implied, or assumes any legal liability or responsibility for the accuracy, completeness, or usefulness of any information, apparatus, product, or process disclosed, or represents that its use would not infringe privately owned rights. Reference herein to any specific commercial product, process, or service by trade name, trademark, manufacturer, or otherwise, does not necessarily constitute or imply its endorsement, recommendation, or favoring by the United States Government or any agency thereof. The views and opinions of authors expressed herein do not necessarily state or reflect those of the United States Government or any agency thereof. 
FY 2015 Consolidated Innovative Nuclear Research (CINR)

Nuclear Energy Enabling Technologies (NEET): Reactor Materials

\title{
REPORT ON THE DOWN-SELECTED NANOPRECIPITATES-STRENGTHENED ADVANCED FERRITIC ALLOYS FOR NUCLEAR REACTOR APPLICATIONS
}

\author{
Lizhen Tan, Tianyi Chen and Ying Yang \\ Oak Ridge National Laboratory \\ Li He and Kumar Sridharan \\ University of Wisconsin-Madison
}

Date Published: February 28, 2019

Prepared by

OAK RIDGE NATIONAL LABORATORY

Oak Ridge, TN 37831-6283

managed by

UT-BATTELLE, LLC

for the

US DEPARTMENT OF ENERGY

under contract DE-AC05-00OR22725 



\section{CONTENTS}

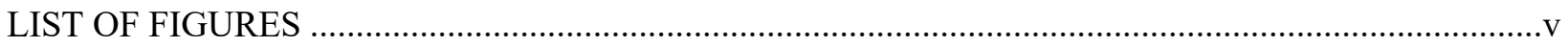

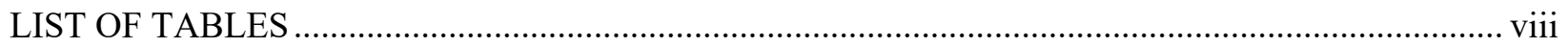

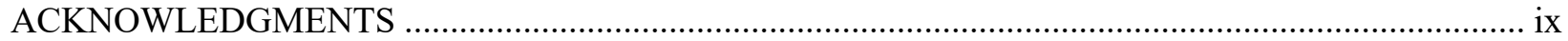

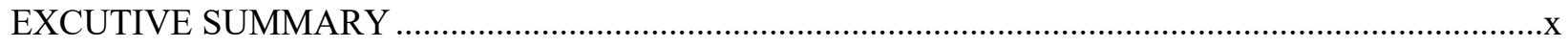

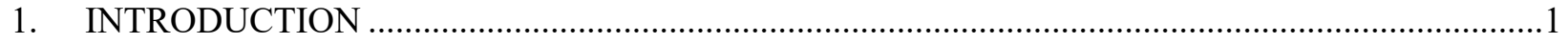

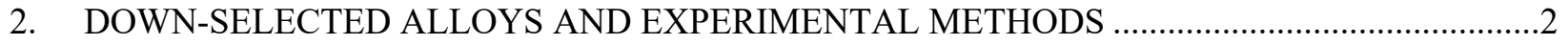

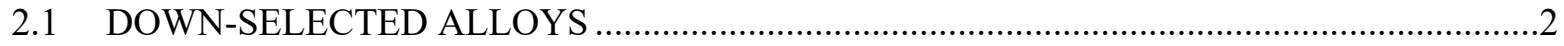

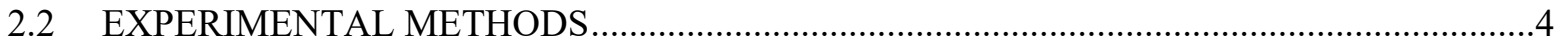

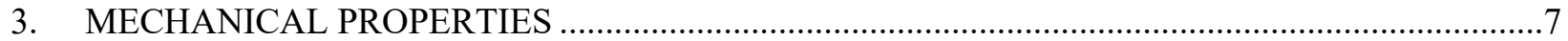

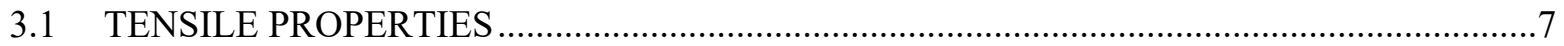

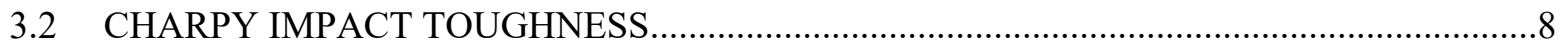

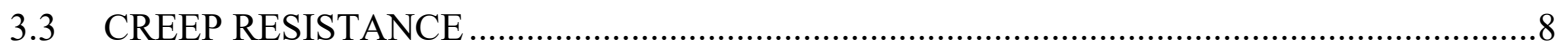

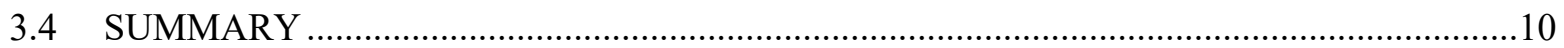

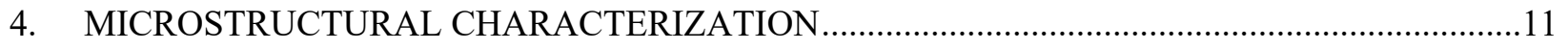

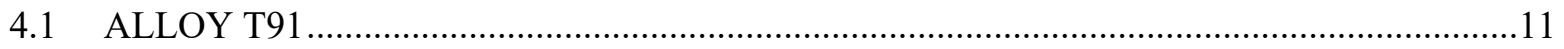

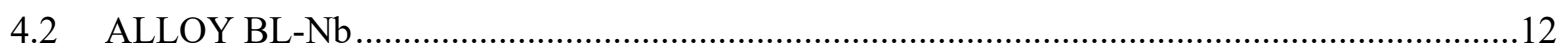

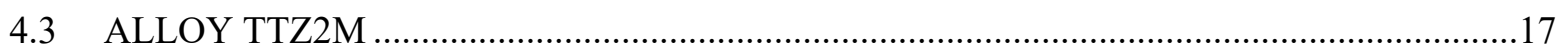

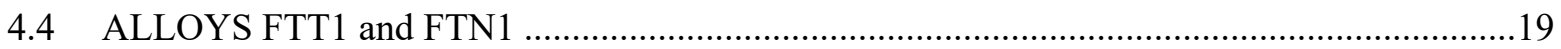

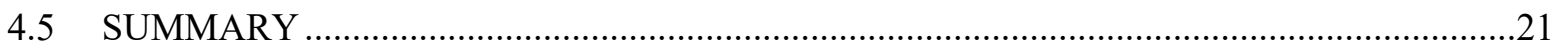

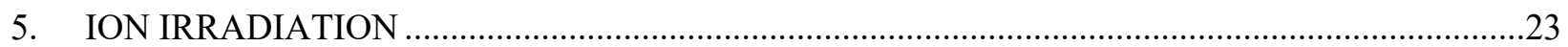

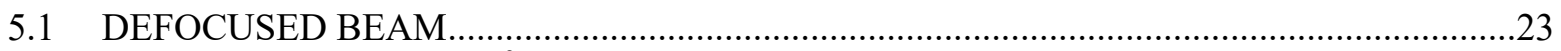

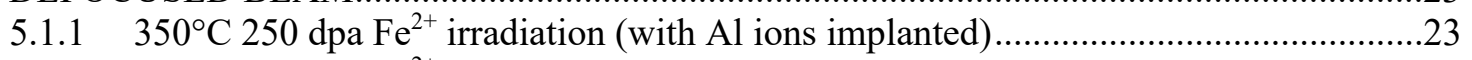

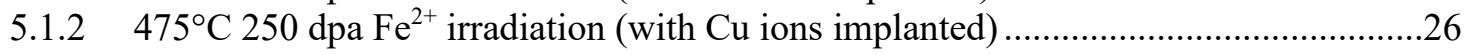

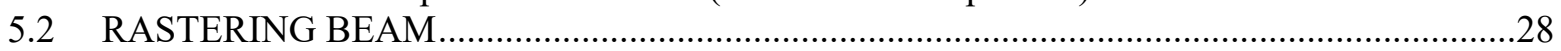

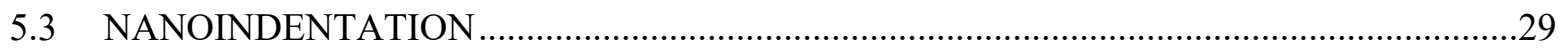

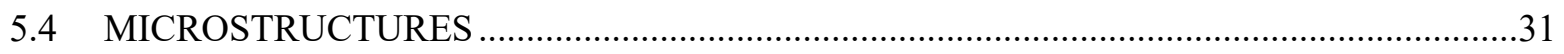

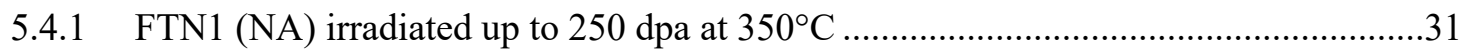

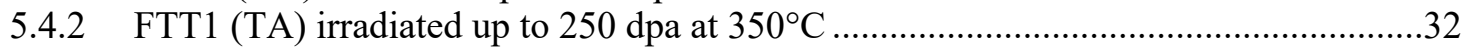

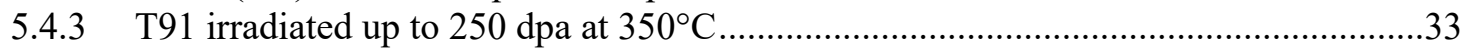

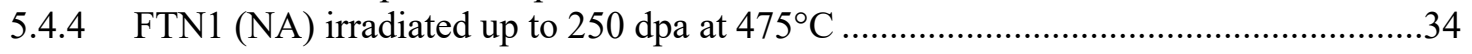

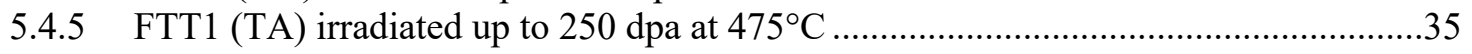

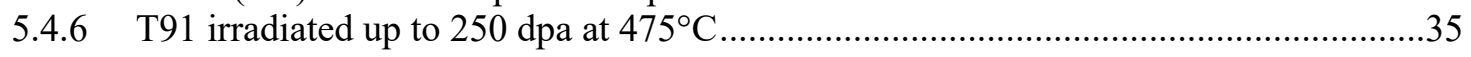

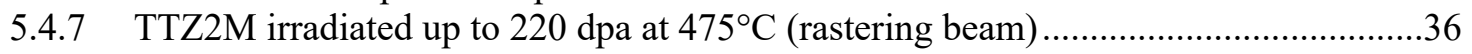

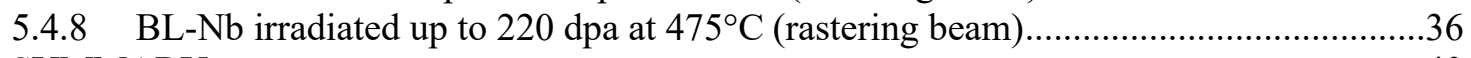

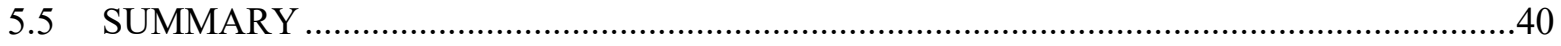

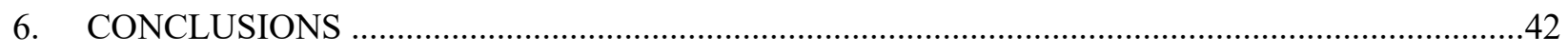

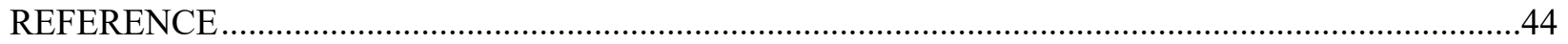




\section{LIST OF FIGURES}

Figure 1. Calculated temperature-dependent phase fractions in alloys (a) BL-Nb, (b) FTN1 (NA),

(c) FTT1 (TA), and (d) T91.

Figure 2. Temperature-dependent dilatometer determined phase transformation temperatures of

FTN1 (NA) and FTT1 (TA).....

Figure 3. Geometry of type SS-3 miniature specimens for tensile and creep tests.....................................5

Figure 4. Geometry of half-size Charpy specimen for impact toughness testing. .....................................5

Figure 5. Temperature-dependent (a) yield strength, (b) tensile strength, (c) uniform elongation, and $(\mathrm{d})$ total elongation of the ferritic (BL-Nb) and ferritic-martensitic (TTZ2M, FTN1, and FTT1) steels, compared to literature data of P91. FTN1-T and FTT1-T are a heattreated version of FTN1 and FTT1, respectively.

Figure 6. Temperature-dependent Charpy absorbed energy of the ferritic (BL-Nb) and ferriticmartensitic (TTZ2M, FTN1, FTT1, and the heat-treated version FTN1-T and FTT1-T) steels, compared to literature data of Grade 91 heat 30176.

Figure 7. Creep strain-time curves for the down-selected alloys BL-Nb, TTZ2M, FTN1, and FTT1 compared with $\mathrm{T} 91$ tested at $650^{\circ} \mathrm{C}$ and $120 \mathrm{MPa}$ (dashed) and $100 \mathrm{MPa}$ (solid)..............9

Figure 8. Stress-dependent minimum creep rates of alloys BL-Nb, TTZ2M, FTN1, and FTT1 compared with $\mathrm{T} 91$ tested at $650^{\circ} \mathrm{C}$.

Figure 9. (a-c) HAADF images of the tab-section T91 creep-tested at $650^{\circ} \mathrm{C}$ and $100 \mathrm{MPa}$ and (df) EDS maps of (c).

Figure 10. BF-STEM images with the [001] zone from the gauge section of T91 creep-tested at $650^{\circ} \mathrm{C}$ and (a) 120 and (b) $100 \mathrm{MPa}$.

Figure 11. (a) BF-STEM and (b) HAADF images near the [001] zone of the bcc matrix in the gauge section of the BL-Nb sample creep-tested at $650^{\circ} \mathrm{C}$ and $100 \mathrm{MPa}$.

Figure 12. (a) BF-STEM and (b) HAADF images near the [001] zone of the bcc matrix in the gauge section of the BL-Nb sample creep-tested at $650^{\circ} \mathrm{C}$ and $100 \mathrm{MPa}$.

Figure 13. (a) BF and (b-d) DF TEM images in the gauge section of the BL-Nb sample creeptested at $650^{\circ} \mathrm{C}$ and $100 \mathrm{MPa}$.

Figure 14. (a) An electron diffraction pattern obtained from the matrix of the as-received sample.

(b) Dark field image of the coherent precipitates. The EDS mappings of (c) Ni and (d) Al

of the as-received sample, and the Ni mappings from the (e) thermal-aged and (f)

deformed regions of the $120 \mathrm{MPa}$ creep sample, and the (g) thermal-aged and (h)

deformed regions of the $100 \mathrm{MPa}$ creep sample.

Figure 15. Time-dependent radius (R) in cubic power of B2-NiAl particles under the thermal aging and stressed conditions at $650^{\circ} \mathrm{C}$.

Figure 16. EDS analyzed relative $\mathrm{Ni}-\mathrm{Al}$ ratio of $\mathrm{B} 2-\mathrm{NiAl}$ particles at the as-received condition and the $650^{\circ} \mathrm{C}$ aged and stressed conditions.

Figure 17. The precipitates of the Laves phase in the bcc matrix presented in (a) bright field image, (b) electron diffraction pattern of the [111] zone of the matrix, (c) DF image from the spot marked by the circle in (b), and (d) dark field image from the spot marked by the square in (b).

Figure 18. The precipitates of the laves phase presented in: (a) and (d) high-angle annular darkfield (HAADF) image, (b) and (e) EDS mapping of Nb, and (c) and (f) EDS mapping of $\mathrm{W}$, for (a-c) the as-received condition and (d-f) the 1852-hour thermal-aged and stressed condition.

Figure 19. The evolution of $\mathrm{W}-\mathrm{Nb}$ atomic ratio in the Laves precipitates.

Figure 20. (a) BF and (b) DF images showing the microstructure and precipitate distributions in the as-received TTZ2M alloy.... 
Figure 21. (a-c) HAADF images of TTZ2M creep-tested at $650^{\circ} \mathrm{C}$ and $100 \mathrm{MPa}$ and (d) EDS map of (c).

Figure 22. BF-STEM images imaged with the [001] zone from the gauge section of TTZ2M creep-tested at $650^{\circ} \mathrm{C}$ and (a) 120 and (b) $100 \mathrm{MPa}$.

Figure 23. Optical micrographs of (a) FTT1 and (b) FTN1 and their heat-treated version (c) FTT1-T and (d) FTN1-T.

Figure 24. Optical micrograph of FTN1-T showing overall grain structure.

Figure 25. Creep-tested FTT 1 at $650^{\circ} \mathrm{C}$ and $100 \mathrm{MPa}$ : (a) BF-TEM image at the tab section, (b) BF-TEM image at the gauge section, (c) DF-TEM image at the gauge section, and (d) BF-STEM image at the gauge section.

Figure 26. 3.7 MeV iron induced damage and implanted iron concentration in FTN1 (NA), FTT1 (TA), T91 (red). The damage and implantation depth profiles were calculated using the Kinchin-Pease Model in the Stopping and Range of Ions in Matter (SRIM) software. Ed is atom displacement energy.

Figure 27. Temperature and flux during $3.7 \mathrm{MeV}$ iron $350^{\circ} \mathrm{C}$ irradiation. (a) Irradiation run 1 of FTT1 (TA); (b) Irradiation run 2 of FTN1 (NA) and T91.

Figure 28. Samples after $350^{\circ} \mathrm{C}, 250 \mathrm{dpa} \mathrm{Fe}{ }^{2+}$ irradiation. (a) Run 1 of FTT1 (TA). (b) Run 2 of T91 and FTN1 (NA). Arrows indicate irradiation boundary. The lower part of T91 and upper part of FTN1 (NA) are irradiated.

Figure 29. Al implantation in the $350^{\circ} \mathrm{C}$ irradiated FTN1 (NA) and T91 samples. ABF images of cross-sectional (a) FTN1 (NA) and (b) T91 with the red lines illustrating the EDS line scan paths for the (c) EDS depth profile and SRIM calculated Al composition from surface.

Figure 30. Temperature and flux during $3.7 \mathrm{MeV}$ iron $475^{\circ} \mathrm{C}$ irradiation. (a) Irradiation run 3 of FTT1 (TA). (b) Irradiation run 4 of FTN1 (NA) and T91.

Figure 31. Samples after $475^{\circ} \mathrm{C}, 250$ dpa Fe ${ }^{2+}$ irradiation: (a) FTT1 (TA); (b) FTN1 (NA); (c) T91. Arrows indicate irradiation area.

Figure 32. (a) Cross-sectional ABF image and (b) EDS line scan profile across the red line in (a) of $\mathrm{Fe}^{2+}$-irradiated FTN1 (NA) up to 250 dpa at $475^{\circ} \mathrm{C}$ showing $\mathrm{Cu}$-rich particles at $\sim 1.1$ $\mu \mathrm{m}$ depth.

Figure 33. $4 \mathrm{MeV}$ iron induced damage in BL-Nb (79Fe-12Cr-3W-3Ni-3 Al). The damage and implantation profiles were calculated using the Kinchin-Pease Model in the SRIM software. $E d$ is atom displacement energy.

Figure 34. Temperature and flux during $4 \mathrm{MeV}$ iron irradiation (a) run 1 and (b) run 2 of BL-Nb.

Figure 35. Nanoindentation hardness of ion-irradiated samples: defocused-beam up to 250 dpa at $350^{\circ} \mathrm{C}$ for (a) FTN1 (NA) and (b) T91 and at $475^{\circ} \mathrm{C}$ for (c) FTN1 (NA) and (d) T91; rastered-beam up to $220 \mathrm{dpa}$ at $475^{\circ} \mathrm{C}$ for (e) TTZ2M and (f) BL-Nb.....

Figure 36. Cross-sectional ABF images of FTN1 (NA) after $350^{\circ} \mathrm{C}$ ion irradiation: (a) Overview and (b) Damaged region at $0.54 \mu \mathrm{m}$ depth with normal direction parallel to [100].

Figure 37. Precipitates in FTN1 (NA): (a) Undamaged region with the arrow-pointed 1 as $(\mathrm{Cr}, \mathrm{W})_{23} \mathrm{C}_{6}$ and 2 as a Ti, W, Nb-rich carbide; (b) Damaged region at $0.54 \mu \mathrm{m}$ showing the particles of $\mathrm{M}_{23} \mathrm{C}_{6}$.

Figure 38. Cross-sectional ABF images of FTT1 (TA) after $350^{\circ} \mathrm{C}$ ion irradiation: (a) Overview and (b) Damaged region at $0.5 \mu \mathrm{m}$ depth with normal direction parallel to [100].

Figure 39. DF image showing MX type precipitates in FTT1 (TA) after $350^{\circ} \mathrm{C}$ ion irradiation at $0.6 \mu \mathrm{m}$ depth.

Figure 40. Cross-sectional ABF images of T91 after irradiation up to 250 dpa at $350^{\circ} \mathrm{C}$ : (a) Overview and (b) Dislocation loops under $<111>$ zone at an irradiation depth of $0.55 \mu \mathrm{m}$..........33

Figure 41. Precipitates in T91. (a) Undamaged. (b) $350{ }^{\circ} \mathrm{C}$ irradiation damaged region. 1 is $\mathrm{M}_{23} \mathrm{C}_{6} .2$ is $\mathrm{V}, \mathrm{Nb}$-rich $\mathrm{MX}$. 
Figure 42. Cross-sectional ABF images of FTN1 (NA) irradiated up to 250 dpa at $475^{\circ} \mathrm{C}$ : (a) Overview of damaged (top part) and undamaged structure; (b) $<100>$ dislocation loops at $0.55 \mu \mathrm{m}$ depth.

Figure 43. Cross-sectional ABF images of FTT1 (TA) irradiated up to 250 dpa at $475^{\circ} \mathrm{C}$ : (a) Overview of damaged (top part) and undamaged structure; (b) Dislocation loops at 0.7 $\mu \mathrm{m}$ depth and (c) corresponding selected area diffraction pattern.

Figure 44. Cross-sectional HAADF image of T91 irradiated up to $250 \mathrm{dpa}$ at $475^{\circ} \mathrm{C}$ along the $<111>$ zone. Arrow indicates damage depth

Figure 45. TTZ2M irradiated up to $250 \mathrm{dpa}$ at $475^{\circ} \mathrm{C}$ along the $<111>$ zone: (a) BF-TEM overview image and (b-c) ABF-STEM images at $\sim 0.6 \mu \mathrm{m}$ depth.

Figure 46. B2-NiAl precipitates in the unirradiated region: (a) DF-TEM image from the [100] zone as indicated in the electron diffraction pattern of the inset, (b) HAADF image, and (c) EDS line scan compositional profiles across the particle pointed by the arrow in (b).

Figure 47. Images of B2-NiAl particles in the irradiated region: DF-TEM images at (a) 0.15-0.6 $\mu \mathrm{m}$ depth and (b) 1.15-1.6 $\mu \mathrm{m}$ depth. The images were taken with the (001) $)_{\mathrm{NiAl}}$ diffraction from the [100] zone axis as shown in the inset of (a); (c) HAADF image at $0.86 \mu \mathrm{m}$ from surface with the inset of an FFT of the original image.....

Figure 48. TEM characterization of BL-Nb after $\mathrm{Fe}^{2+}$ ion irradiation up to $220 \mathrm{dpa}$ at $475^{\circ} \mathrm{C}$ : (a-b) Cross-sectional ABF images along $<100>$; (c) Nanobeam electron diffraction of particle $A$ in (b) with red and blue circles indicating matrix and particle diffraction spots, respectively; (d) EDS measured compositional profile along particle B in (b).

Figure 49. TEM characterization of irradiated particles in $\mathrm{BL}-\mathrm{Nb}$ after $\mathrm{Fe}^{2+}$ ion irradiation up to $220 \mathrm{dpa}$ at $475^{\circ} \mathrm{C}$ : (a) $\mathrm{ABF}$ image along $<100>$ with the image center at $1.2 \mu \mathrm{m}$ depth ( $\sim 200$ dpa); (b) ABF image along $<100>$ with the image center at $0.83 \mu \mathrm{m}$ depth $(\sim 164$ dpa); (c-d) EDS peak intensity profile along the arrow line cross the damaged particle in (b). Dashed and solid arrows in (c) indicate widths of particle and core, respectively.

Figure 50. Irradiation induced particles. (a) ABF image at $0.9 \mu \mathrm{m}$ depth, about $180 \mathrm{dpa}$. (b) EDS peak intensity profile along the arrow in (a). (c) HAADF image of a particle at $0.78 \mu \mathrm{m}$ depth, about 150 dpa.

Figure 51. TEM characterization of a partially damaged micron-scale particle: (a) ABF image showing a contrast line inside the particle, as indicated by two short white arrows, at 1.5 $\mu \mathrm{m}$ depth ( $\sim 30$ dpa near the end of damage range); (b) Nanobeam electron diffraction patterns of points A and B labeled in (a); (c) EDS measured compositional profile along red arrow line in (a), with a dashed line indicating the $\mathrm{ABF}$ contrast line location. 


\section{LIST OF TABLES}

Table 1. Down-selected steels and reference steel........................................................................2

Table 2. Minimum creep rates $\left(\mathrm{h}^{-1}\right)$ of the designed alloys compared to T91 tested at $650^{\circ} \mathrm{C}$.................9

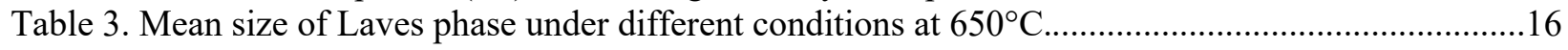




\section{ACKNOWLEDGMENTS}

This research was sponsored by the U.S. Department of Energy (DOE), Office of Nuclear Energy (NE), the Nuclear Energy Enabling Technologies (NEET) program, Reactor Materials FY 2015 Award. We gratefully acknowledge the support provided by Sue Lesica of DOE-NE and Stuart Maloy of Los Alamos National Laboratory.

The authors are grateful to Tom Geer, Douglas Stringfield, Dorothy Coffey, and Eric Manneschmidt of Oak Ridge National Laboratory (ORNL) for sample preparation and mechanical testing. Kevin Field and Xiang Chen of ORNL are appreciated for technical review of this report. 


\section{EXCUTIVE SUMMARY}

One ferritic steel (BL-Nb) and one ferritic-martensitic steel (TTZ2M) were down-selected for further investigation. Based on the TTZ2M, two large-scale ferritic-martensitic heats, i.e., FTT1 and FTN1, were produced at industrial steelmaking facilities, which are in contrast to the small laboratory heats BL-Nb and TTZ2M. Other than the standard normalization and tempering condition of the ferritic-martensitic steels, a heat-treated condition was explored for the FTT1 and FTN1, which is named as FTT1-T and FTN1-T, respectively. Two-step aging was applied to BL-Nb to favor the precipitation of Laves and B2-NiAl phases. The alloy compositions and heat treatment temperatures were guided by computational thermodynamics and dilatometry. Tensile, Charpy impact, and creep tests were conducted on the samples of the steels in air, using a commercial heat of T91 as a reference. Microstructural characterization was primarily using transmission electron microscopy and energy dispersive x-ray spectroscopy with occasional uses of optical microscopy.

The developed new alloys BL-Nb, TTZ2M, FTN1, and FTT1 exhibited noticeable enhancements in strength, Charpy impact toughness, and creep resistance compared to T91, except for BL-Nb having significantly lower impact toughness than T91. For example, the new alloys showed up to $\sim 170-350 \mathrm{MPa}$ increases in yield/tensile strength than T91 at test temperatures of $\sim 23-700^{\circ} \mathrm{C}$. The heat-treated condition FTT1-T and FTN1-T exhibited comparable mechanical properties, with slightly lower strength but noticeably higher Charpy impact toughness than their standard condition.

Microstructure characterizations of the creep-ruptured samples indicate noticeable recovery of T91 with diminished lath/block/packet sub-structures and reduced dislocations. In contrast, the large number of B2$\mathrm{NiAl}$ and Laves $\mathrm{Fe}_{2}(\mathrm{~W}, \mathrm{Nb})$ in BL-Nb and the high-density of ultrafine Ti-rich precipitates in TTZ2M and FTT1 helped retain their sub-structures and dislocations during the creep tests. The refined grains $(\sim 10 \mu \mathrm{m})$ in the untested FTN1-T and FTT1-T compared to the larger prior-austenite grains $(\geq \sim 50 \mu \mathrm{m})$ of the standard condition would explain the enhanced Charpy impact toughness of the heat-treated condition with compromised yield/tensile strength and creep resistance.

FTN1 and FTT1 showed comparable radiation resistance, superior to T91 irradiated under the same conditions up to $250 \mathrm{dpa}$ at 350 and $475^{\circ} \mathrm{C}$, in terms of stabilities of grain structures, dislocations, precipitates, and radiation-hardening. For example, noticeably diminished martensitic sub-boundaries, formation of Z-phase by transformation from MX precipitates, and the greatest radiation-hardening were observed in T91. Although a direct comparison between the rastered-beam (TTZ2M and BL-Nb) and defocused-beam (FTN1, FTT1, and T91) irradiated samples is not available, the radiation resistance of TTZ2M and BL-Nb was not significantly different from the FTN1 and FTT1. However, BL-Nb did show instability of Lave phase, e.g., amorphization of coarse Laves precipitates and disintegration of fine $(\sim 100$ $\mathrm{nm})$ Laves precipitates to form ultrafine $(\sim 8 \mathrm{~nm})$ Z-phase particles.

In summary, the large-scale industrial heats FTN1 and FTT1 showed comparable or superior mechanical properties compared with the small laboratory heat TTZ2M, which suggest the property sustainability and scale-up fabrication feasibility of the developed ferritic-martensitic steels. The systematic study indicates the successful development of the new ferritic-martensitic steels FTN1 and FTT1. 


\section{INTRODUCTION}

Advanced nuclear reactors as well as the life extension of light water reactors require advanced alloys capable of satisfactory operations up to neutron damage levels approaching 200 displacements per atom (dpa) [1]. Extensive studies, including fundamental theories, have demonstrated the superior resistance to radiation-induced swelling in ferritic steels, primarily inherited from their body-centered cubic (bcc) structure [2]. In our previous work [3], novel $\mathrm{Fe}-\mathrm{Cr}-\mathrm{Zr}$ ferritic alloys strengthened by $\mathrm{Fe}_{2} \mathrm{Zr}$-based Laves phase precipitates showed superior strength, ductility, and creep resistance at high temperatures, however, a consistent improvement on their radiation resistance data has yet to be achieved. Preliminary self-ion irradiation at $400^{\circ} \mathrm{C}$ exhibited amorphization of some phases in the $\mathrm{Fe}-\mathrm{Cr}-\mathrm{Zr}$ ferritic alloys.

With the high amorphization tendency of Laves phase, other types of precipitates such as B2-NiAl and general $\mathrm{MX}(\mathrm{M}=$ metal, $\mathrm{X}=\mathrm{C} / \mathrm{N})$ were engineered into the new alloys. By routine screening of the microstructures, basic mechanical properties such as tensile, Charpy impact toughness, and creep resistance, and self-ion $\left(\mathrm{Fe}^{2+}\right)$ irradiation studies, a few alloys have been down-selected for detailed property and microstructure studies to understand the evolution of Laves and other types of precipitates and their influence on properties.

This report summarizes the basic mechanical properties, radiation resistance and relevant microstructural characterization of the down-selected steels. 


\section{DOWN-SELECTED ALLOYS AND EXPERIMENTAL METHODS}

\subsection{DOWN-SELECTED ALLOYS}

A series of ferritic and ferritic-martensitic steels were designed using the recently developed thermodynamic database [4] and fabricated using laboratory arc-melting and casting followed by standard normalization and tempering or aging. A systematic screening tests, including microstructure, hardness, tensile, Charpy impact, creep, ion irradiation, and nanoindentation, were conducted on the steels. Based on the testing results, one ferritic steel (BL-Nb) and one ferritic-martensitic steel (TTZ2M) were downselected. Referring to the TTZ2M, two scale-up heats of ferritic-martensitic steels, named as FTN1 (or NA) and FTT1 (or TA), were procured with a weight of $\sim 60 \mathrm{lbs}$. per heat in contrast to the $\sim 1 \mathrm{lb}$. of a laboratory heat, which were fabricated using an industrial vacuum induction melting facility. The nominal compositions in weight percentage (wt.\%) of the down-selected steels and scale-up heats, together with a reference steel T91, are listed in Table 1.

Table 1. Down-selected steels and reference steel.

\begin{tabular}{|l|l|l|l|}
\hline Alloy ID & Nominal composition (with Fe balance) & Fabrication & Alloy type \\
\hline BL-Nb & 12Cr-3W-3Ni-3Al-1Nb & $\begin{array}{l}\text { Small laboratory heat by } \\
\text { arc-melting/casting }\end{array}$ & Ferritic \\
\cline { 2 - 3 } TTZ2M & $9 \mathrm{Cr}-1.4 \mathrm{~W}-0.1 \mathrm{~V}-0.1 \mathrm{Ti}-0.05 \mathrm{Nb}-0.1 \mathrm{C}$ & \\
FTN1 (NA) & 9Cr-1.5W-0.1V-0.1Ti-0.05Nb-0.1C & $\begin{array}{l}\text { Large industrial heat by } \\
\text { vacuum induction melting }\end{array}$ & $\begin{array}{l}\text { Ferritic- } \\
\text { martensitic }\end{array}$ \\
\hline FTT1 (TA) & $9 \mathrm{Cr}-1.5 \mathrm{~W}-0.1 \mathrm{~V}-0.1 \mathrm{Ti}-0.05 \mathrm{Ta}-0.1 \mathrm{C}$ & Commercial heat & \\
\hline T91 & 9Cr-1Mo-0.2V-0.1Nb-0.1C & & \\
\hline
\end{tabular}

${ }^{*}$ Used as a reference during the ion irradiation experimental study. Literature data of P91 and Grade 91 are used as references for mechanical tests.

The calculated temperature-dependent phase fractions of the steels, presented in Table 1, are plotted in Figure 1. Figure 1a shows alloy BL-Nb, being composed of a large amount of B2 (e.g., NiAl) and Laves $\left(\mathrm{Fe}_{2} \mathrm{~W}\right.$ and/or $\left.\mathrm{Fe}_{2} \mathrm{Mo}\right)$ phases in ferrite $(\alpha)$. The highly $\mathrm{Cr}$-enriched $\alpha^{\prime}$ phase appears at temperatures below $\sim 480^{\circ} \mathrm{C}$, which is difficult to form under a thermal aging condition because of its slow kinetics. Figure 1bc display alloys FTN1 (NA) and FTT1 (TA), respectively, showing nearly identical phase amount distribution layout. The calculated temperature-dependent phase fraction plot of alloy TTZ2M is not shown here because it has the same layout as alloys FTN1 and FTT1 in Figure 1b-c, except for slightly different formation temperatures of the phases. In contrast, the reference steel T91 in Figure 1d shows a higher fraction of $\mathrm{M}_{23} \mathrm{C}_{6}(\mathrm{M}=\mathrm{Cr}$ primarily), a lower fraction of Laves phase, and a more distinctive transformation of $\mathrm{MX}(\mathrm{M}=\mathrm{V} / \mathrm{Nb} / \mathrm{Ta}, \mathrm{X}=\mathrm{C} / \mathrm{N})$ into a $\mathrm{Z}$ phase $(\mathrm{e} . \mathrm{g}$., $\mathrm{CrVN})$ at lower temperatures. The $\alpha^{\prime}$ phase exists in all the ferritic-martensitic steels, but forms at a lower temperature than alloy BL-Nb because of the lower $\mathrm{Cr}$ content in the ferritic-martensitic steels, e.g., $\alpha^{\prime}$ phase below $400^{\circ} \mathrm{C}$ in T91 (not appear in Figure 1d). Unlike the ferritic steel BL-Nb, the ferritic-martensitic steels have a decent temperature range of austenite $(\gamma)$, in which MX phase mostly dissolves during a high-temperature normalization and starts to precipitate during cooling and a follow-up tempering treatment.

Guided by the thermodynamic calculations, the BL-Nb was annealed at $1000^{\circ} \mathrm{C}$ for 20 minutes and aged at $800^{\circ} \mathrm{C}$ for 20 minutes and $650^{\circ} \mathrm{C}$ for $5 \mathrm{~h}$ to favor the formation of Laves and $\mathrm{B} 2$ phases after hot-rolling to a 0.3 "-thick plate. Alloys FTN1 (NA) and FTT1 (TA) were normalized at $1170^{\circ} \mathrm{C}$ for 20 minutes and tempered at $750^{\circ} \mathrm{C}$ for $1 \mathrm{~h}$ after hot-forging to 0.75 "-thick plates. 

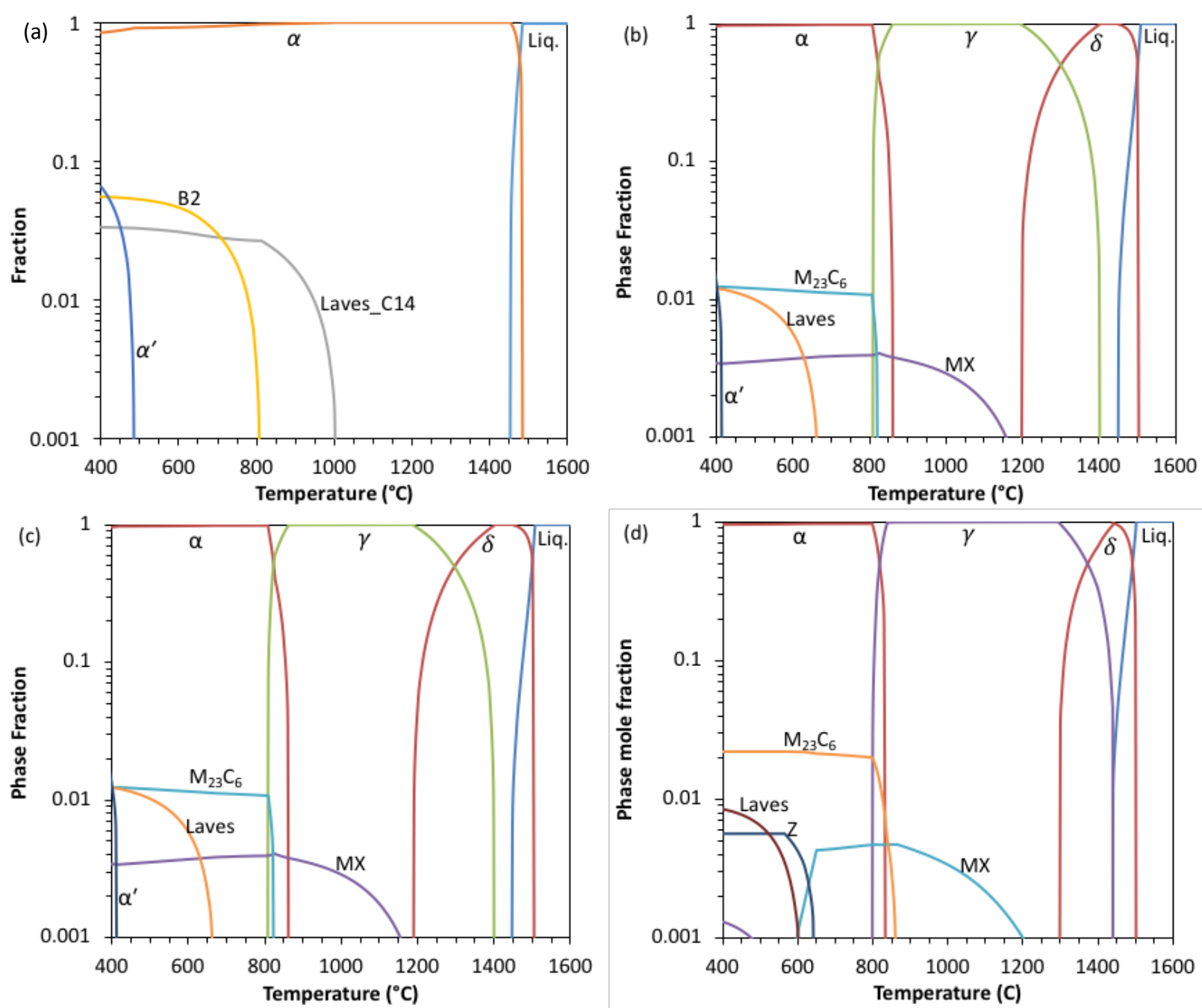

Figure 1. Calculated temperature-dependent phase fractions in alloys (a) BL-Nb, (b) FTN1 (NA), (c) FTT1 (TA), and (d) T91.

Other than the standard heat treatment condition mentioned above, a special heat treatment was applied to part of alloys FTN1 (NA) and FTT1 (TA) and designated as FTN1-T and FTT1-T, respectively, by two cycles of $15 \mathrm{~min}$ annealing at $970^{\circ} \mathrm{C}$ followed by water quench after the standard normalization and before the final tempering. The annealing temperature was $\sim 50^{\circ} \mathrm{C}$ above the austenite finish temperature $\left(\mathrm{A}_{\mathrm{f}}\right.$ or Ac3) determined by Gleeble dilatometry with the test results of NA and TA as shown in Figure 2. The brief secondary annealing is believed to be able to refine grain size by converting martensitic packet and maybe also block boundaries into austenitic grain boundaries. 


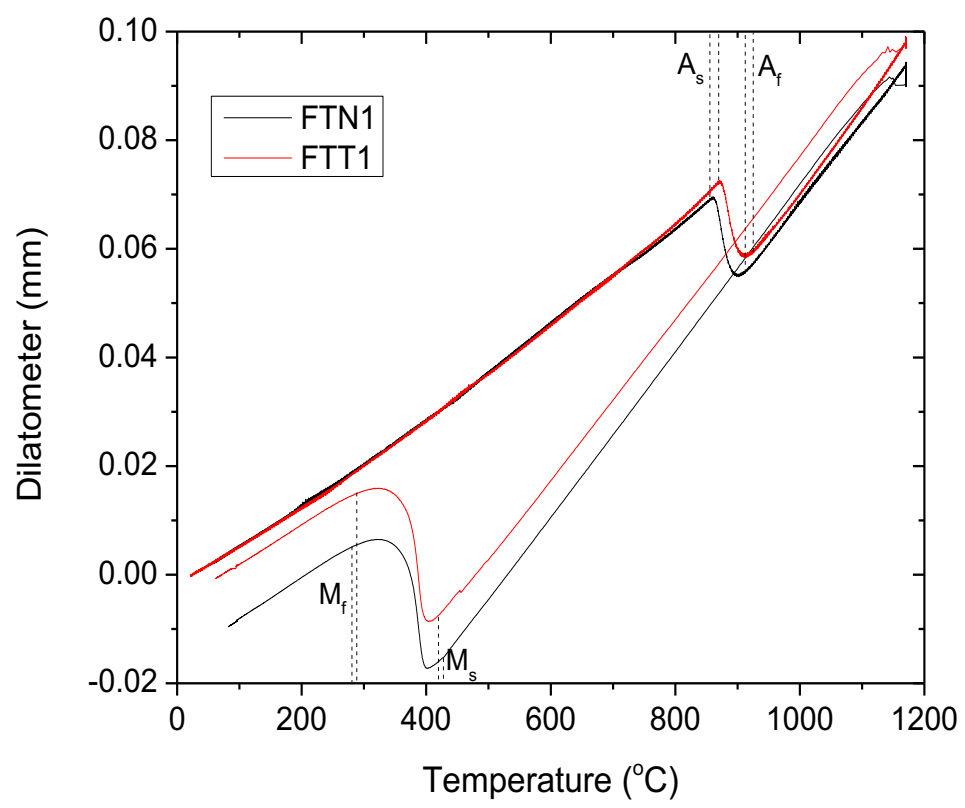

Figure 2. Temperature-dependent dilatometer determined phase transformation temperatures of FTN1 (NA) and FTT1 (TA).

\subsection{EXPERIMENTAL METHODS}

Mechanical tests of the down-selected steels include tensile, Charpy impact, and creep. Type SS-3 miniature specimens with a gauge section of $7.62 \times 1.52 \times 0.76 \mathrm{~mm}$ were machined from the steels for tensile and creep tests, with the specimen length aligned with the longitudinal direction of the alloy heats. Half-size Charpy V-notch specimens with a size of $5 \times 5 \times 25.4 \mathrm{~mm}$ and a 1-mm deep $45^{\circ} \mathrm{V}$-notch at the length center were machined from the steels in the transverse-longitudinal orientation. The geometries of type SS3 miniature specimen and half-size Charpy specimen are shown in Figure 3 and Figure 4, respectively.

- Tensile tests were conducted in air using shoulder load at a crosshead-controlled strain rate of 0.001 $\mathrm{s}^{-1}$ from room temperature up to $800^{\circ} \mathrm{C}$ in accordance with the American Society of Testing and Materials (ASTM) Standard E8/E8M-13a (Standard Test Methods for Tension Testing of Metallic Materials) and E21/E21M-09 (Standard Test Methods for Elevated Temperature Tension Tests of Metallic Materials).

- Charpy impact tests were performed in air on a Tinius Olsen Charpy $300 \mathrm{ft}-\mathrm{lb}$ machine according to the ASTM Standard E23-12c (Standard Test Methods for Notched Bar Impact Testing of Metallic Materials). Measurement validation of the Charpy machine was performed on an annual basis through testing of specimens with certified values to verify the accuracy of the machine; the certified specimens were obtained from the National Institute of Standards and Technology (NIST).

- Creep tests were conducted in air using shoulder load primarily at $650^{\circ} \mathrm{C}$ with different loads, following the ASTM Standard E139-11 (Standard Test Methods for Conducting Creep, CreepRupture, and Stress-Rupture Tests of Metallic Materials). Creep strains were monitored with extensometers attached to the shoulders of the specimens. 


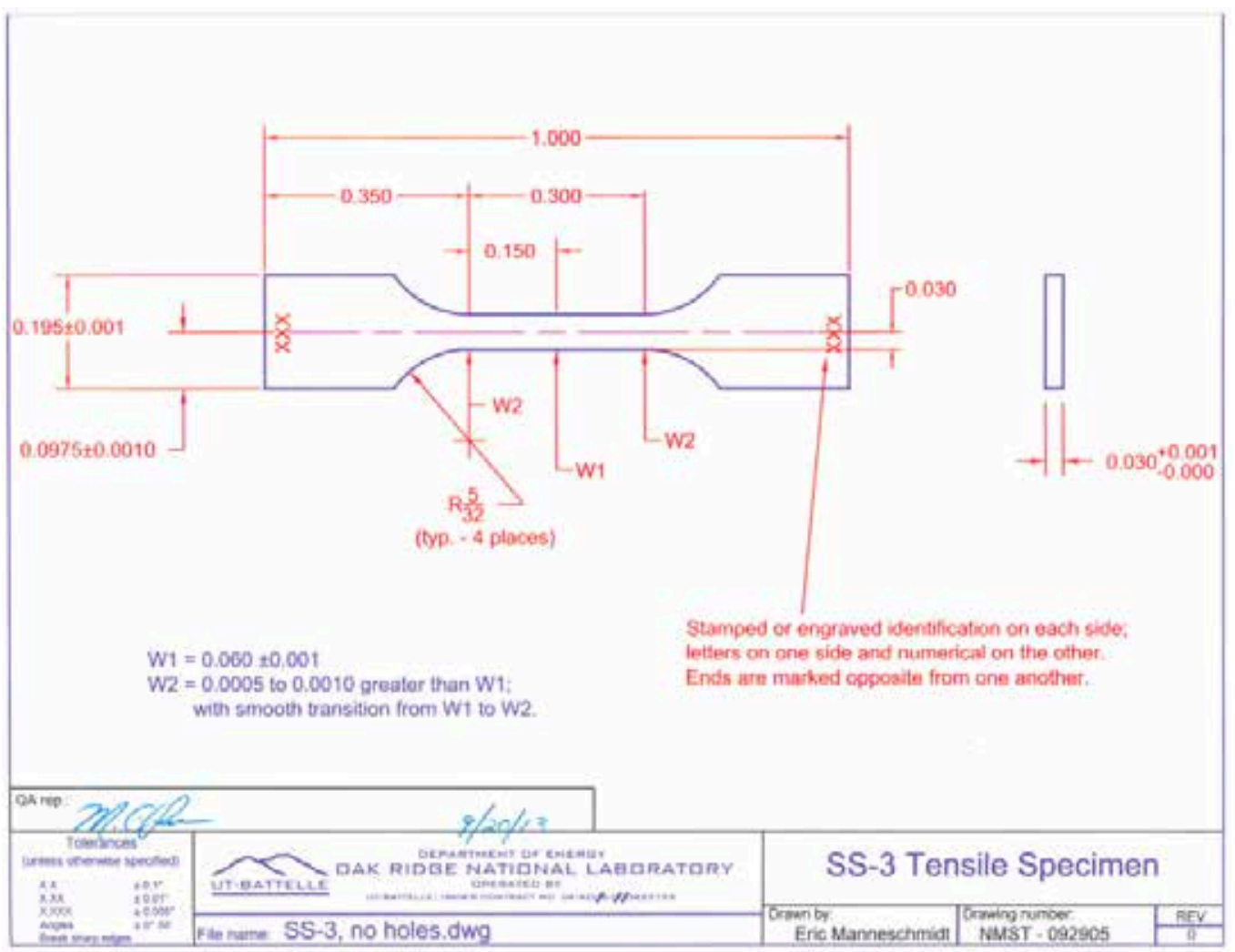

Figure 3. Geometry of type SS-3 miniature specimens for tensile and creep tests.

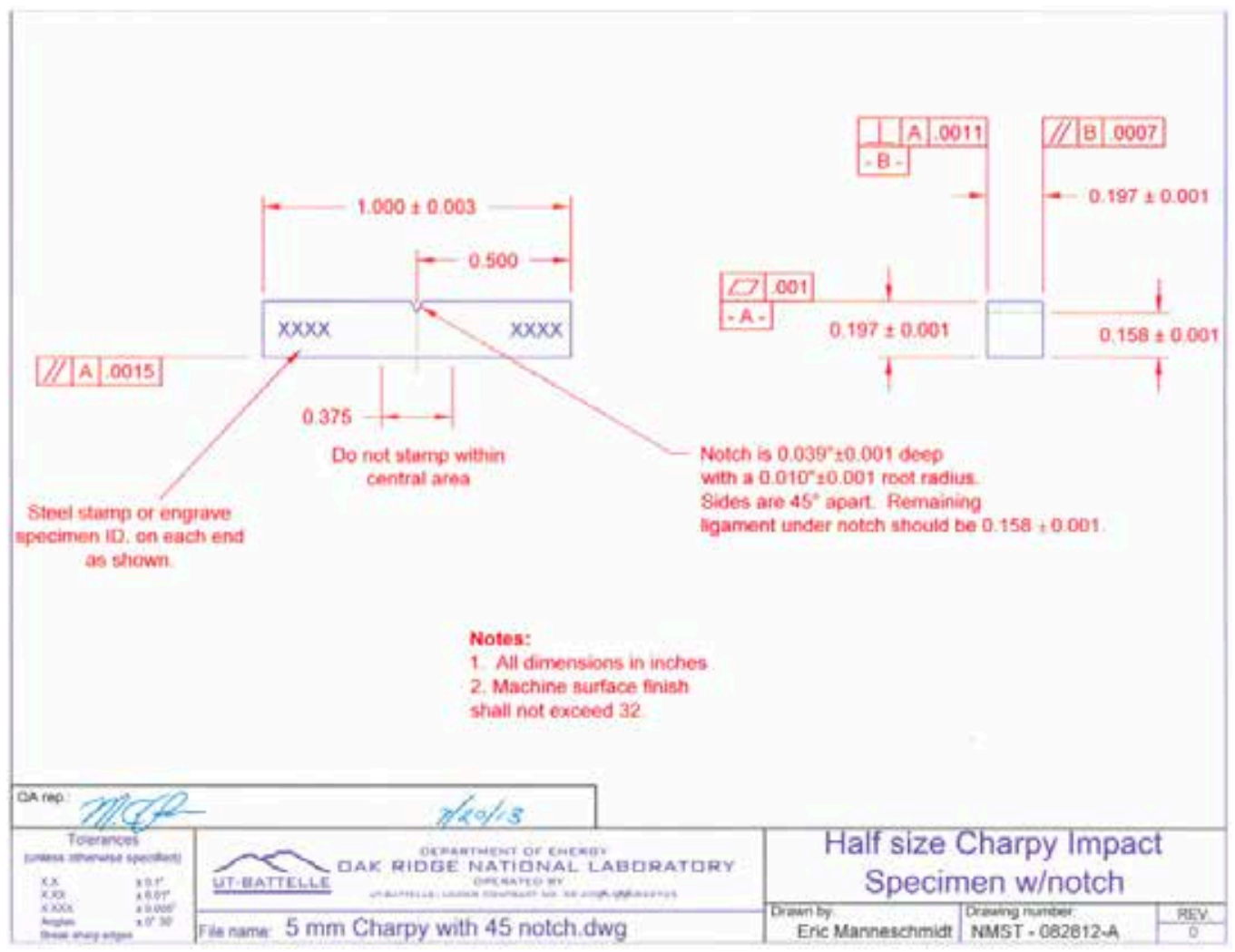

Figure 4. Geometry of half-size Charpy specimen for impact toughness testing. 
Self-ion $\left(\mathrm{Fe}^{2+}\right)$ irradiation experiments were conducted at the ion beam lab of the University of WisconsinMadison. The irradiation experiments were controlled at 350 and $475^{\circ} \mathrm{C}$ with a nominal peak damage up to 250 dpa. Post-irradiation examinations were conducted through nanoindentation measurements and microstructural characterization. Nanoindentation was conducted at room temperature on the ion-irradiated samples as well as their unirradiated counterparts to evaluate radiation-induced hardening.

Transmission electron microscopy (TEM) and energy dispersive x-ray spectroscopy (EDS) were primarily employed to investigate the as-received and deformed samples. Both conventional and scanning TEM, i.e., CTEM and STEM, imaging techniques were used, which produce bright-field (BF), dark-field (DF), highangle annular dark-field (HAADF) images. As will be detailed later, such investigation provides insight understanding of the roles of precipitates in strengthening the materials. Focus-ion beam (FIB) technique was used to prepare electron transparent lamellae for TEM characterization. Two TEM lamellae were lifted out from each creep-ruptured sample, with one lamella from the gauge section $(\sim 1.2 \mathrm{~mm}$ away from the fracture end) to represent the microstructure evolved to the steady-state deformation and the other lamella from the tab section considered as stress-free thermally aged condition. Other than FIB-TEM/EDS, optical microscopy was occasionally used. Additionally, dilatometry using Dynamic Systems Inc. Gleeble System 3500 was used to determine phase transformation temperatures as shown in Figure 2. 


\section{MECHANICAL PROPERTIES}

\subsection{TENSILE PROPERTIES}

Figure 5 plots the temperature-dependent yield strength, tensile strength, uniform elongation, and total elongation of the four alloys. Literature data of P91 are included as a reference [5]. The four alloys, BL$\mathrm{Nb}$, TTZ2M, FTT1, and FTN1, generally exhibited greater strength with somewhat compromised total elongation compared with P91. The ferritic steel BL-Nb showed slightly higher strengths with lower total elongations than the ferritic-martensitic steels TTZ2M, FTT1, and FTN1 at temperatures below $500^{\circ} \mathrm{C}$, above which the relationship became opposite. The abnormal change in the strength of FTN1 and in the uniform elongation of $\mathrm{BL}-\mathrm{Nb}$ at 400 and $500^{\circ} \mathrm{C}$ may suggest the presence of inhomogeneous microstructures in the two alloys. The heat-treated version FTT1-T and FTN1-T exhibited nearly identical strengths lower than their standard version with comparable elongations higher than their standard version.
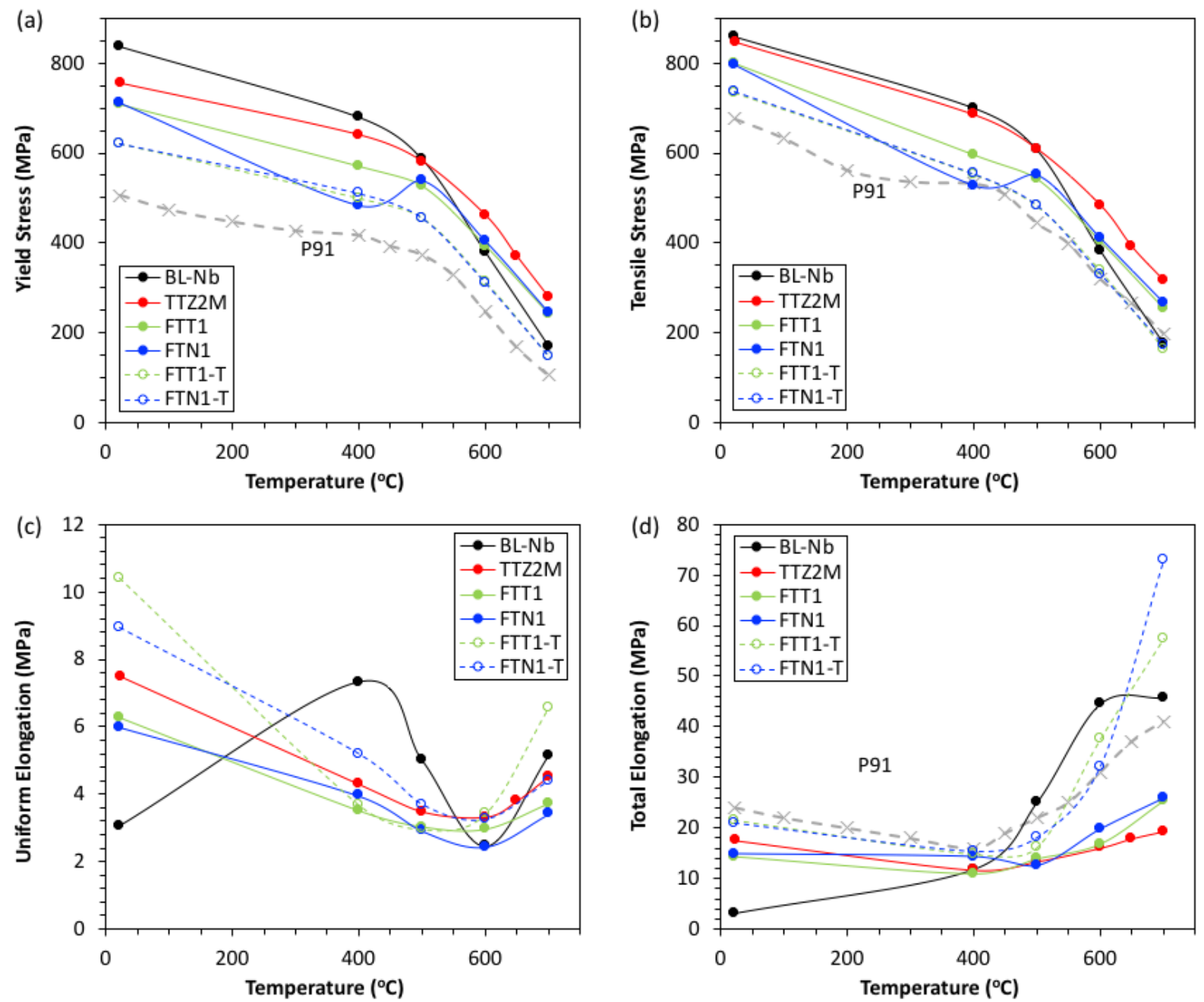

Figure 5. Temperature-dependent (a) yield strength, (b) tensile strength, (c) uniform elongation, and (d) total elongation of the ferritic (BL-Nb) and ferritic-martensitic (TTZ2M, FTN1, and FTT1) steels, compared to literature data of P91. FTN1-T and FTT1-T are a heat-treated version of FTN1 and FTT1, respectively. 


\subsection{CHARPY IMPACT TOUGHNESS}

Figure 6 plots the temperature-dependent absorbed energy for the interested steels, with Grade 91 heat 30176 as a reference [6]. To obtain the ductile-brittle transition temperature (DBTT) and upper-shelf energy (USE), the data were fitted by the general hyperbolic tangent function $\mathrm{E}=\mathrm{a}+\mathrm{b} \tanh \left[\left(\mathrm{T}-\mathrm{T}_{0}\right) / \mathrm{c}\right]$, where $\mathrm{T}$ is test temperature and $\mathrm{a}, \mathrm{b}, \mathrm{c}$, and $\mathrm{T}_{0}$ are regression coefficients. $\mathrm{T}_{0}$ gives the mathematical DBTT, corresponding to the mean value of USE and the lower-shelf energy (LSE), i.e., USE/2 assuming LSE $=0$ in Figure 6. Comparison of the materials with the same sample size and orientation indicates the comparable Charpy impact toughness of FTT1 and FTN1, which is superior to TTZ2M and significantly greater than Grade 91. The forging process applied to the large-scale heats FTT1 and FTN1 might have benefited their superior Charpy impact toughness compared with the lab-scale TTZ2M without forging. The heat-treated version FTT1-T and FTN1-T showed gradual decrease of absorbed energy with decreasing temperature, which is in contrast to the sharp decrease of the standard version but similar to the behavior of austenitic steels. Following the NRC regulatory guide of 68-J of full-size Charpy specimens for pressure vessels, the corresponding threshold energy would be 8.5-J for the half-size Charpy specimens assuming linear relationship between the energy and the nominal fracture volume of $(W b)^{3 / 2}$, where $W$ is the specimen width and $b$ is the ligament depth beneath the V-notch. Consequently, the DBTT of TTZ2M, FTT1, and FTN1 are 20 to $60^{\circ} \mathrm{C}$ lower than that of Grade 91 of $-47^{\circ} \mathrm{C}$. While the DBTT of FTT1-T and FTN1-T are way below $-150^{\circ} \mathrm{C}$. Ferritic steel BL-Nb exhibited the lowest impact toughness with USE comparable to general oxide-dispersion-strengthened ferritic alloys.

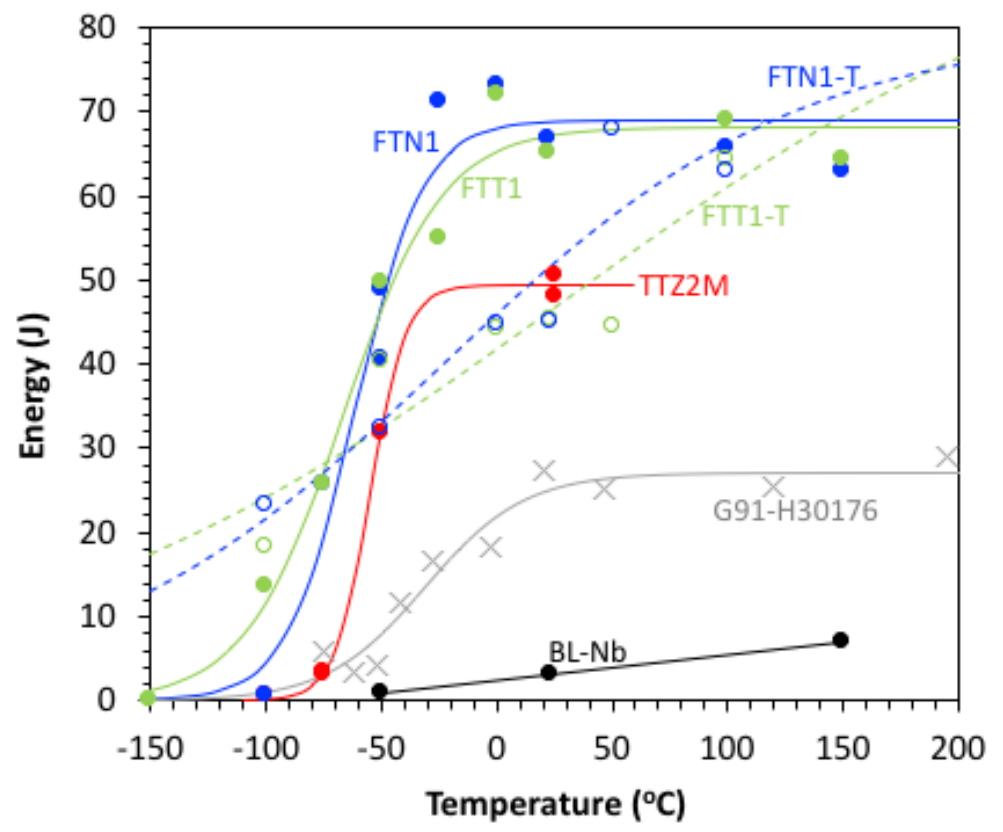

Figure 6. Temperature-dependent Charpy absorbed energy of the ferritic (BL-Nb) and ferritic-martensitic (TTZ2M, FTN1, FTT1, and the heat-treated version FTN1-T and FTT1-T) steels, compared to literature data of Grade 91 heat 30176.

\subsection{CREEP RESISTANCE}

Figure 7 plots the creep strain as a function of creep time for the down-selected steels BL-Nb, TTZ2M, FTN1, and FTT1 compared with a commercial heat of T91, which were tested using type SS-3 miniature specimens in air at $650^{\circ} \mathrm{C}$ and 100 and $120 \mathrm{MPa}$. Other conditions such as $110 \mathrm{MPa}$ were also tested but 
are not reported here because only T91 and TTZ2M were tested. The test of FTN1 under $100 \mathrm{MPa}$ at $650^{\circ} \mathrm{C}$ is still running during the preparation of this report. The creep curves indicate the superior creep resistance of the down-selected steels compared to reference steel T91.

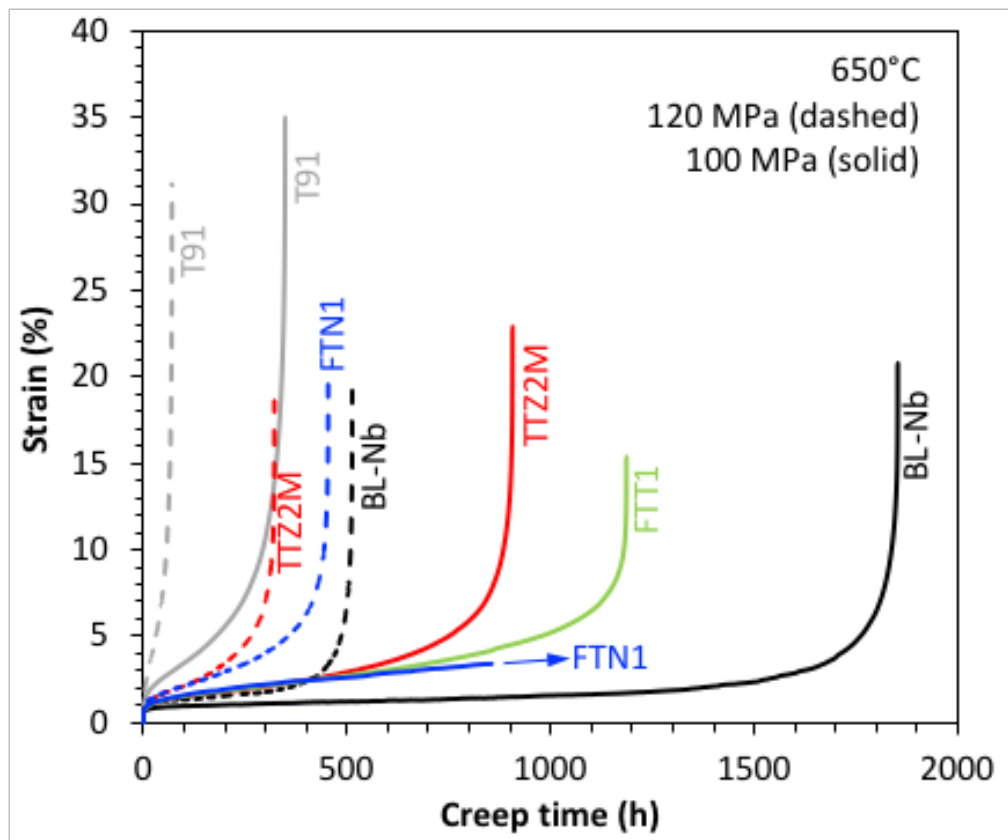

Figure 7. Creep strain-time curves for the down-selected alloys BL-Nb, TTZ2M, FTN1, and FTT1 compared with $\mathrm{T} 91$ tested at $650^{\circ} \mathrm{C}$ and $120 \mathrm{MPa}$ (dashed) and $100 \mathrm{MPa}$ (solid).

The creep curves were analyzed to deduce their minimum creep rates and the ratios of creep-rupture life of BL-Nb, TTZ2M, FTN1, and FTT1 over that of T91 at $650^{\circ} \mathrm{C}$, which are summarized in Table 2 . The minimum creep rate as a function of stress is plotted in Figure 8. The alloys showed similar slopes of the fitting lines for the alloys. Alloy BL-Nb had the lowest minimum creep rates compared to the highest minimum creep rates of T91. The ferritic-martensitic steels had comparable minimum creep rates. The creep-rupture lives of the down-selected steels were 2.60 to 7.29 times of that of T91. The ferritic steel BL$\mathrm{Nb}$ exhibited the best creep resistance. The large-scale heats FTT1 and FTN1 showed slightly superior creep resistance than the small laboratory heat TTZ2M. Alloy FTN1 tends to be slightly superior to FTT1 and TTZ2M in terms of creep rupture life and minimum creep rate.

Table 2. Minimum creep rates $\left(\mathrm{h}^{-1}\right)$ of the designed alloys compared to $\mathrm{T} 91$ tested at $650^{\circ} \mathrm{C}$.

\begin{tabular}{|c|c|c|c|c|}
\hline \multirow{2}{*}{ Alloy } & \multicolumn{2}{|c|}{ Minimum creep rate $\left(\mathrm{h}^{-1}\right)$} & \multicolumn{2}{c|}{ Creep-rupture life ratio over T91 } \\
\cline { 2 - 5 } & $120 \mathrm{MPa}$ & $100 \mathrm{MPa}$ & $120 \mathrm{MPa}$ & $100 \mathrm{MPa}$ \\
\hline BL-Nb & $1.93 \times 10^{-5}$ & $5.68 \times 10^{-6}$ & 7.29 & 5.32 \\
\hline TTZ2M & $8.72 \times 10^{-5}$ & $2.97 \times 10^{-5}$ & 4.57 & 2.60 \\
\hline FTN1 & $7.65 \times 10^{-5}$ & $2.16 \times 10^{-5}$ & 6.45 & NA \\
\hline FTT1 & NA & $2.87 \times 10^{-5}$ & NA & 3.41 \\
\hline T91 & $1.04 \times 10^{-3}$ & $1.72 \times 10^{-4}$ & 1 & 1 \\
\hline
\end{tabular}

NA: not available during the preparation of the report. 


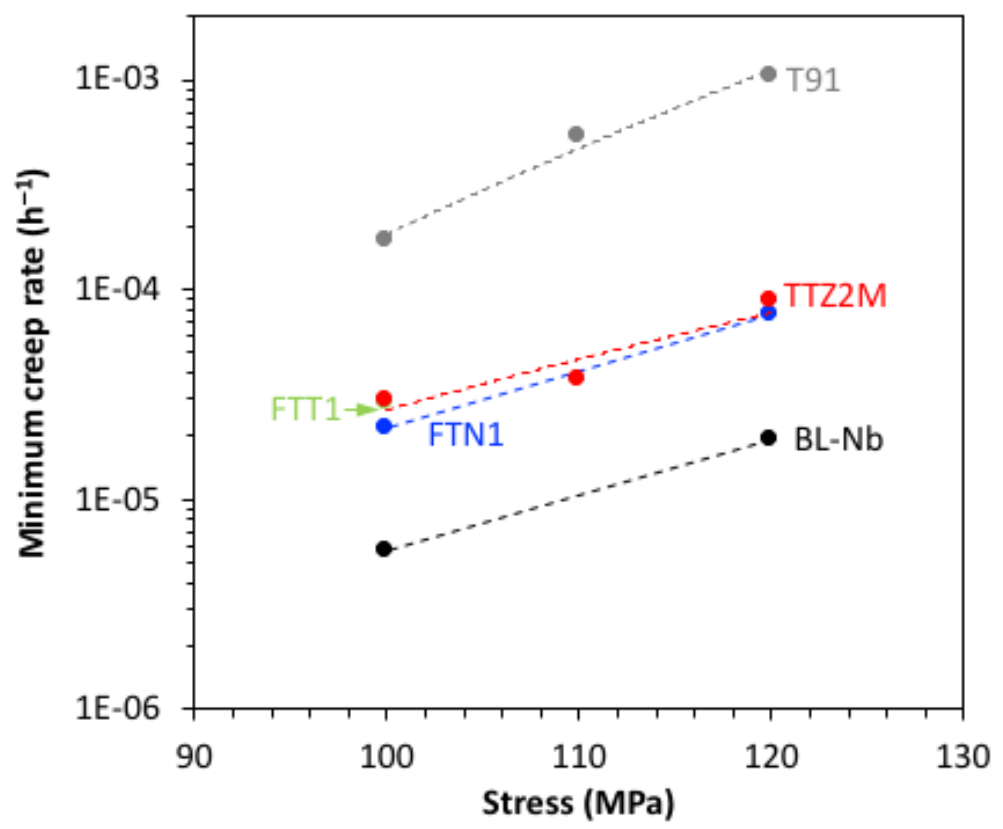

Figure 8. Stress-dependent minimum creep rates of alloys BL-Nb, TTZ2M, FTN1, and FTT1 compared with T91 tested at $650^{\circ} \mathrm{C}$.

\subsection{SUMMARY}

The developed new alloys BL-Nb, TTZ2M, FTN1, and FTT1 exhibited noticeable enhancements in strength, Charpy impact toughness, and creep resistance compared to T91, except for BL-Nb having significantly lower impact toughness than T91. The results of the basic mechanical tests are summarized below:

- The ferritic steel BL-Nb had the highest strength and creep resistance but the worst Charpy impact toughness.

- The ferritic-martensitic steels TTZ2M, FTN1, and FTT1 had noticeably enhanced strength, creep resistance, and Charpy impact toughness compared to reference steel T91.

- The heat-treated condition FTN1-T and FTT1-T exhibited comparable tensile properties and Charpy impact toughness, with lower strength but noticeably higher Charpy impact toughness than their standard condition.

- The large-scale industrial heats FTN1 and FTT1 had slightly inferior tensile properties but slightly superior creep resistance and Charpy impact toughness compared to the small laboratory heat TTZ2M, which suggest the property sustainability and scale-up fabrication feasibility of the developed ferritic-martensitic steels. 


\section{MICROSTRUCTURAL CHARACTERIZATION}

\subsection{ALLOY T91}

Figure 9 shows the tab-section microstructures of T91 creep-tested at $650^{\circ} \mathrm{C}$ and $100 \mathrm{MPa}$ in HAADF images and EDS maps, which indicate noticeable recovery of the pre-existing lath sub-structures, especially for the grains near sample surfaces (top of Figure 9a) in contrast to some of the grains in the substrate (Figure 9b). Primary two types of precipitates, likely to be $\mathrm{Cr}_{23} \mathrm{C}_{6}$ and $(\mathrm{Nb}, \mathrm{V})(\mathrm{C}, \mathrm{N})$, were suggested by EDS mapping (Figure 9d-f) of Figure 9c, which have sizes of $\sim 150 \mathrm{~nm}$ and $\sim 20-100 \mathrm{~nm}$ and densities of $\sim 3 \times 10^{19}$ and $\sim 1 \times 10^{20} \mathrm{~m}^{-3}$, respectively. The real densities of the precipitates in T91 are expected to be lower because Figure $9 \mathrm{c}$ was the only local area having such a high density of precipitates.

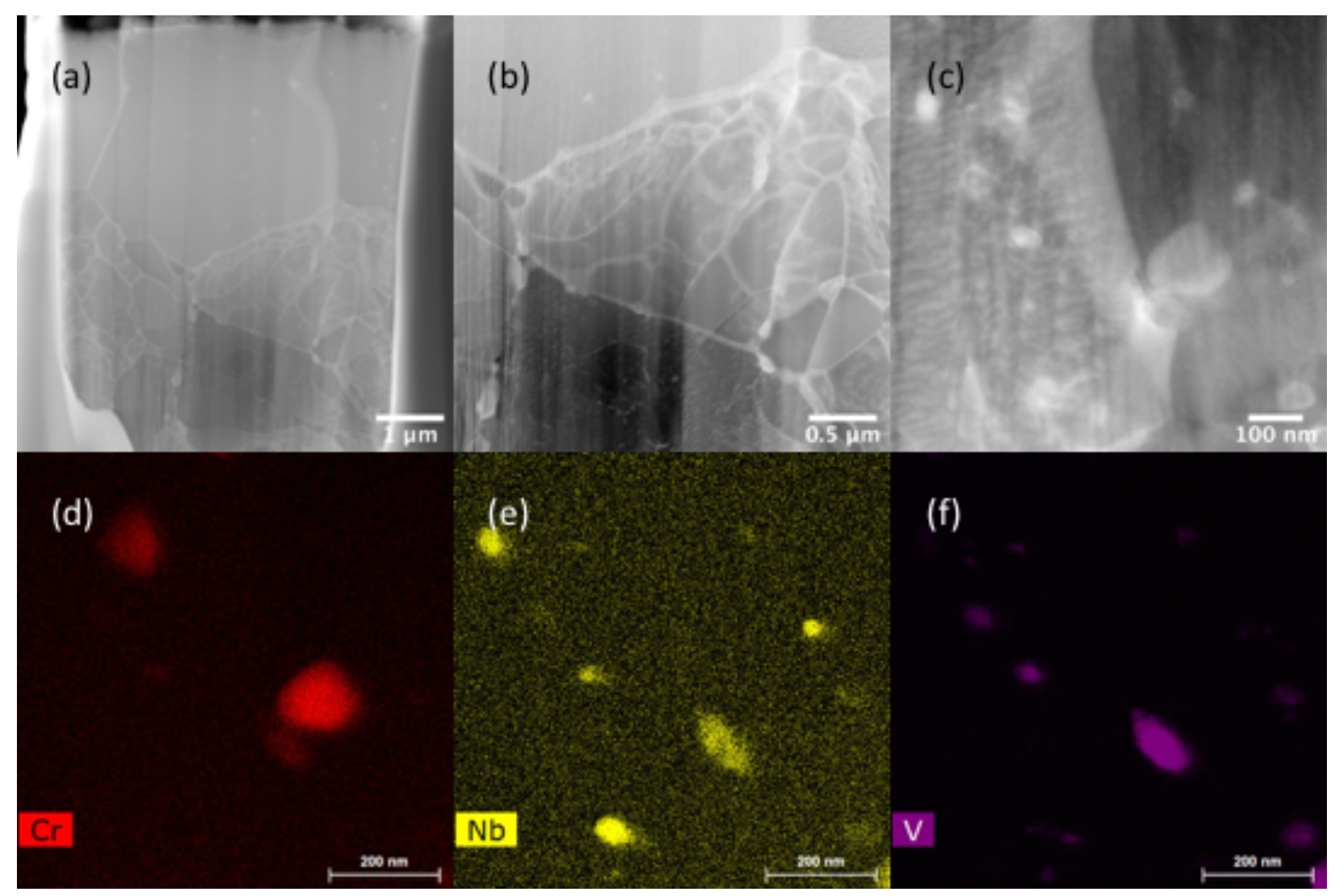

Figure 9. (a-c) HAADF images of the tab-section T91 creep-tested at $650^{\circ} \mathrm{C}$ and $100 \mathrm{MPa}$ and (d-f) EDS maps of (c).

Figure 10 shows the dislocation structures in the STEM BF images obtained at the [001] zone of the grains from the gauge section of T91 creep-tested at 120 and $100 \mathrm{MPa}$. In general, the dislocation densities are very low, with $7.5 \times 10^{13}$ and $2.9 \times 10^{13} \mathrm{~m}^{-2}$ for the 120 and $100 \mathrm{MPa}$ conditions, respectively, which are nearly one order of magnitude lower than the free dislocation density in the as-received condition. The low dislocation density might be attributable to the limited precipitates that could not retain the dislocations at $650^{\circ} \mathrm{C}$. The lower stress and longer exposure time resulted in less and shorter dislocation sections. 

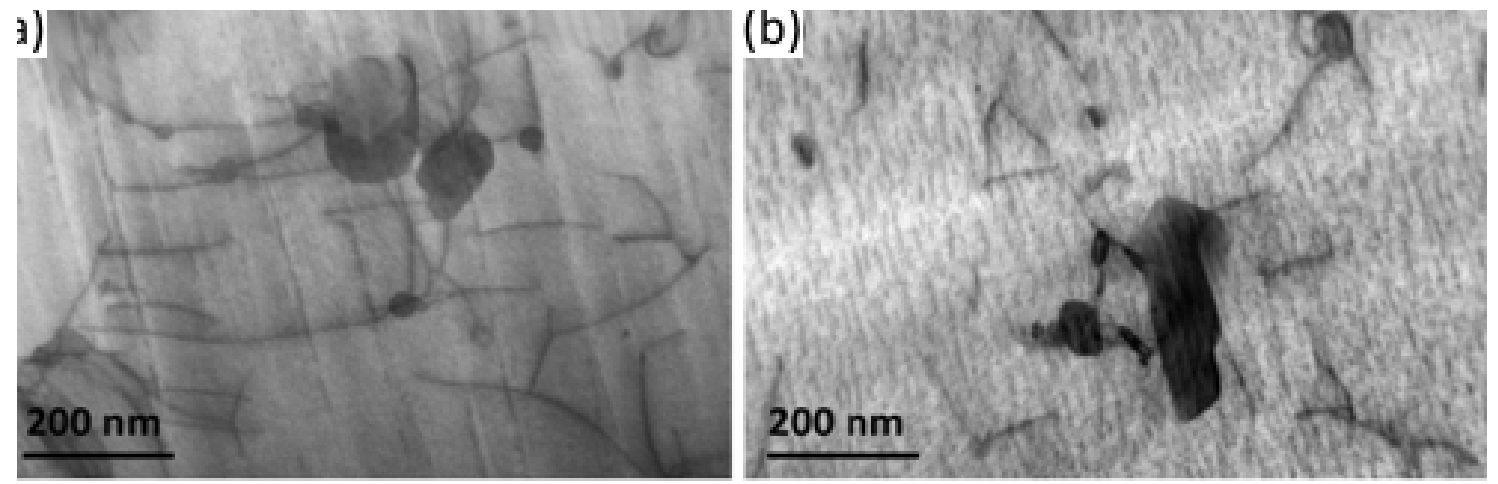

Figure 10. BF-STEM images with the [001] zone from the gauge section of $\mathrm{T} 91$ creep-tested at $650^{\circ} \mathrm{C}$ and (a) 120 and (b) 100 MPa.

\subsection{ALLOY BL-Nb}

Figure 11 shows the microstructures of $\mathrm{BL}-\mathrm{Nb}$, indicating the coarsened grains near the surfaces and retained sub-micrometer grains in the substrate in Figure 11a. EDS mapping of Figure $11 \mathrm{~b}$ revealed two types of precipitates as $\mathrm{NiAl}$ and $\mathrm{Fe}_{2}(\mathrm{~W}, \mathrm{Nb})$ with comparable densities of $\sim 6 \times 10^{19}$ and $\sim 7 \times 10^{19} \mathrm{~m}^{-3}$, respectively. The Ni-map was coincident with the Al-map in Figure 11c and the Nb-map was coincident with the W-map in Figure 11d. Unlike NiAl primarily in a spherical shape $(\sim 40-180 \mathrm{~nm})$ dispersed in matrix, $\mathrm{Fe}_{2}(\mathrm{~W}, \mathrm{Nb})$ is in an irregular shape $(\sim 45-230 \mathrm{~nm}$ in length) primarily pinning the fine grain boundaries as shown in Figure 11e. The white $\mathrm{Fe}_{2}(\mathrm{~W}, \mathrm{Nb})$ particles are diminished in the near surface grains, which might have facilitated the coarsening of the near surface grains. However, the fate of the $\mathrm{Fe}_{2}(\mathrm{~W}, \mathrm{Nb})$ in the near surface grains is not clear yet.

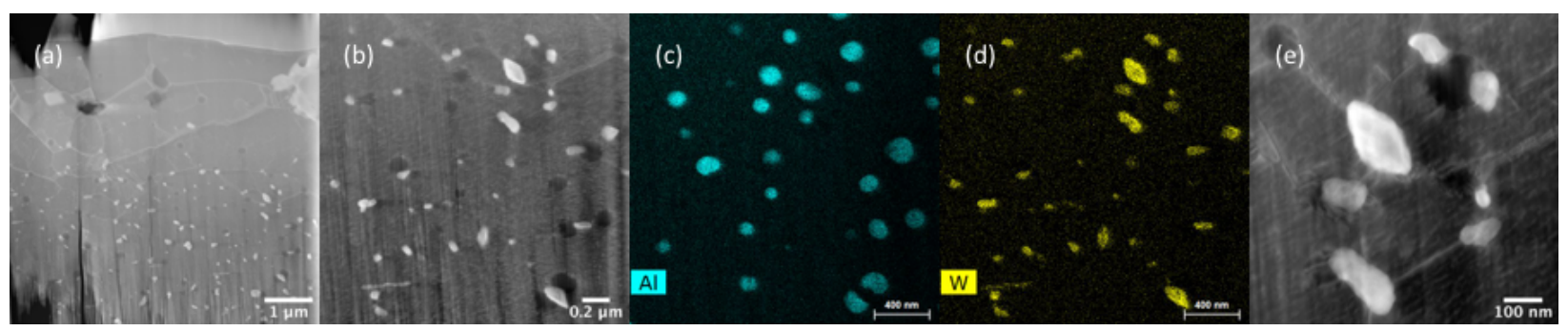

Figure 11. (a) BF-STEM and (b) HAADF images near the [001] zone of the bec matrix in the gauge section of the BL-Nb sample creep-tested at $650^{\circ} \mathrm{C}$ and $100 \mathrm{MPa}$.

Figure 12 shows the bright-field (BF) STEM and high-angle annular dark field (HAADF) images taken near the [001] zone of the matrix in the gauge section of the BL-Nb sample creep-tested at $650^{\circ} \mathrm{C}$ and 100 $\mathrm{MPa}$. The line features are dislocations and the particles are of the Laves phase. Having a mean $\mathrm{Z}$ number close to that of the matrix, the B2-NiAl particles are not obvious in the BF-STEM and HAADF images. Dislocations are not uniformly distributed. The subgrain at the bottom left corner contains a higher density of dislocations. Straight dislocation segments were observed, with some of them being marked by white triangles. Referring to the inserted diffraction pattern, the marked dislocation segments are on the $<110>$ planes. It is also frequently observed that one end of the dislocation is tied to the particles, suggesting that some dislocations were generated at the particle-matrix interfaces. 

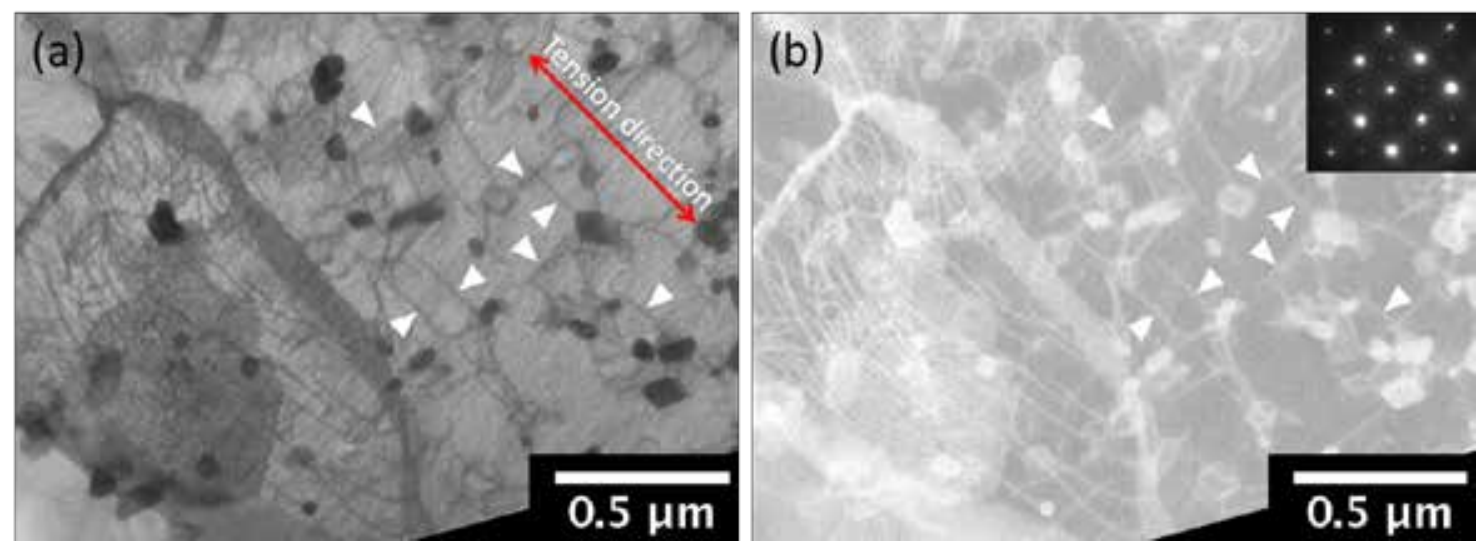

Figure 12. (a) BF-STEM and (b) HAADF images near the [001] zone of the bcc matrix in the gauge section of the BL-Nb sample creep-tested at $650^{\circ} \mathrm{C}$ and $100 \mathrm{MPa}$.

Dislocation-particle interactions were observed in the samples. The dislocation line marked by a white arrow in Figure 13a appears to be interacting with a B2-NiAl particle. The DF-TEM image of Figure 13b from the same region of Figure 13a highlights the B2-NiAl particles. The B2-NiAl precipitate marked by a white arrow in Figure 13b is located at the cusp of the dislocation shown in Figure 13a. Due to the obstacle effect of the B2-NiAl particle, the dislocation line bends over the B2-NiAl particle, as shown in the DFTEM image of Figure 13c obtained at the (200) beam condition. Figure 13d is obtained at the (110) beam condition showing that some segments of the dislocation line is not on contrast. This indicates that the Burgers vector of the dislocation changed due to its interaction with the B2 precipitate. As a result of the interactions, defects were developed in the $\mathrm{B} 2-\mathrm{NiAl}$ precipitates, as shown by the dark stripes inside of the B2-NiAl particles in Figure 13b.
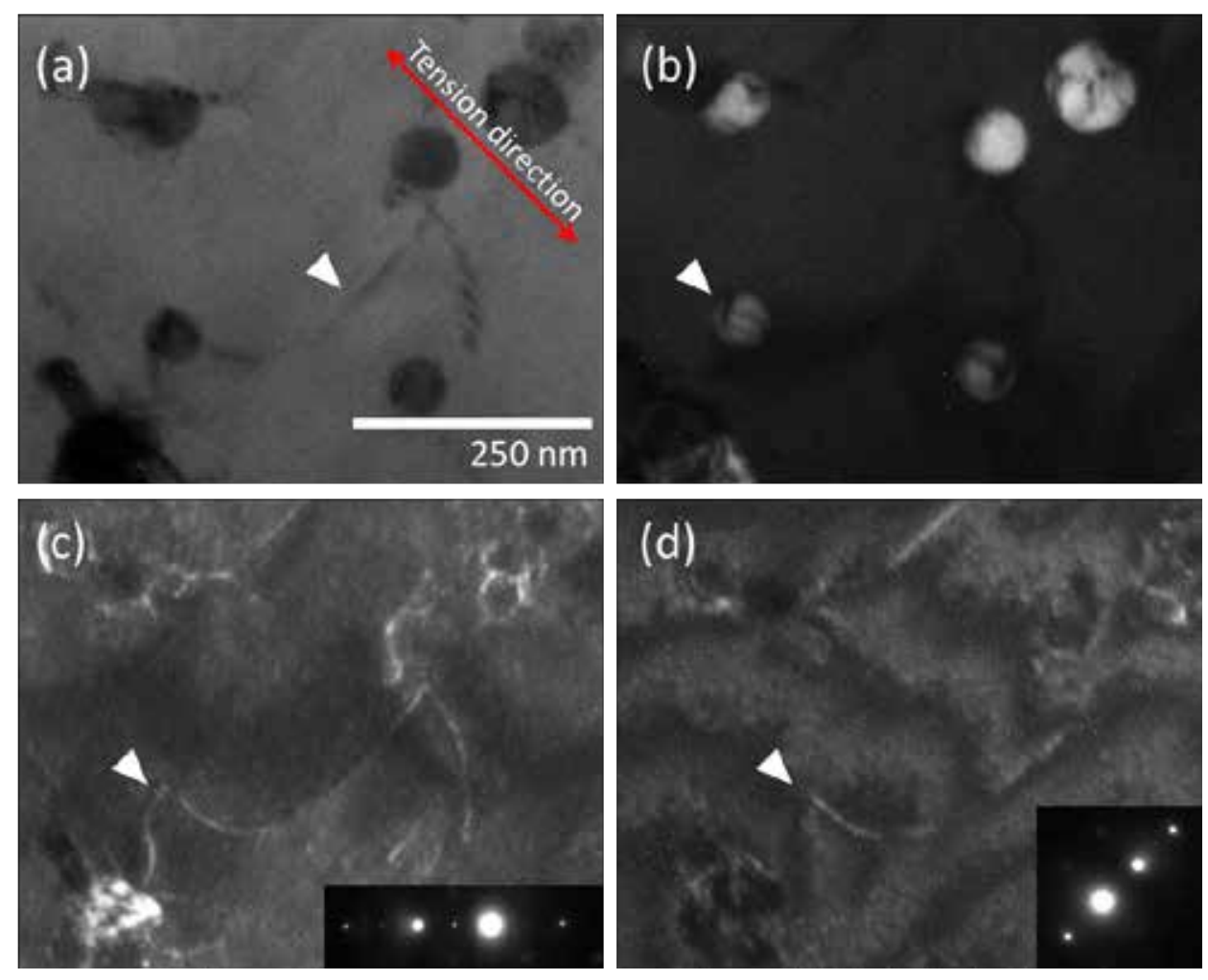
Figure 13. (a) BF and (b-d) DF TEM images in the gauge section of the BL-Nb sample creep-tested at $650^{\circ} \mathrm{C}$ and $100 \mathrm{MPa}$.

Figure 14 shows the evolution of B2 precipitates induced by thermal aging (end section of the creep sample without stress) and creep stresses (gauge section of the creep sample). Figure 14a presents the electron diffraction pattern obtained from the matrix of the as-received sample. The dashed rectangle marks the diffraction pattern of the bcc structured matrix on its [011] zone. The super lattice spots of the bcc pattern are visible, attributed to the presence of the coherent B2 precipitates. The $( \pm 100)$ spots of the B2 precipitates in Figure 14a are marked by the solid circles. Figure 14b is a dark-field (DF) micrograph imaged using the (100) spot of the B2 phase. The bright spherical features are the B2 precipitates uniformly distributed in the bcc matrix. The chemical composition of the precipitates was investigated using EDS technique. The EDS maps of $\mathrm{Ni}$ and $\mathrm{Al}$ in the as-received sample are presented in Figure $14 \mathrm{c}$ and d, respectively. The crystal structure identification and the chemical composition investigation of the precipitates indicate that the precipitates are NiAl phase having a B2 structure. The diameter of the precipitates is measured to be $16 \pm$ $3 \mathrm{~nm}$. Figure 14e-h present the Ni map to show the distribution of B2 precipitates in the creep-ruptured samples of $120 \mathrm{MPa}$ in (e-f) and $100 \mathrm{MPa}$ in (g-h). Figure 14e-g were captured from the thermal-aged region and Figure 14f-h from the deformed (gauge) region. After the thermal aging for 512 and 1852 hours, the diameters of the B2 precipitates increased to $77 \pm 25$ and $122 \pm 41$, as respectively shown in Figure 14e and g, respectively. The mean diameter of the precipitates measured from the deformed region is slightly larger than that from the thermal-aged region, i.e., $81 \pm 23$ and $127 \pm 37$ for the 100 and $120 \mathrm{MPa}$ samples, respectively.
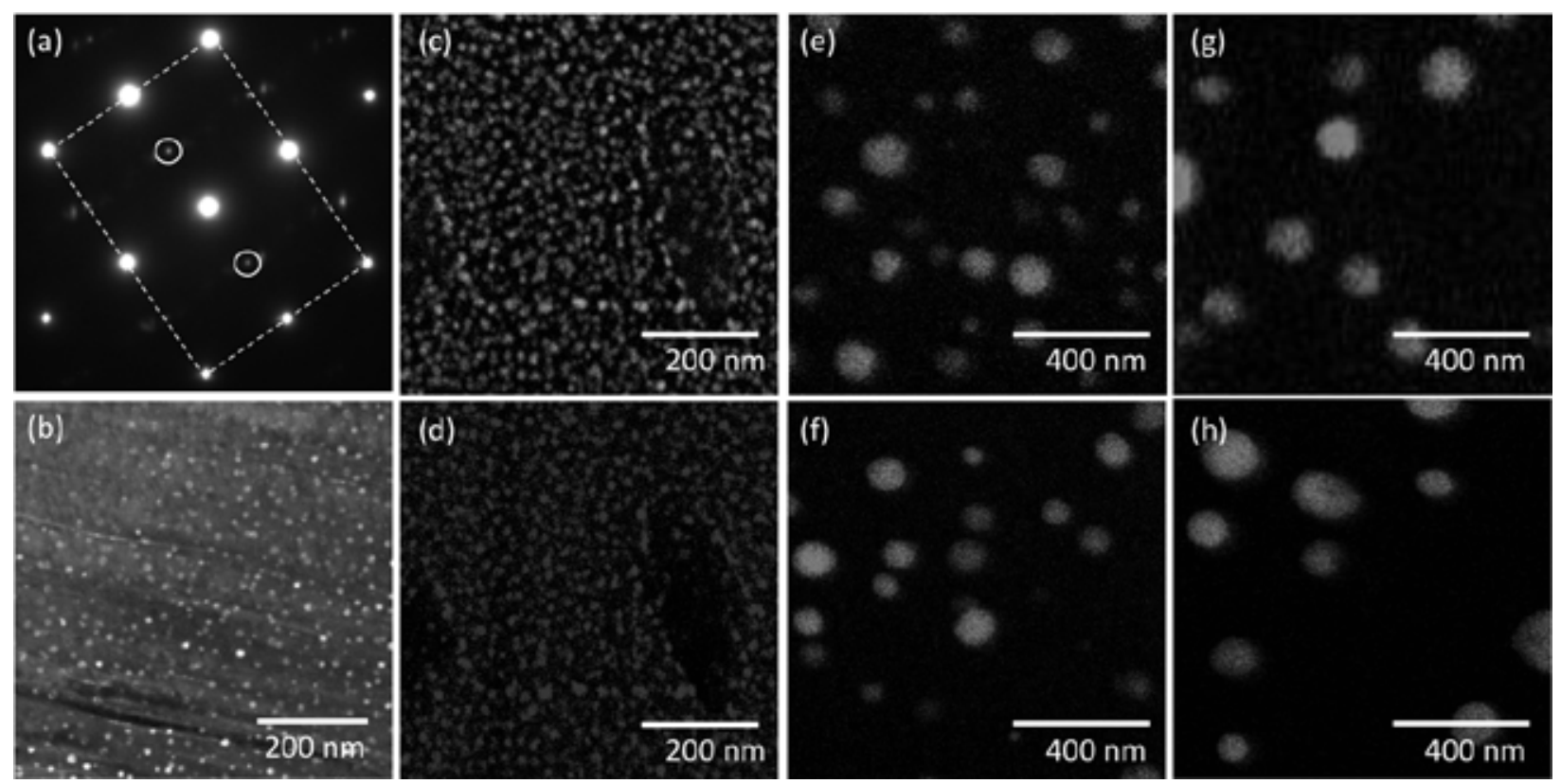

Figure 14. (a) An electron diffraction pattern obtained from the matrix of the as-received sample. (b) Dark field image of the coherent precipitates. The EDS mappings of (c) $\mathrm{Ni}$ and (d) $\mathrm{Al}$ of the as-received sample, and the $\mathrm{Ni}$ mappings from the (e) thermal-aged and (f) deformed regions of the $120 \mathrm{MPa}$ creep sample, and the (g) thermal-aged and (h) deformed regions of the 100 MPa creep sample.

Following the size analysis in Figure 14, Figure 15 plots B2-NiAl particle radius (R) in cubic power as a function of time $(\mathrm{t})$, which shows that stress enhances the coarsening of B2-NiAl precipitates. The kinetic constants $(\mathrm{k})$ of the thermal aged and stressed conditions are estimated to be 125 and $138 \mathrm{~nm}^{3} / \mathrm{h}$, respectively, according to $\mathrm{k}=\left(\mathrm{R}^{3}-\mathrm{R}_{0}{ }^{3}\right) / \mathrm{t}$. 


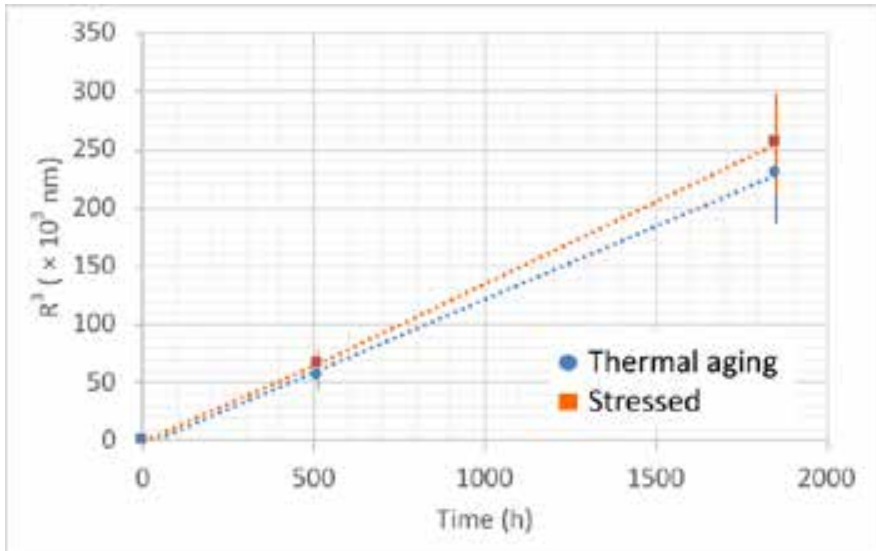

Figure 15. Time-dependent radius $(\mathrm{R})$ in cubic power of $\mathrm{B} 2-\mathrm{NiAl}$ particles under the thermal aging and stressed conditions at $650^{\circ} \mathrm{C}$.

Other than coarsening kinetics, the chemistry evolution of B2-NiAl particles were also investigated using EDS mapping under the STEM mode. The EDS-mapped B2-NiAl particles that are standalone without overlapping with other particles were analyzed by excluding the interference from matrix chemistry. Figure 16 shows the relative $\mathrm{Ni}-\mathrm{Al}$ ratios of $\mathrm{B} 2-\mathrm{NiAl}$ particles in thermal aged and stressed conditions, normalized to the ratio of the as-received condition, of the $1852 \mathrm{~h}$ creep-ruptured sample. The compositional change in B2-NiAl precipitates induced by thermal aging and stress is not significant.

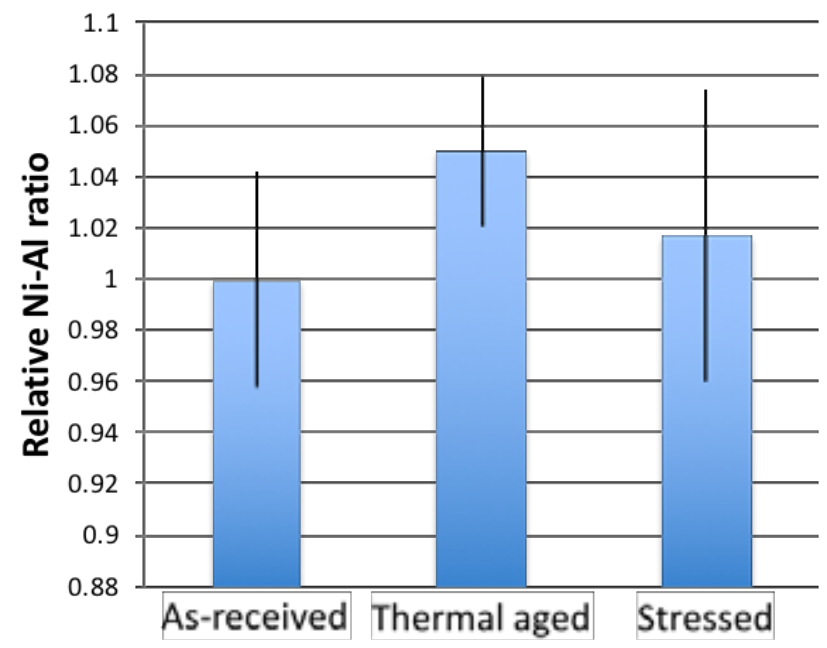

Figure 16. EDS analyzed relative Ni-Al ratio of $\mathrm{B} 2-\mathrm{NiAl}$ particles at the as-received condition and the $650^{\circ} \mathrm{C}$ aged and stressed conditions.

Figure 17a shows the precipitates of the Laves phase in the as-received condition. The precipitates have facet interface $\{110\}$ planes of the bcc matrix and irregular morphology. The electron diffraction pattern of the area containing precipitates of the Laves phase is shown in Figure 17b, where the stronger and weaker spots are attributed to the electron diffraction of the matrix and the Laves precipitates, respectively. The alignment between the diffraction patterns of the precipitates and the matrix indicates a planar coherency relationship between the lattice planes of the precipitates and the $\{110\}$ planes of the bcc. When imaged using different diffraction spots of the precipitates, for instance, the spots marked by the circle and the square in Figure 17b, different precipitates are highlighted in the corresponding DF images in Figure 17c 
and d, respectively. This indicate that different precipitates are coherent to different lattice planes of the bcc matrix.
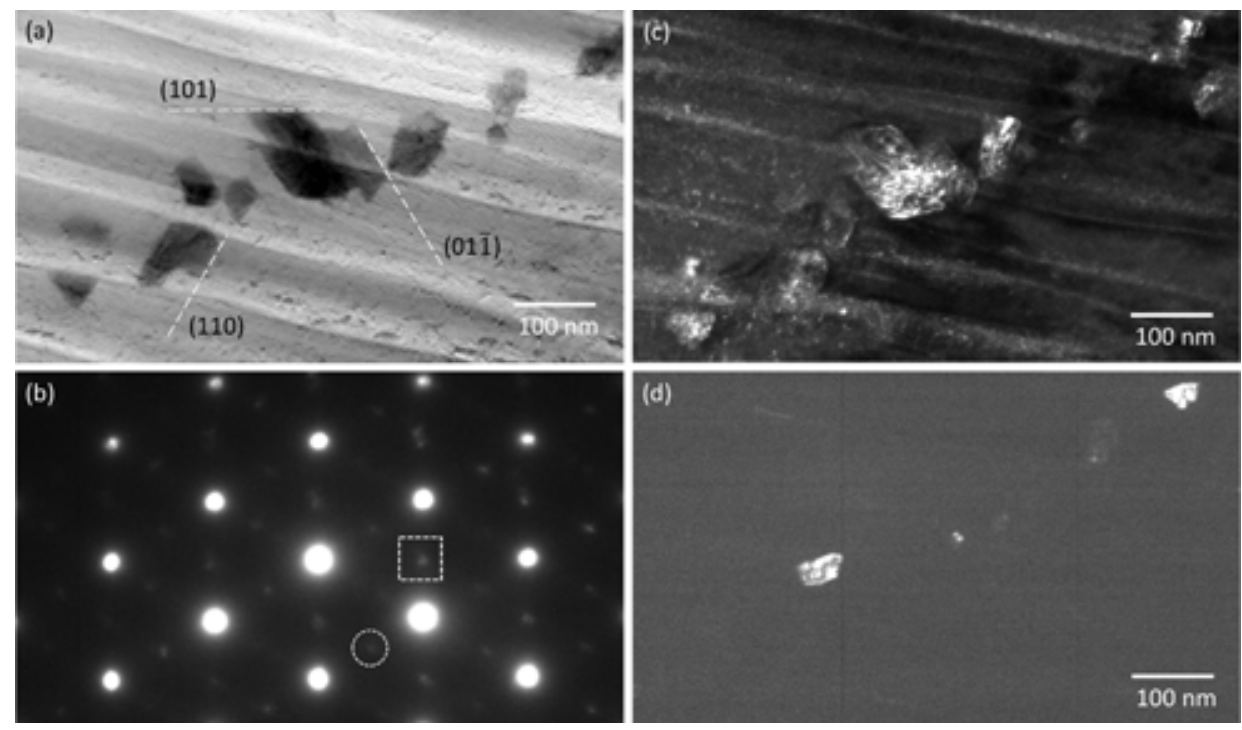

Figure 17. The precipitates of the Laves phase in the bec matrix presented in (a) bright field image, (b) electron diffraction pattern of the $[\overline{\mathbf{1}} 11]$ zone of the matrix, (c) DF image from the spot marked by the circle in (b), and (d) dark field image from the spot marked by the square in (b).

As shown in Figure 18, the chemical composition of the Laves precipitates was determined to be $\mathrm{Fe}_{2}(\mathrm{Nb}, \mathrm{W})$. EDS quantification shows a W-Nb atomic ratio of $0.87: 1$. The EDS maps in Figure 18b-c show that $\mathrm{Nb}$ and $\mathrm{W}$ are not uniformly distributed in the precipitates. $\mathrm{W}$ is slightly enriched in the shell of the precipitates, particularly at some portion of the precipitate-matrix interface. The slight segregation of $\mathrm{Nb}$ and $\mathrm{W}$ still presents in the creep-tested samples, as shown in Figure 18d-f. The mean sizes of the Laves precipitates in different samples are summarized in Table 3 . The differences in the precipitate sizes are within the experimental error.
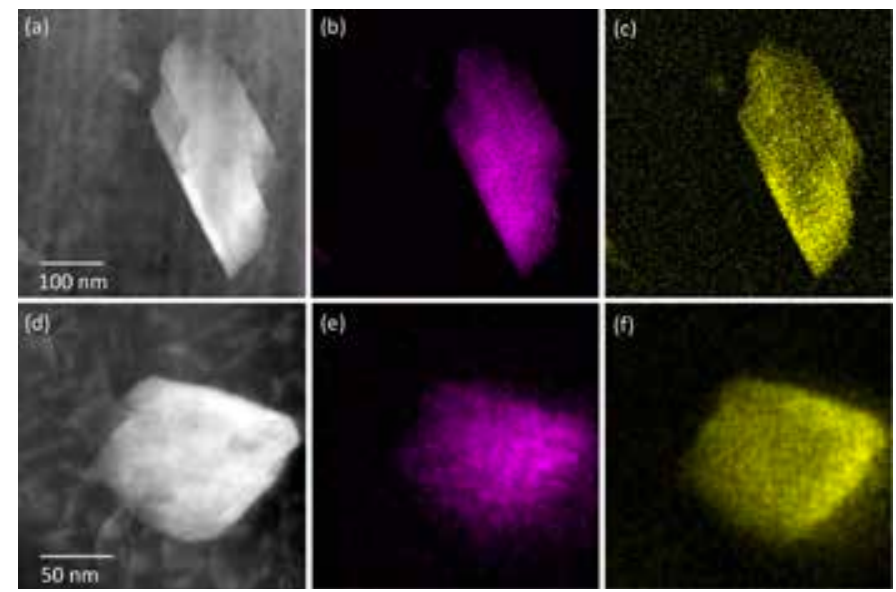

Figure 18. The precipitates of the laves phase presented in: (a) and (d) high-angle annular dark-field (HAADF) image, (b) and (e) EDS mapping of Nb, and (c) and (f) EDS mapping of W, for (a-c) the as-received condition and (d-f) the 1852-hour thermal-aged and stressed condition.

Table 3. Mean size of Laves phase under different conditions at $650^{\circ} \mathrm{C}$. 


\begin{tabular}{|c|c|c|c|c|c|}
\hline Condition & As-received & $\begin{array}{c}512-\mathrm{h} \\
\text { thermal aged }\end{array}$ & $\begin{array}{c}512-\mathrm{h} \\
120 \mathrm{MPa}\end{array}$ & $\begin{array}{c}1852-\mathrm{h} \\
\text { thermal aged }\end{array}$ & $\begin{array}{c}1852-\mathrm{h} \\
100 \mathrm{MPa}\end{array}$ \\
\hline Mean size $(\mathrm{nm})^{*}$ & $70 \pm 30$ & $80 \pm 30$ & $70 \pm 40$ & $70 \pm 30$ & $80 \pm 30$ \\
\hline
\end{tabular}

* Geometric mean value of a long and short axes of the precipitates. The uncertainty is the standard deviation.

As shown in Figure 19, the W-Nb atomic ratios in the Laves phase are higher in the thermal-aged samples than the as-received sample. This implies that precipitation of $\mathrm{Fe}_{2} \mathrm{~W}$ on the existing $\mathrm{Fe}_{2}(\mathrm{Nb}, \mathrm{W})$ precipitates took place during the thermal annealing. Figure 19 also shows that the most significant change in the W$\mathrm{Nb}$ atomic ratio occurred within the shorter time 512 hours of thermal aging, suggesting that the driving force for continuous precipitation of the Laves phase was the supersaturation of tungsten, which was decreased with time.

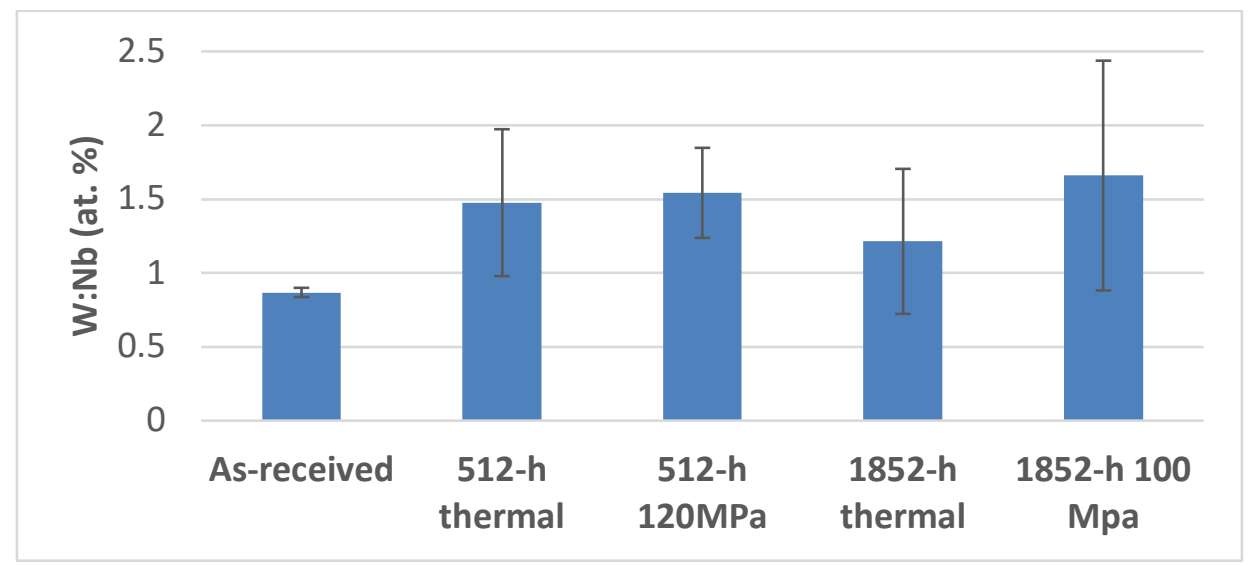

Figure 19. The evolution of $\mathrm{W}-\mathrm{Nb}$ atomic ratio in the Laves precipitates.

\subsection{ALLOY TTZ2M}

Figure 20 shows TEM images of the microstructure of the as-received TTZ2M alloy. The insert in Figure 20a shows the electron diffraction pattern of the beam condition that yielded the micrograph. Two sets of secondary reflections are identified and labeled for $\mathrm{M}_{23} \mathrm{C}_{6}$ and $\mathrm{MX}$ in addition to the primary reflections of $\{200\}_{\text {bcc }}$ matrix. The distance relationships of the secondary reflections were found to be in agreement with $\mathrm{M}_{23} \mathrm{C}_{6}$ and $\mathrm{MX}$ with lattice parameters of 1.089 and $0.414 \mathrm{~nm}$, respectively, assuming the lattice parameter of matrix (bcc) as $0.287 \mathrm{~nm}$. The DF image in Figure 20b was imaged using the $\mathrm{M}_{23} \mathrm{C}_{6}(33 \overline{1})$ diffraction spot, yielding the bright features in Figure 20b showing the distribution of the coherent precipitates with a size of $5-10 \mathrm{~nm}$. 


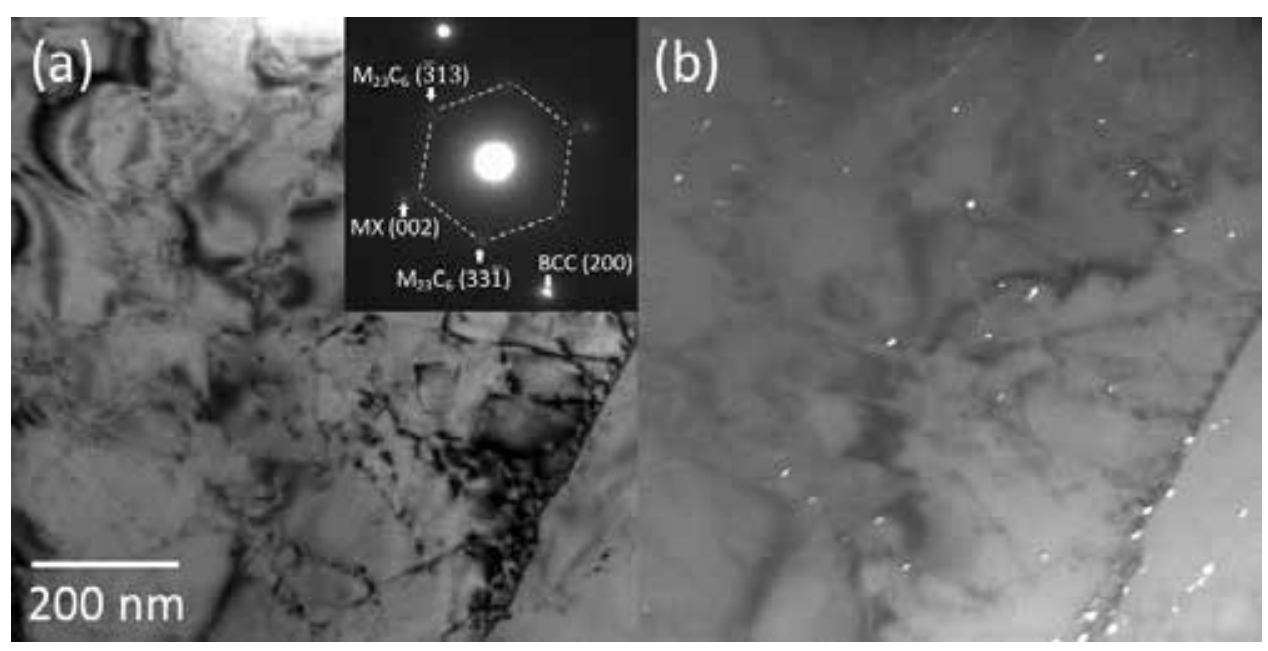

Figure 20. (a) BF and (b) DF images showing the microstructure and precipitate distributions in the as-received TTZ2M alloy.

The microstructures of TTZ2M after the creep test at $100 \mathrm{MPa}$ are shown in Figure 21, which indicate that the lath and dislocation sub-structures were mostly retained after the creep test. A high density $\left(\sim 4 \times 10^{21} \mathrm{~m}^{-}\right.$ ${ }^{3}$ ) of Ti-rich nanoprecipitates (likely to be TiC) with sizes $<\sim 20 \mathrm{~nm}$ exists in the sample, most of which are pinning dislocations. Other than the dominant Ti-rich nanoprecipitates, Cr-rich (likely $\mathrm{Cr}_{23} \mathrm{C}_{6}$ ) and Ti-rich (likely TiN) coarse precipitates were occasionally observed.

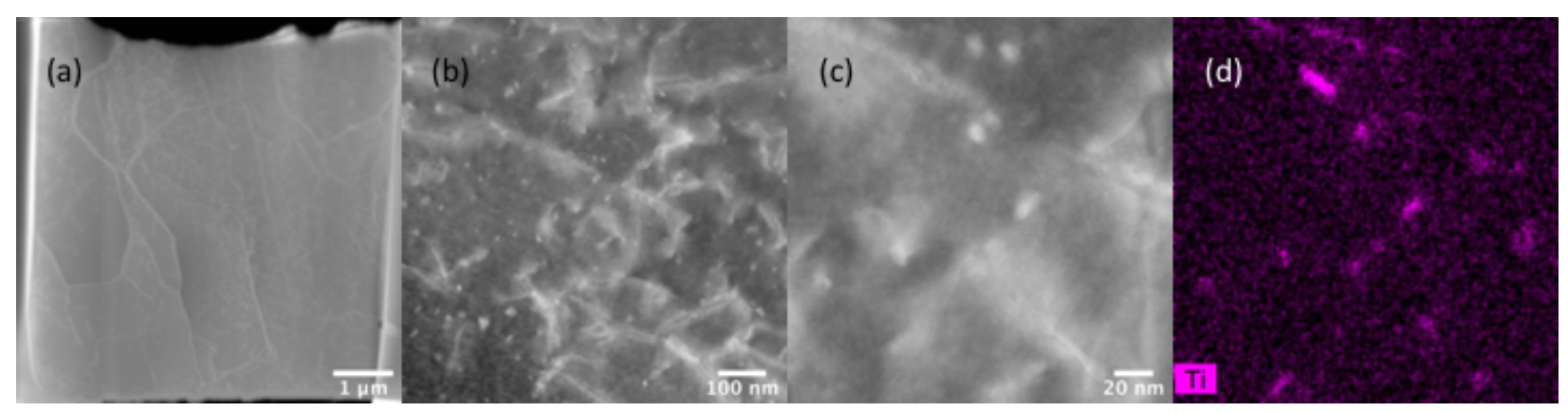

Figure 21. (a-c) HAADF images of TTZ2M creep-tested at $650^{\circ} \mathrm{C}$ and $100 \mathrm{MPa}$ and (d) EDS map of (c).

Figure 22a-b show the STEM BF images from the gauge section of the samples after creep tests under the stresses of 120 and $100 \mathrm{MPa}$, respectively. Dislocation features developed in both samples with a density of $2.1 \times 10^{14}$ and $1.3 \times 10^{14} \mathrm{~m}^{-2}$ for the 120 and $100 \mathrm{MPa}$ conditions, respectively. In addition, the black dot features dispersed in the matrix are believed to be the carbide precipitates, which seem to interact with the dislocations and possibly impeded their motion. The dislocation structures appear to be more tangled for the $100 \mathrm{MPa}$ stressed sample than the $120 \mathrm{MPa}$ stressed sample. 

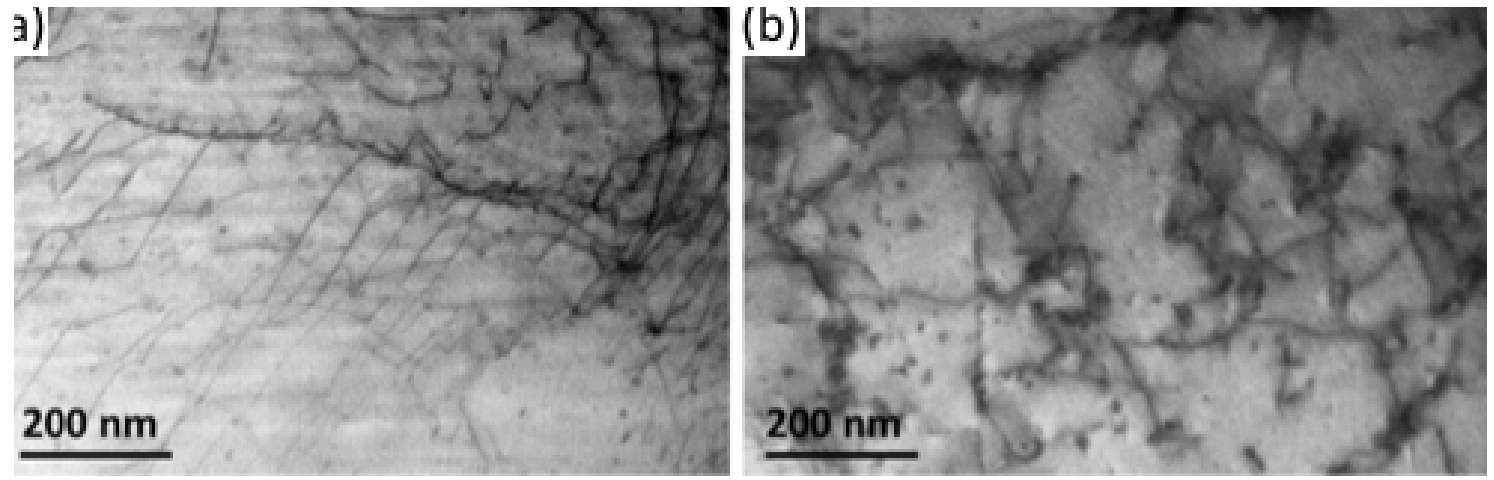

Figure 22. BF-STEM images imaged with the [001] zone from the gauge section of TTZ2M creep-tested at $650^{\circ} \mathrm{C}$ and (a) 120 and (b) $100 \mathrm{MPa}$.

\subsection{ALLOYS FTT1 and FTN1}

Figure 23 shows the optical micrographs of the standard normalized and tempered condition of FTT1 and FTN1, as well as the heat-treated condition FTT1-T and FTN1-T. Conventional tempered martensite structures developed in the standard condition with grain size on the order of $50 \mu \mathrm{m}$ or larger. In contrast, the heat-treated condition shows noticeably refined grains with sizes on the order of $10 \mu \mathrm{m}$. The refined grains are attributed to the noticeably enhanced Charpy impact toughness with DBTT way below $-150^{\circ} \mathrm{C}$ and USE above $76 \mathrm{~J}$ compared to the standard condition with DBTT of $-90^{\circ} \mathrm{C}$ and $-107^{\circ} \mathrm{C}$ and USE of $\sim 69$ $\mathrm{J}$.
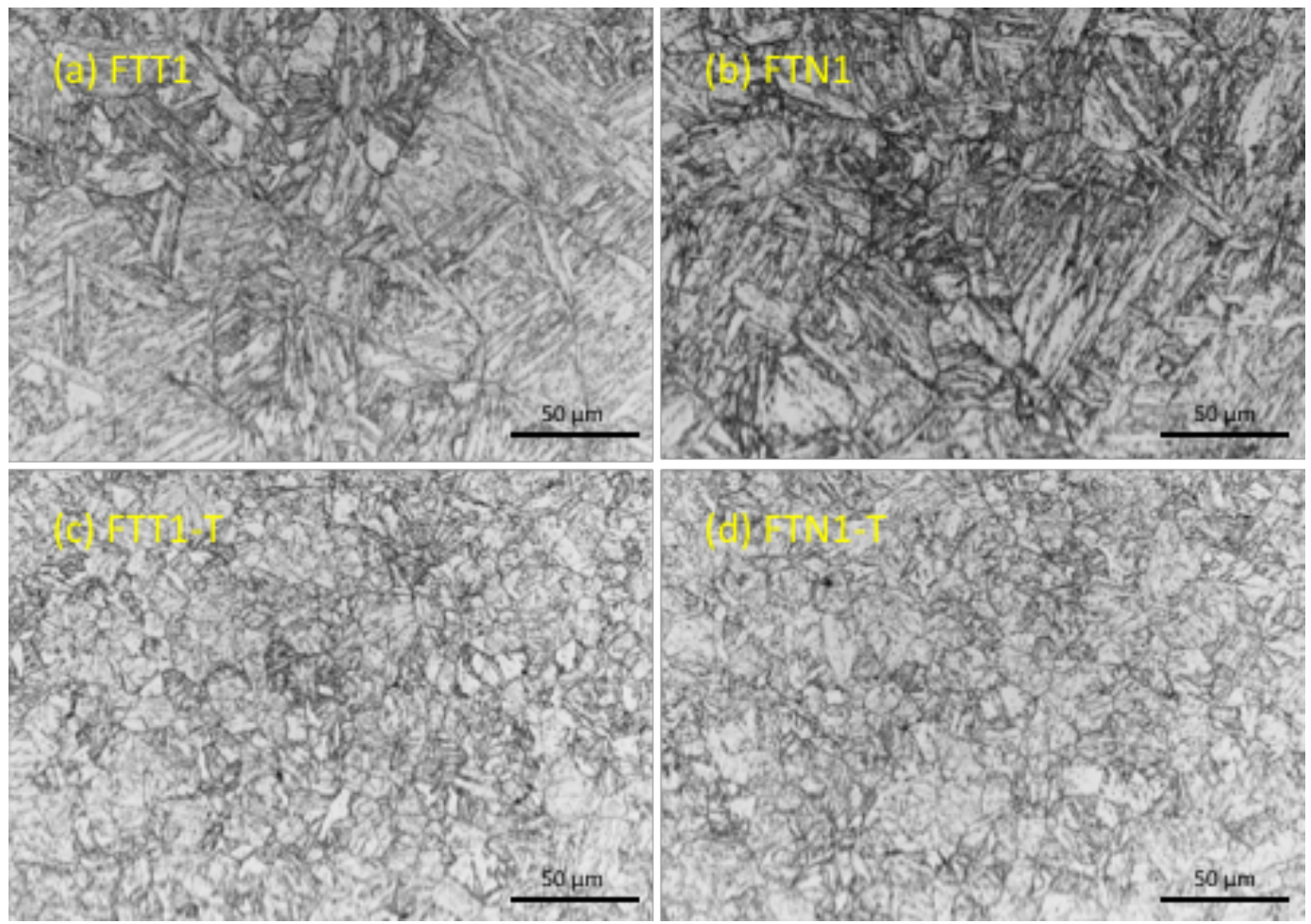

Figure 23. Optical micrographs of (a) FTT1 and (b) FTN1 and their heat-treated version (c) FTT1-T and (d) FTN1-T. 
The overall grain structure of FTN1-T at a lower magnification is shown in Figure 24, which indicates few large grains close to the top-left corner. The presence of some large grains would explain the Charpy impact curve of FTN1-T in Figure 6, tending to have a ductile-brittle transition unlike FTT1-T having a nearly linear fitting curve.

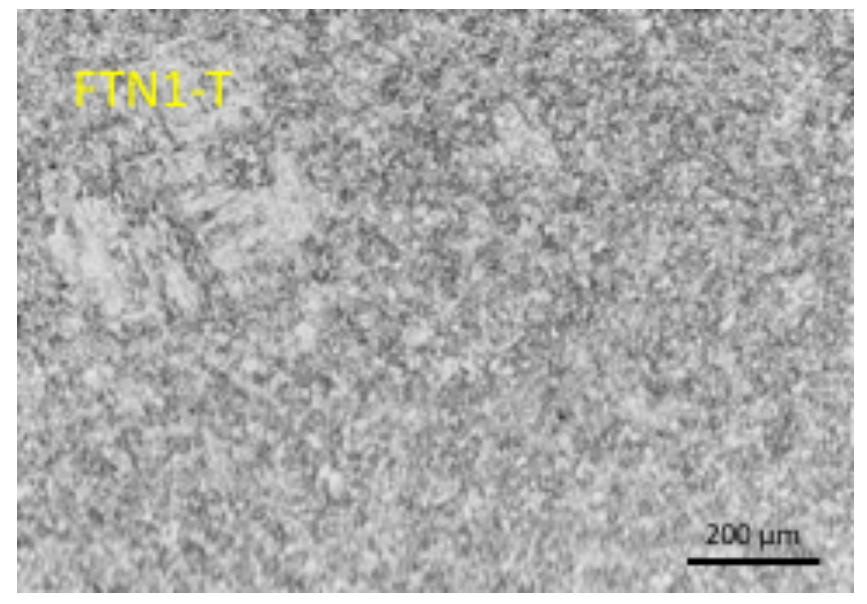

Figure 24. Optical micrograph of FTN1-T showing overall grain structure.

The FTT1 sample, creep-tested at $650^{\circ} \mathrm{C}$ and $100 \mathrm{MPa}$, was characterized. Figure 25 shows the BF and DF TEM and STEM images taken from the [001] zone axis, expect for the DF-TEM image in Figure 25c taken from the (020) two-beam condition near [001] zone axis. The dark region in Figure 25a-b are the [001] onzone region, with the grey region deviated from the on-zone condition. Martensitic lath structure, with a lath width $<200 \mathrm{~nm}$, retained in the tab section (Figure 25a) after nearly $1200 \mathrm{~h}$ exposure at $650^{\circ} \mathrm{C}$. In contrast, the stress in the gauge section (Figure 25b) impaired the lath structure and initiated the formation of polygonal ferrite grains, with the lower-left grain in a size of $\sim 1.1 \mu \mathrm{m}$ in Figure $25 \mathrm{~b}$ as an example. The ferrite grains are noticeably smaller than that $(\sim 3 \mu \mathrm{m})$ at the tab-section of T91 creep-tested at the same condition as shown in Figure 9a, suggesting superior heat resistance of FTT1 compared to T91. The DFTEM image from the gauge section in Figure $25 \mathrm{c}$ shows nanoprecipitates in a pair of parallel white streaks, which is somewhat resemble butterflies or coffee beans, suggesting coherent relationship with the matrix, i.e., aligned with $g_{020}$ of bcc. The white streaks have length in the range of $\sim 3-12 \mathrm{~nm}$. Similar to the rel-rod method determining radiation-induced Frank-loops in austenitic stainless steels, a factor of four was applied to the characterized density in the one of the four $\{200\}$ two-beam conditions near the [001] zone axis, leading to the precipitate density of $(2.8 \pm 0.5) \times 10^{21} \mathrm{~m}^{-3}$. BF-STEM image from the gauge section in Figure $25 \mathrm{~d}$ reveals a high-density of dislocation, suggesting the intensive role of dislocations in the ferriticmartensitic steel under the creep test at $650^{\circ} \mathrm{C}$. 

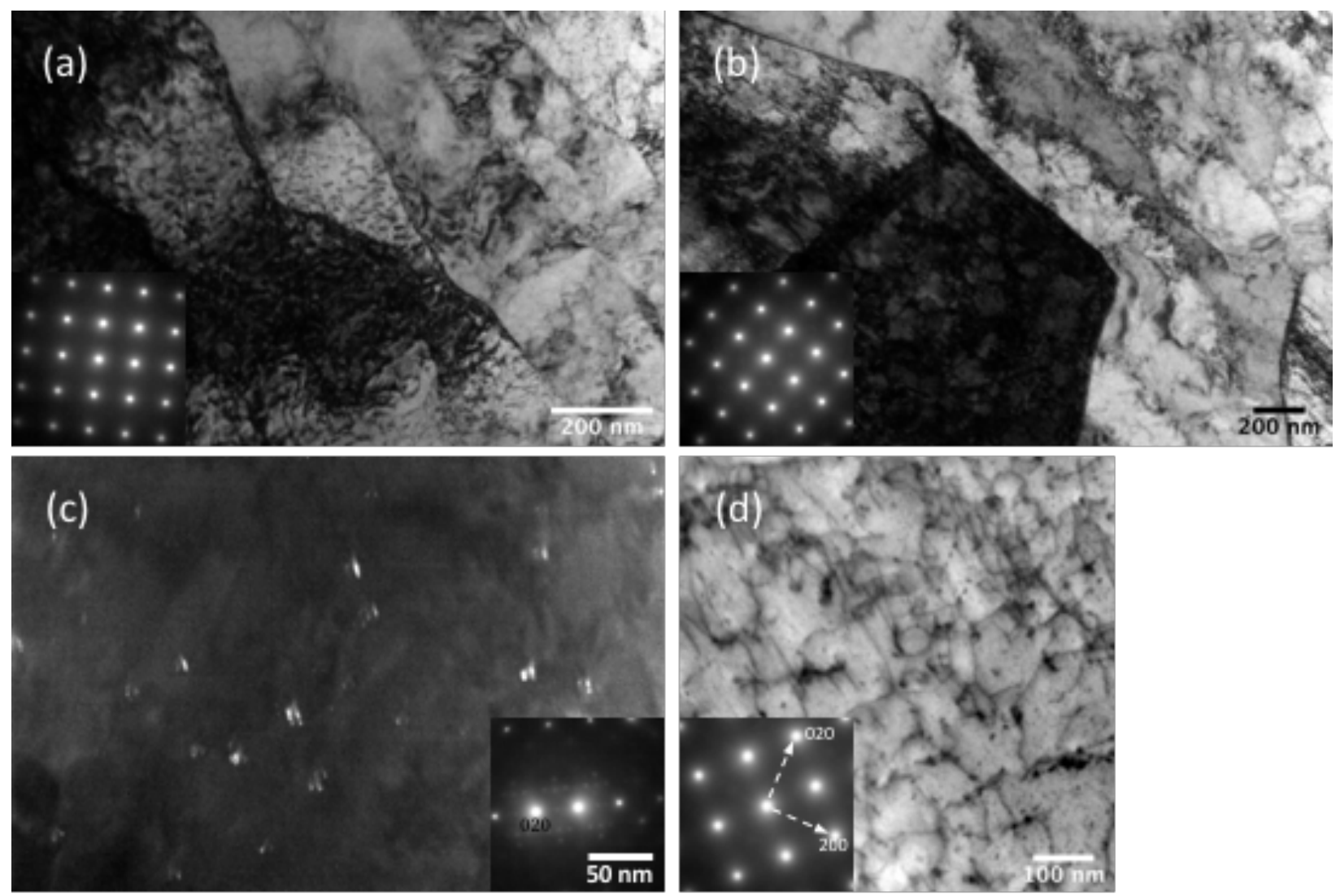

Figure 25. Creep-tested FTT1 at $650^{\circ} \mathrm{C}$ and 100 MPa: (a) BF-TEM image at the tab section, (b) BF-TEM image at the gauge section, (c) DF-TEM image at the gauge section, and (d) BF-STEM image at the gauge section.

The creep test of a FTN1 sample at $650^{\circ} \mathrm{C}$ and $100 \mathrm{MPa}$ is running, and thus its microstructural characterization was not available during the preparation of this report, which will be completed for journal paper publication for comparing with the FTT1 sample. The heat-treated version FTN1-T and FTT1-T were not creep tested yet, but are expected to have creep resistance inferior to their standard counterpart FTN1 and FTT1 as suggested by their tensile properties in Figure 5.

\subsection{SUMMARY}

Microstructure characterizations of the creep-ruptured samples indicate noticeable recovery of T91 with diminished lath/block/packet sub-structures and reduced dislocations to the order of $10^{13} \mathrm{~m}^{-2}$. The limited precipitates with a density on the order of $10^{19} \mathrm{~m}^{-3}$ would not effectively help retain the dislocations and the sub-structures at $650^{\circ} \mathrm{C}$. In contrast, the large number of $\mathrm{B} 2-\mathrm{NiAl}$ and Laves $\mathrm{Fe}_{2}(\mathrm{~W}, \mathrm{Nb})$ with about comparable sizes on the order of $100 \mathrm{~nm}$ and a combined density on the order of $10^{20} \mathrm{~m}^{-3}$ after the creep tests helped retain sub-grain structures of $\mathrm{BL}-\mathrm{Nb}$, although the size/density and the chemistry of the precipitates evolved during the creep tests. Similarly, the high-density (on the order of $10^{21} \mathrm{~m}^{-3}$ ) of ultrafine $(<\sim 20 \mathrm{~nm})$ precipitates in TTZ2M and FTT1 helped retain the sub-structures and dislocations during the creep tests.

The microstructures of the untested condition indicated refined grains $(\sim 10 \mu \mathrm{m})$ for the heat-treated version FTN1-T and FTT1-T compared to the general $\sim 50 \mu \mathrm{m}$ or larger prior-austenite grains of the standard condition (FTN1 and FTT1) with tempered martensite structures. The refined grains would explain the 
enhanced Charpy impact toughness of the heat-treated version with compromised yield/tensile strength and creep resistance. 


\section{ION IRRADIATION}

Rastering ion beam was used for the small laboratory heats, e.g., BL-Nb and TTZ2M, in previous irradiation experiments. However, defocused ion beam was employed for the large-scale industrial heats FTN1 and FTT1 in the latest irradiation experiments because literatures reported that rastering beam could suppress radiation-induced swelling. Samples of T91 were irradiated together with the other alloys during the rastering or defocused beam irradiation experiments.

\subsection{DEFOCUSED BEAM}

\subsection{1 $350^{\circ} \mathrm{C} 250$ dpa $\mathrm{Fe}^{2+}$ irradiation (with $\mathrm{Al}$ ions implanted)}

Two runs of $3.7 \mathrm{MeV} \mathrm{Fe}^{2+}$ irradiation for samples TA (FTT1) (run 1), NA (FTN1) and T91 (run 2) at $350^{\circ} \mathrm{C}$ to a peak damage of 250 dpa were performed with defocused and non-rastering ion beam, with irradiation parameters as:

- Energy and Irradiating Ion Species: defocused 3.7 $\mathrm{MeV} \mathrm{Fe}^{2+}$ defocused beam. Aluminum implantation was found, as shown in Figure 29.

- Damage Level: peak damage $251 \mathrm{dpa}$ in TA, NA, and T91 at $\sim 1.0 \mu \mathrm{m}$ depth, as shown in Figure 26.

- Irradiation Temperature: $351 \pm 1^{\circ} \mathrm{C}$ for run 1 on TA, as shown in Figure $27 \mathrm{a}$, and $351 \pm 4^{\circ} \mathrm{C}$ for run 2 on NA and T91, as shown in Figure 27b.

- Irradiation Flux: $(7.5 \pm 0.6) \times 10^{12} \mathrm{ion} / \mathrm{cm}^{2} / \mathrm{s}$ (run 1, Figure $27 \mathrm{a}$ ) and $(8 \pm 3) \times 10^{12} \mathrm{ion} / \mathrm{cm}^{2} / \mathrm{s}($ run 2 , Figure 27b). The large standard deviation of flux in run 2 came from the beam current spikes as shown in Figure 27b.

- Vacuum/Base Pressure: $(3.4-5.5) \times 10^{-7}$ Torr (base), $1.3 \times 10^{-6}-4 \times 10^{-7}$ Torr (irradiation vacuum)

Figure 26 shows the damage depth profile of $3.7 \mathrm{MeV} \mathrm{Fe}^{2+}$ irradiation in the alloys. To achieve a peak damage of $\sim 250 \mathrm{dpa}$, a fluence of $2.43 \times 10^{17} \mathrm{Fe}^{2+} / \mathrm{cm}^{2}$ was used. The peak damage took place at $\sim 1.0 \mu \mathrm{m}$ under surface. A sample of an austenitic alloy 2AT35 with a nominal composition of Fe-35Ni-3Al-2Ti was irradiated in the run- 1 with the TA sample to study radiation effects on the stability of the $\mathrm{L}_{2}-\mathrm{Ni}_{3} \mathrm{Al}$ nanoprecipitates for another project.

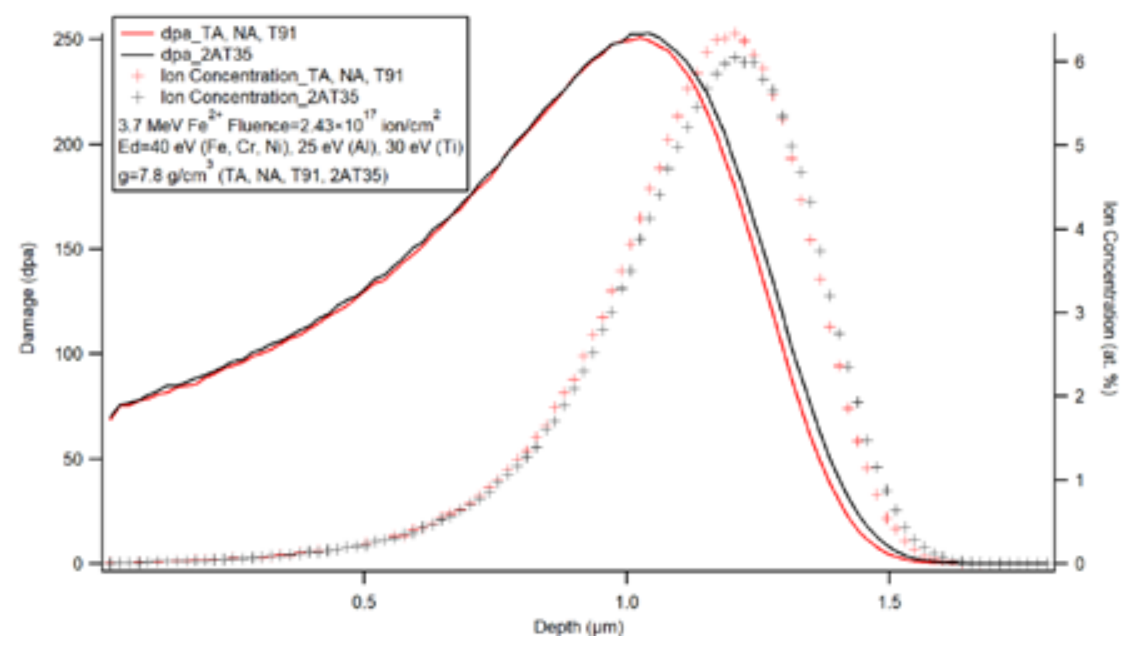


Figure 26. 3.7 MeV iron induced damage and implanted iron concentration in FTN1 (NA), FTT1 (TA), T91 (red). The damage and implantation depth profiles were calculated using the Kinchin-Pease Model in the Stopping and Range of Ions in Matter (SRIM) software. $E d$ is atom displacement energy.

Irradiation temperature and flux are shown in Figure 27. Temperature is average readings of two thermocouples welded at opposite corners of the sample stage. Flux was calculated from ion beam current and beam confining aperture size $\left(0.5 \mathrm{~cm} \times 0.5 \mathrm{~cm}=0.25 \mathrm{~cm}^{2}\right)$. Flux spikes resulted from spikes of ion current or possibly secondary electron currents. In run 2 , there were high ion current / flux spikes, as shown in Figure $27 \mathrm{~b}$. The source of the beam instability was uncertain.

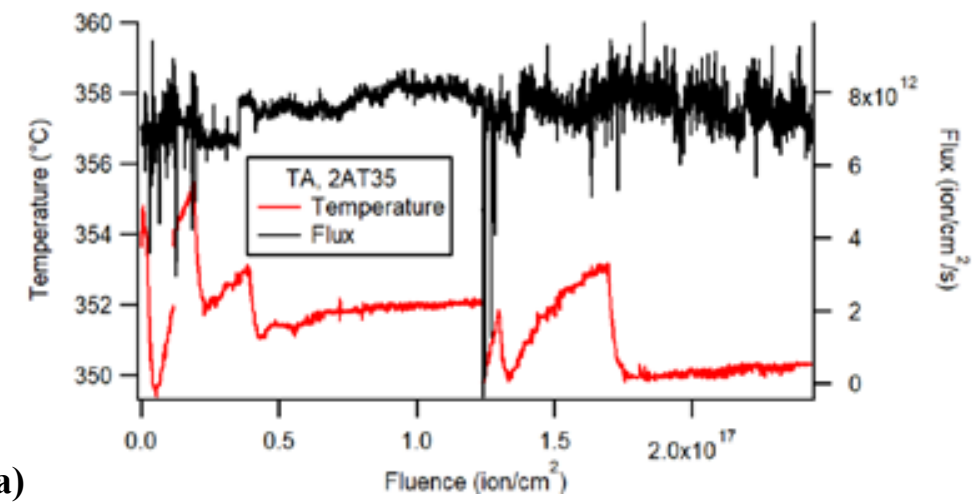

(a)

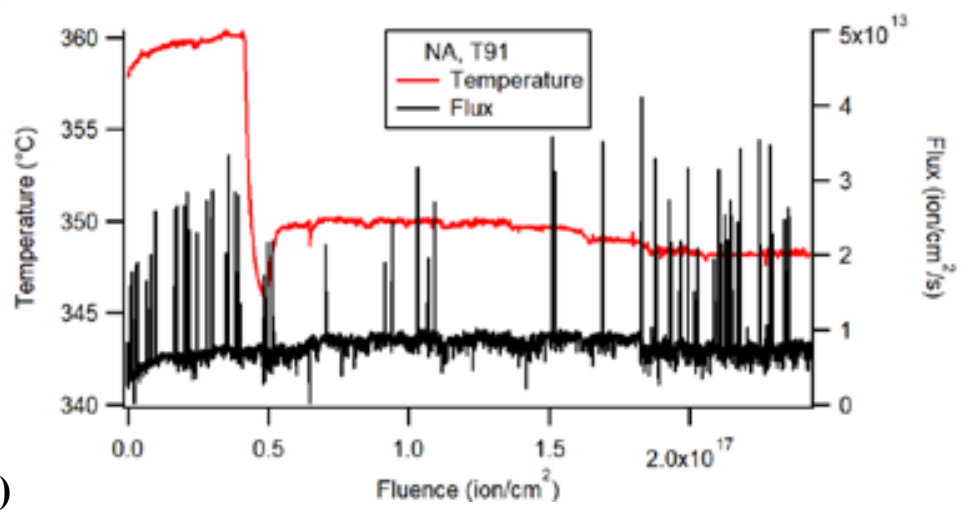

Figure 27. Temperature and flux during $3.7 \mathrm{MeV}$ iron $350^{\circ} \mathrm{C}$ irradiation. (a) Irradiation run 1 of FTT1 (TA); (b) Irradiation run 2 of FTN1 (NA) and T91.

Figure 28 shows sample pictures after irradiation. Samples were partially irradiated as the irradiation area in one run was about $0.5 \mathrm{~cm} \times 0.5 \mathrm{~cm}$. There is no visible irradiation boundary on TA and 2AT35 as shown in Figure 28a. The irradiated area in Figure 28b is darker while unirradiated parts are of silver color. 

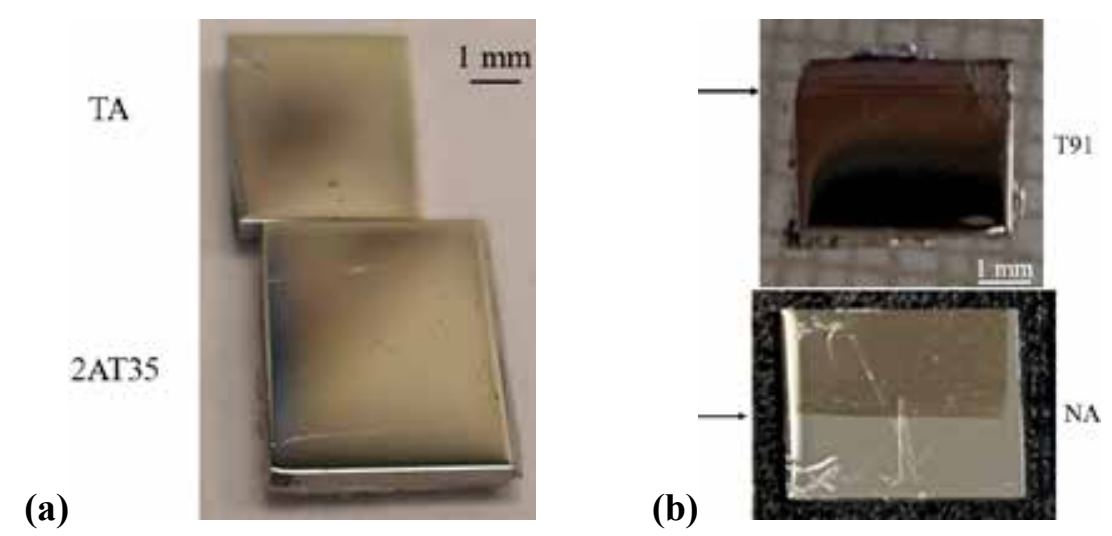

Figure 28. Samples after $350^{\circ} \mathrm{C}, 250 \mathrm{dpa} \mathrm{Fe} \mathrm{Ci}^{2+}$ irradiation. (a) Run 1 of FTT1 (TA). (b) Run 2 of T91 and FTN1 (NA). Arrows indicate irradiation boundary. The lower part of T91 and upper part of FTN1 (NA) are irradiated.

Figure 29 shows Al concentration measured with transmission electron microscopy (TEM) and EDS in NA and T91 after the irradiation. Following the red lines on the annular bright-field (ABF) images on Figure $29 \mathrm{a}-\mathrm{b}$, EDS depth profiles are shown in Figure 29c with Al peak concentration at depth of $\sim 1 \mu \mathrm{m}$. It has to be high energy Al ions to reach this implantation peak depth. The ion beam for the irradiation of NA and T91 thus was possibly consisted of significant Al ions. Al concentration calculated with SRIM is shown in Figure $29 \mathrm{c}$ assuming $\mathrm{Al}^{+}$ions of $2.47 \mathrm{MeV}$ and $4.86 \times 10^{17} \mathrm{ion} / \mathrm{cm}^{2}$.
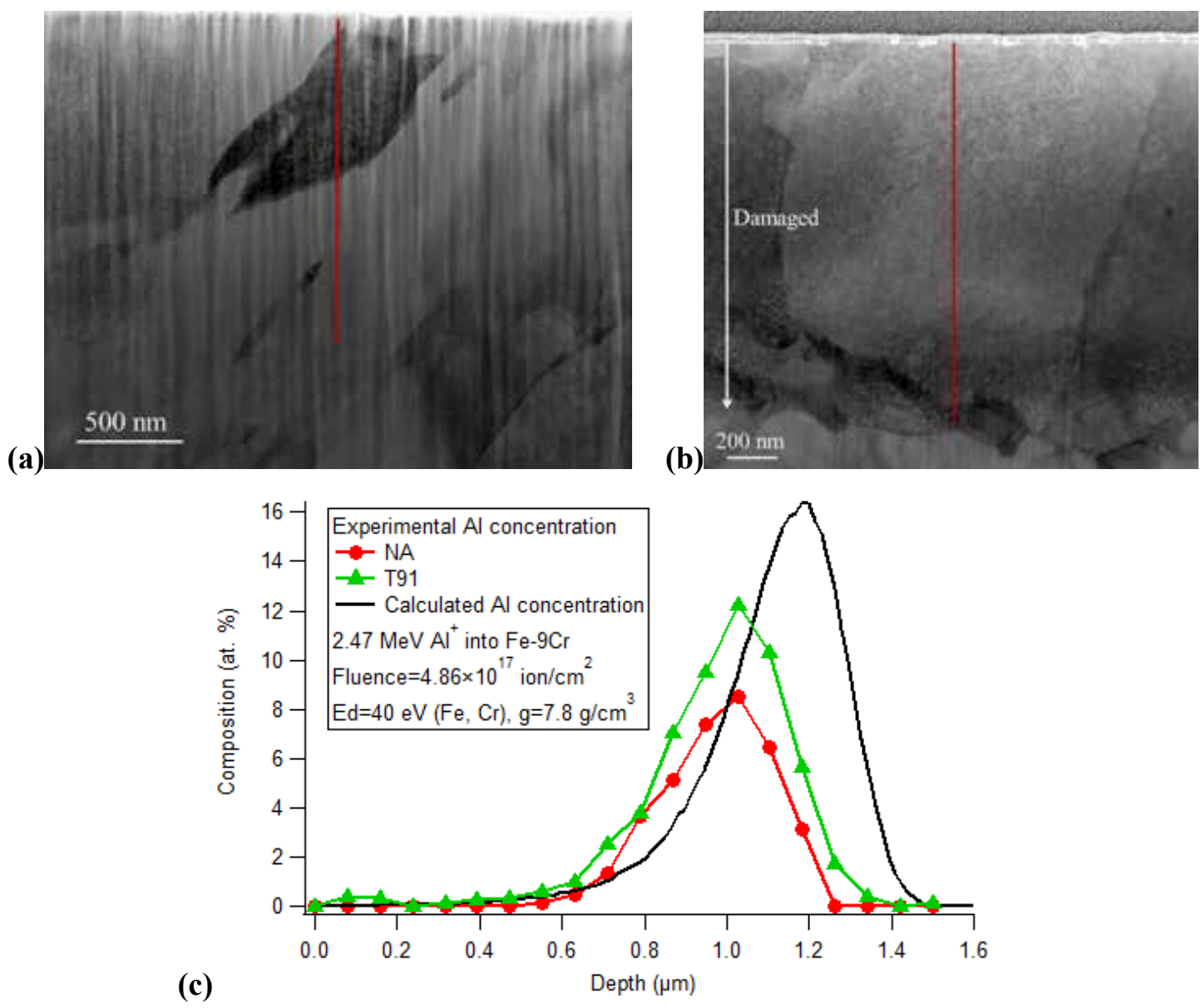
Figure 29. Al implantation in the $350^{\circ} \mathrm{C}$ irradiated FTN1 (NA) and T91 samples. ABF images of cross-sectional (a) FTN1 (NA) and (b) T91 with the red lines illustrating the EDS line scan paths for the (c) EDS depth profile and SRIM calculated Al composition from surface.

\subsection{2 $\quad 475^{\circ} \mathrm{C} 250$ dpa $\mathrm{Fe}^{2+}$ irradiation (with $\mathrm{Cu}$ ions implanted)}

A new Fe cathode was used in the following two runs of $3.7 \mathrm{MeV} \mathrm{Fe}^{2+}$ irradiation of samples TA (run 3), NA and T91 (run 4) at $475^{\circ} \mathrm{C}$ to a peak damage of $\sim 250$ dpa with defocused, non-rastering ion beam. Temperature was measured by average of two-thermocouple readings attached to the opposite corners of the irradiation sample stage. Irradiation parameters are the following:

- Energy and Irradiating Ion Species: defocused 3.7 $\mathrm{MeV} \mathrm{Fe}^{2+}$ defocused beam. $\mathrm{Cu}$ implantation is found, as shown in Figure 32.

- Damage Level: peak damage $\sim 250$ dpa at $\sim 1.0 \mu \mathrm{m}$ depth, as shown in Figure 26.

- Fluence: $2.43 \times 10^{17} \mathrm{ion} / \mathrm{cm}^{2}$ (run 3), $2.39 \times 10^{17} \mathrm{ion} / \mathrm{cm}^{2}$ (run 4).

- Irradiation Temperature: $474 \pm 2{ }^{\circ} \mathrm{C}$ for run 3 on TA, as shown in Figure 30a, and $474 \pm 2{ }^{\circ} \mathrm{C}$ for run 4 on NA and T91, as shown in Figure 30b.

- Irradiation Flux: $(8 \pm 2) \times 10^{12} \mathrm{ion} / \mathrm{cm}^{2} / \mathrm{s}($ run 3, Figure $30 \mathrm{a})$ and $(7 \pm 1) \times 10^{12} \mathrm{ion} / \mathrm{cm}^{2} / \mathrm{s}($ run 4 , Figure 30b).

- Vacuum/Base Pressure: $4 \times 10^{-7}$ Torr (base), $2 \times 10^{-6}-4.5 \times 10^{-7}$ Torr (irradiation vacuum)

To achieve a peak damage of $\sim 250 \mathrm{dpa}$, a fluence of $2.4 \times 10^{17} \mathrm{Fe}^{2+} / \mathrm{cm}^{2}$ was used. The peak damage took place at $\sim 1.0 \mu \mathrm{m}$ under surface. Irradiation temperature and flux are shown in Figure 30. Flux was calculated from ion beam current and beam confining aperture size $\left(0.5 \mathrm{~cm} \times 0.5 \mathrm{~cm}=0.25 \mathrm{~cm}^{2}\right)$. Flux spikes resulted from spikes of ion current or possibly secondary electron currents.

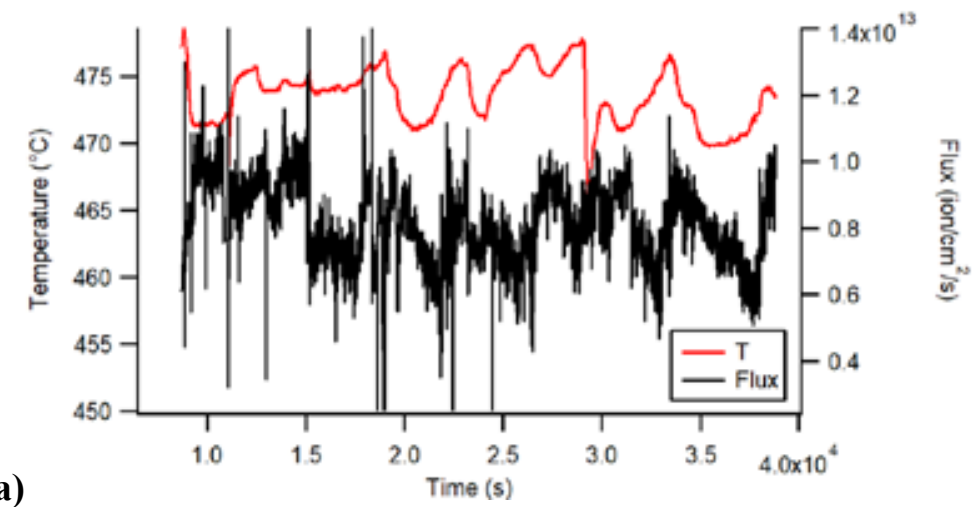

(a)

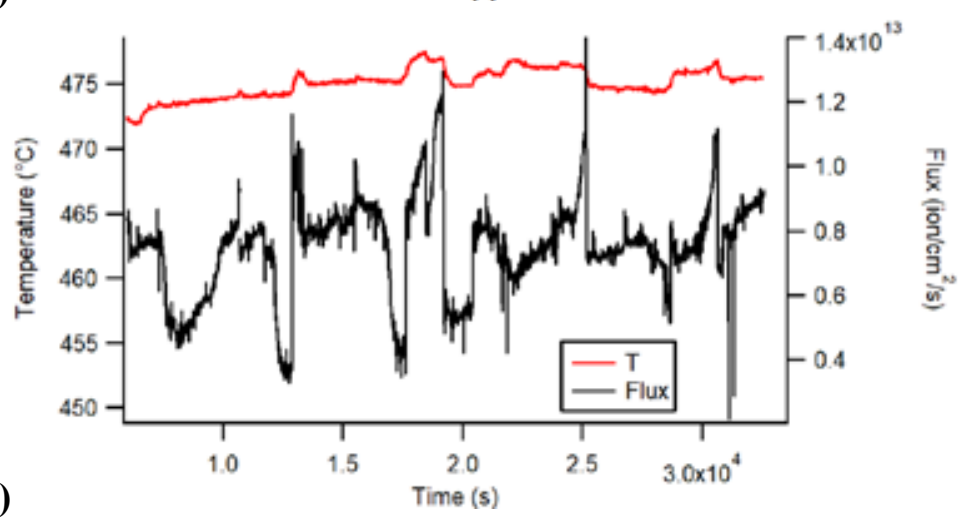


Figure 30. Temperature and flux during 3.7 MeV iron $475^{\circ} \mathrm{C}$ irradiation. (a) Irradiation run 3 of FTT1 (TA). (b) Irradiation run 4 of FTN1 (NA) and T91.

Figure 31 shows sample pictures after irradiation. Samples were partially irradiated as the total irradiation area for two samples was about $0.5 \mathrm{~cm} \times 0.5 \mathrm{~cm}$. The irradiated area is darker while unirradiated parts are of silver color.

(a)

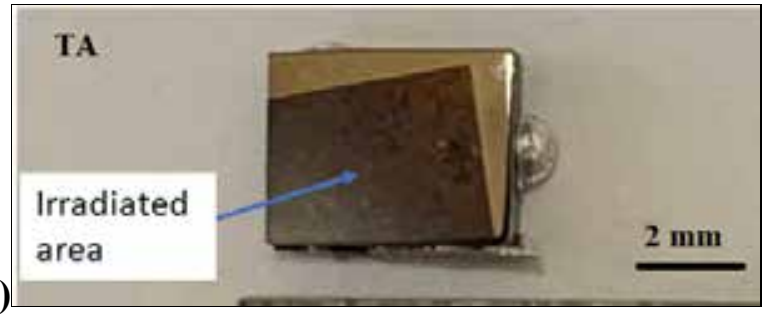

(b)

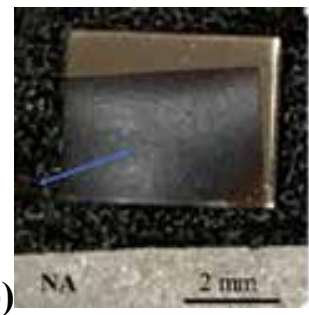

(c)

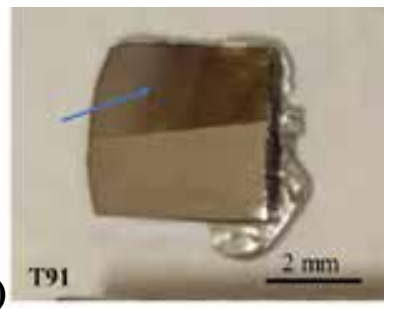

Figure 31. Samples after $475^{\circ} \mathrm{C}, 250$ dpa Fe ${ }^{2+}$ irradiation: (a) FTT1 (TA); (b) FTN1 (NA); (c) T91. Arrows indicate irradiation area.

(a)

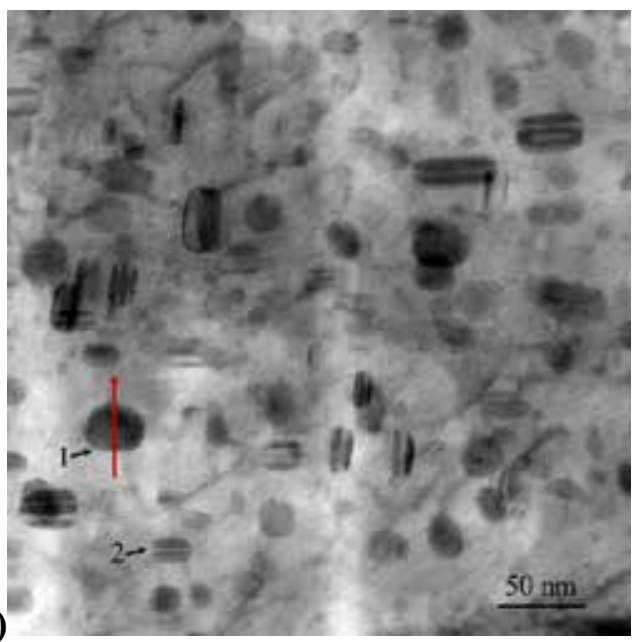

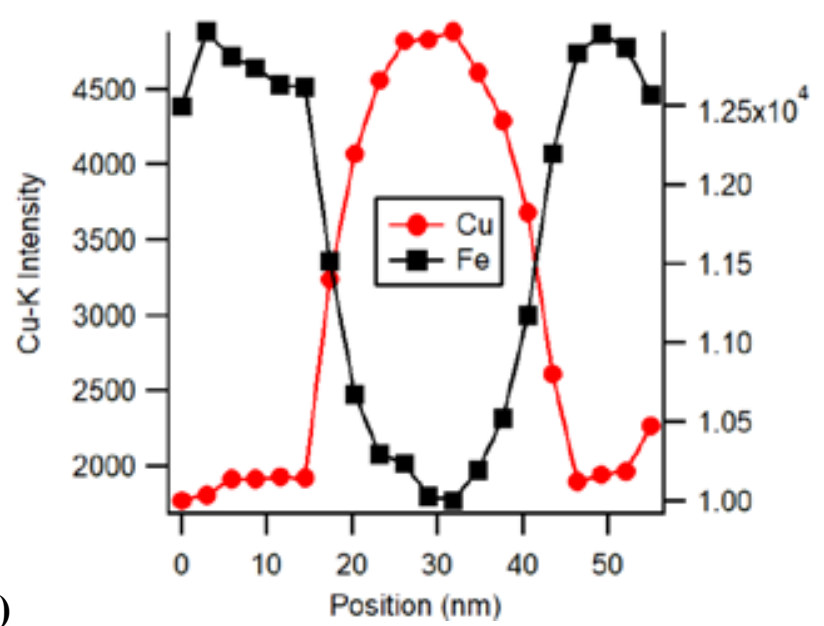

(b)

Figure 32. (a) Cross-sectional ABF image and (b) EDS line scan profile across the red line in (a) of $\mathrm{Fe}^{2+}$ irradiated FTN1 (NA) up to 250 dpa at $475^{\circ} \mathrm{C}$ showing Cu-rich particles at $\sim 1.1 \mu \mathrm{m}$ depth.

$\mathrm{Cu}$ is the material of cathode jacket. It is possible that the injector and switch magnets did not correctly select $\mathrm{Fe}^{2+}$ only but instead mixture of $\mathrm{Fe}^{2+}$ and $\mathrm{Cu}^{2+}$. This issue is under inspection. On the other hand, no Al implantation is found from the run 4 samples.

In summary, defocused beam ion irradiation was employed. However, two issues arose with the defocused $\mathrm{Fe}^{2+}$ ion beam irradiations:

- $\mathrm{Al}$ ion contamination in NA and T91 irradiated at $350^{\circ} \mathrm{C}$. It is associated with Fe depletion in the cathode. With a new Fe cathode, there is no $\mathrm{Al}$ found in the $475^{\circ} \mathrm{C}$ irradiated sample NA.

- $\mathrm{Cu}$ ion contamination in NA irradiated at $475^{\circ} \mathrm{C} . \mathrm{Cu}$ is the material of cathode jacket. We are inspecting magnetic settings to solve the issue.

The comparison of FTN1 (NA) and FTT1 (TA) samples to the reference T91 samples irradiated under the same conditions could provide meaningful indications regarding their relative radiation resistance despite 
the unexpected $\mathrm{Al} / \mathrm{Cu}$ contamination preventing the results from direct comparison to literature data of similar steels.

\subsection{RASTERING BEAM}

The irradiation condition of the rastering beam ion irradiation was:

- Energy and Irradiating Ion Species: $4.0 \mathrm{MeV} \mathrm{Fe}^{2+}$ irradiation

- Damage Level: peak damage 217 dpa at $1.11 \mu \mathrm{m}$ depth, as shown in Figure 33.

- Irradiation Temperature: about $475^{\circ} \mathrm{C}\left(474 \pm 3^{\circ} \mathrm{C}\right.$ for run 1 as shown in Figure $34 \mathrm{a}$, and $472 \pm$ $2{ }^{\circ} \mathrm{C}$ for run 2 as shown in Figure $\left.34 \mathrm{~b}\right)$.

- Irradiation Flux: $(6.4 \pm 0.8) \times 10^{12} \mathrm{ion} / \mathrm{cm}^{2} / \mathrm{s}$ (run 1) and $(6.6 \pm 0.9) \times 10^{12} \mathrm{ion} / \mathrm{cm}^{2} / \mathrm{s}($ run 2$)$.

- Vacuum/Base Pressure: $5 \times 10^{-7}$ Torr (base), $2.6 \times 10^{-6}-5.8 \times 10^{-7}$ Torr (irradiation vacuum)

Figure 33 shows the damage profile of $4.0 \mathrm{MeV} \mathrm{Fe}^{2+}$ irradiation in $\mathrm{BL}-\mathrm{Nb}$ with a nominal composition of $79 \mathrm{Fe}-12 \mathrm{Cr}-3 \mathrm{~W}-3 \mathrm{Ni}-3 \mathrm{Al}$. To achieve a damage of $100 \mathrm{dpa}$ at $0.48 \mu \mathrm{m}$ where the damage profile is relatively flat (damage vs. depth slope is relatively small), a fluence of $2.14 \times 10^{17} \mathrm{Fe}^{2+} / \mathrm{cm}^{2}$ was used. The peak damage is $217 \mathrm{dpa}$ at $1.1 \mu \mathrm{m}$ under surface. Similar calculation was conducted for TTZ2M, which generated nearly identical damage and implantation depth profiles.

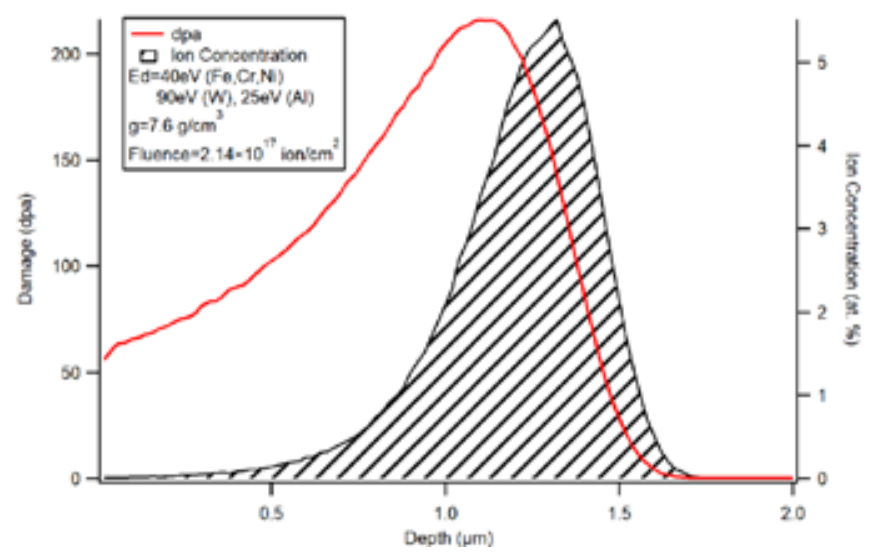

Figure 33. $4 \mathrm{MeV}$ iron induced damage in BL-Nb (79Fe-12Cr-3W-3Ni-3Al). The damage and implantation profiles were calculated using the Kinchin-Pease Model in the SRIM software. $E d$ is atom displacement energy.

Irradiation temperature and flux are shown in Figure 34. Temperature is average value of two-thermocouple readings from opposite corners of the sample stage. Flux was calculated from ion beam current and beam scanning area $\left(2 \mathrm{~cm}^{2}\right)$. Occasional positive or negative flux spikes resulted from spikes of ion current or possibly secondary electron currents. In run 1 , temperature is $474 \pm 3^{\circ} \mathrm{C}$ and flux is $(6.4 \pm 0.8) \times 10^{12}$ ion $/ \mathrm{cm}^{2} / \mathrm{s}$. In run 2 , temperature is $472 \pm 2{ }^{\circ} \mathrm{C}$ and flux is $(6.6 \pm 0.9) \times 10^{12} \mathrm{ion} / \mathrm{cm}^{2} / \mathrm{s}$. 


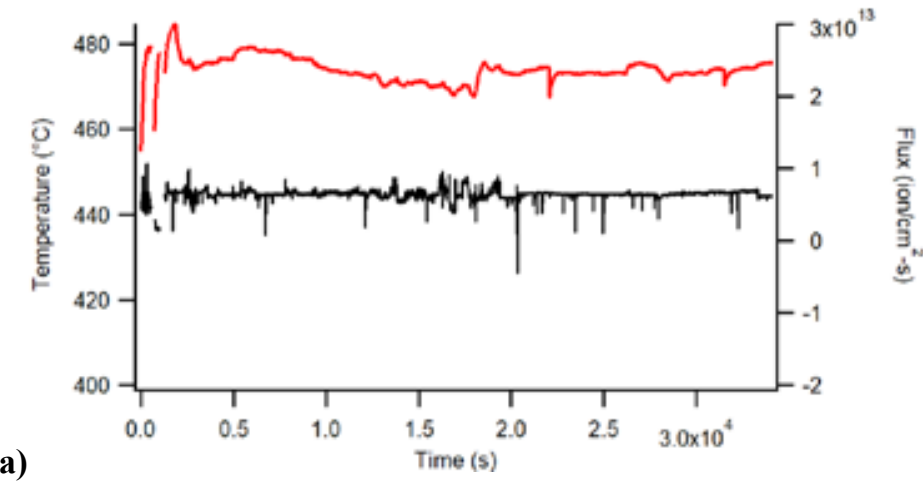

(a)

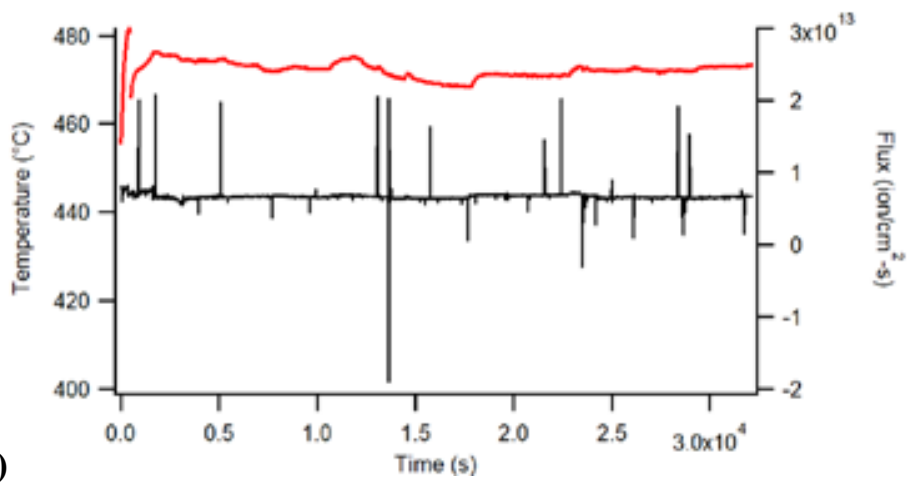

Figure 34. Temperature and flux during $4 \mathrm{MeV}$ iron irradiation (a) run 1 and (b) run 2 of BL-Nb.

\subsection{NANOINDENTATION}

A Hysitron TI-950 TriboIndenter with a Berkovich tip and a High Load transducer was used to measure hardness of alloys at a displacement control mode. Ten indentation measurements were performed at each displacement. Average and standard deviation results are reported in Figure 35. Measurement was made on both irradiated and unirradiated area (masked during irradiation). The masked area did not experience irradiation but experienced the same thermal history as the irradiated area. Hardness of unirradiated and irradiated area are plotted in Figure 35 for the defocused-beam-irradiated up to 250 dpa for (a) NA at $350^{\circ} \mathrm{C}$, (b) $\mathrm{T} 91$ at $350^{\circ} \mathrm{C}$, (c) $\mathrm{NA}$ at $475^{\circ} \mathrm{C}$, (d) $\mathrm{T} 91$ at $475^{\circ} \mathrm{C}$, and the rastered-beam-irradiated up to 220 dpa for (e) TTZ2M and (f) BL-Nb at $475^{\circ} \mathrm{C}$. The sample T91 irradiated at $350^{\circ} \mathrm{C}$ has a very small unirradiated area near the sample edge that did not have reliable hardness result. Therefore, results of as-received T91 are plotted in Figure 35b with the irradiated hardness. 

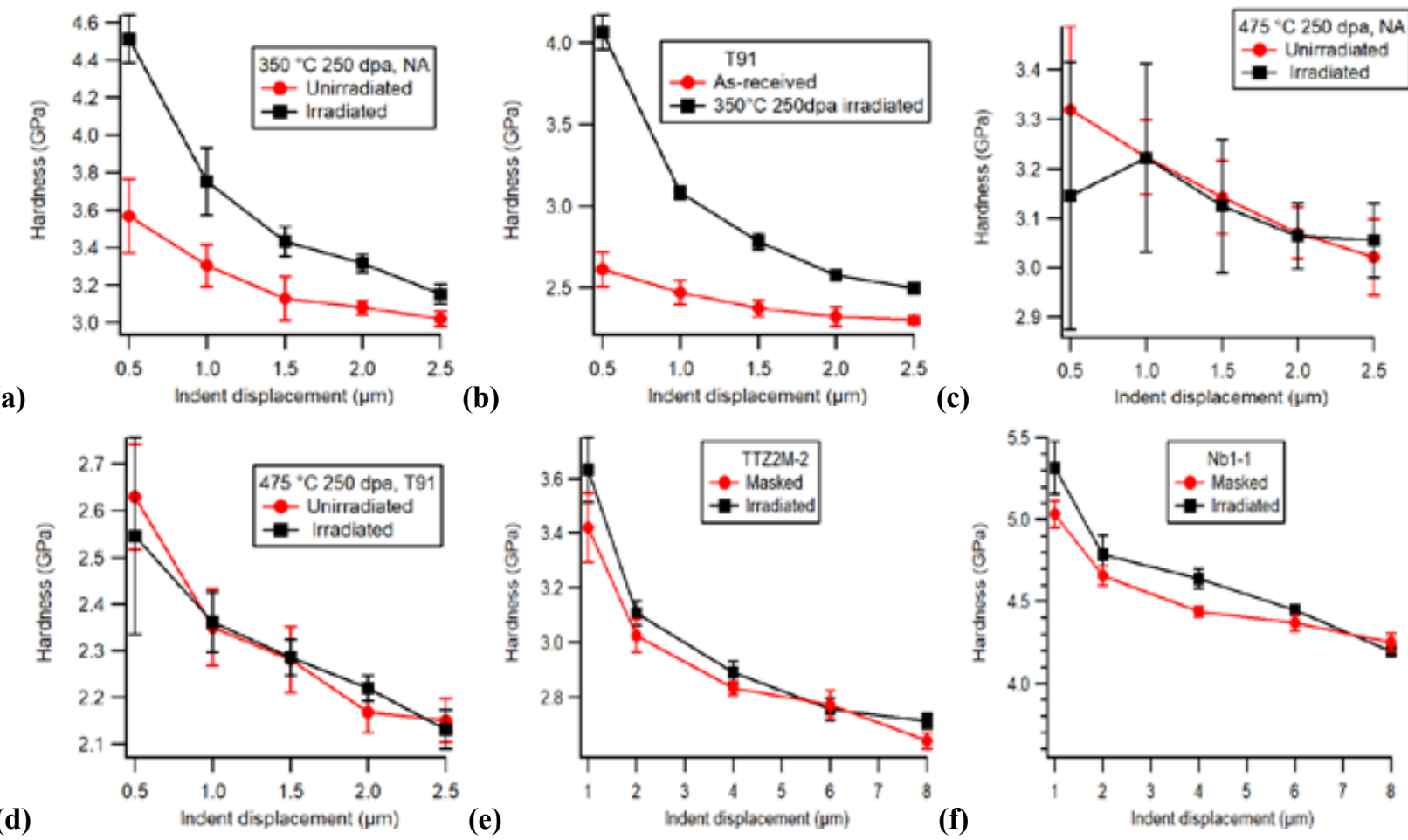

Figure 35. Nanoindentation hardness of ion-irradiated samples: defocused-beam up to $250 \mathrm{dpa}$ at $350^{\circ} \mathrm{C}$ for (a) FTN1 (NA) and (b) T91 and at $475^{\circ} \mathrm{C}$ for (c) FTN1 (NA) and (d) T91; rastered-beam up to 220 dpa at $475^{\circ} \mathrm{C}$ for (e) TTZ2M and (f) BL-Nb.

The results of irradiation induced hardening for FTN1 (NA), T91, TTZ2M, and BL-Nb are:

- Ion irradiation up to $250 \mathrm{dpa}$ (peak damage depth at $\sim 1 \mu \mathrm{m}$ ) at $350^{\circ} \mathrm{C}$ increased the hardness of FTN1 (NA) by $26.4 \pm 7.8 \%$, as measured at $0.5 \mu \mathrm{m}$ indent displacement, which is about half of the hardening in T91 by $55.7 \pm 7.5 \%$, assuming the hardness of as-received T91 does not change significantly after heating at $350^{\circ} \mathrm{C}$ for 10.6 hours (irradiation timespan).

- Hardness appears similar for unirradiated and irradiated FTN1 (NA) and T91 up to 250 dpa at $475^{\circ} \mathrm{C}$, except for the larger deviations of the hardness data of NA.

- The rastered-beam-irradiated TTZ2M and BL-Nb up to $220 \mathrm{dpa}$ at $475^{\circ} \mathrm{C}$ showed comparable slight hardening by $\sim 6 \pm 5 \%$ and $\sim 6 \pm 3 \%$, respectively, as measured at $1 \mu \mathrm{m}$ indent displacement. The radiation-hardening of TTZ2M and BL-Nb is believed to be measurably larger than the defocusedbeam-irradiated FTN1 (NA) and T91 because the hardening at $0.5 \mu \mathrm{m}$ of TTZ2M and BL-Nb (not measured) is expected to be greater than that at $1 \mu \mathrm{m}$.

In summary, irradiation at $350^{\circ} \mathrm{C}$ to 250 dpa induced significant hardening in both FTN1 (NA) and T91. Hardening in FTN1 (NA) was about half of that in T91. Irradiation up to $250 \mathrm{dpa}$ at $475^{\circ} \mathrm{C}$ did not induce noticeably hardening in FTN1 (NA) and T91, but the rastered-beam-irradiated TTZ2M and BL-Nb showed slightly larger hardening at $475^{\circ} \mathrm{C}$. 


\subsection{MICROSTRUCTURES}

\subsubsection{FTN1 (NA) irradiated up to 250 dpa at $350^{\circ} \mathrm{C}$}

Figure 36 shows cross-sectional ABF images of the $350^{\circ} \mathrm{C}$-irradiated FTN1 (NA) sample. Irradiation damaged the sample from surface to $\sim 1.5 \mu \mathrm{m}$ deep, as denoted in Figure 36a. There are dislocation loops in the damaged region, as shown in dark spot contrast along [100] zone in Figure 36b at $0.54 \mu \mathrm{m}$ depth. The size of dislocation loops that are visible under [100] zone is $3.0 \pm 1.5 \mathrm{~nm}$ with a dislocation loop density of $9 \times 10^{22} \mathrm{~m}^{-3}$.
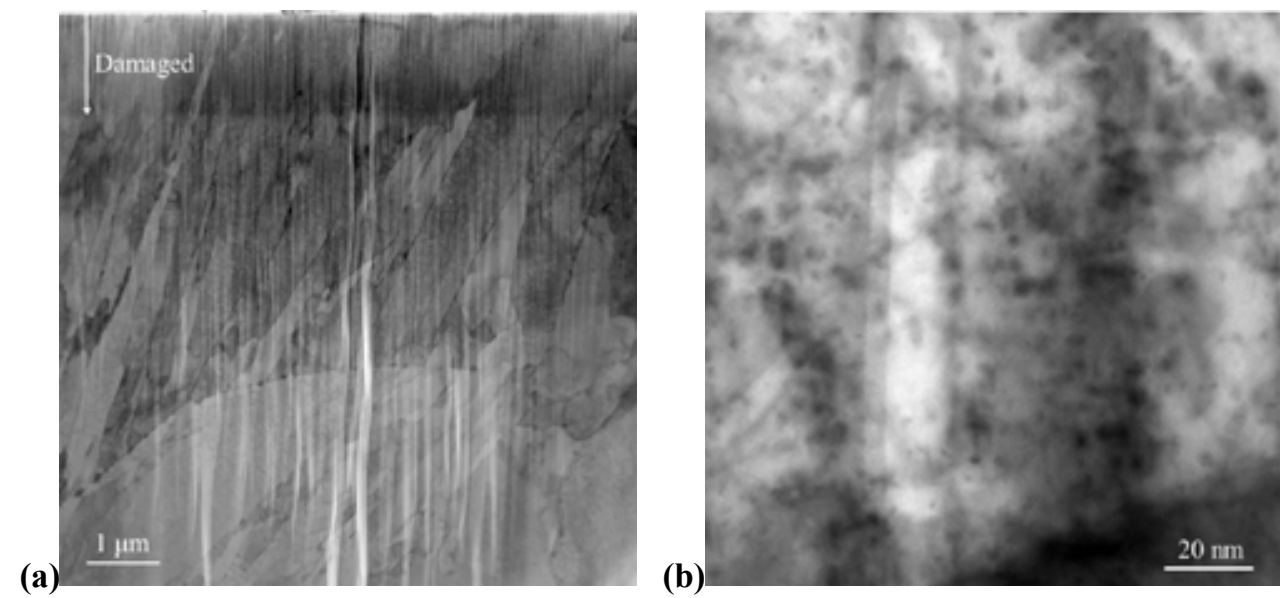

Figure 36. Cross-sectional ABF images of FTN1 (NA) after $350^{\circ} \mathrm{C}$ ion irradiation: (a) Overview and (b) Damaged region at $0.54 \mu \mathrm{m}$ depth with normal direction parallel to [100].

Precipitates in FTN1 (NA) are shown in Figure 37. Two types of precipitates were found in the undamaged region, as shown in Figure 37a: $\mathrm{M}_{23} \mathrm{C}_{6}$ (about $97 \mathrm{Cr}-2.5 \mathrm{~W}-0.5 \mathrm{~V}$ metal components, at. \%), and finer Ti, $\mathrm{W}$, $\mathrm{Nb}$-rich carbide (about $72 \mathrm{Ti}-25 \mathrm{~W}-3 \mathrm{Nb}$ metal components, at.\%). In the damaged region as shown in Figure $37 \mathrm{~b}, \mathrm{Ti}, \mathrm{W}, \mathrm{Nb}$-rich carbide has not been found. It may be because the contrast of dislocation loops made it harder to find these particles. $\mathrm{M}_{23} \mathrm{C}_{6}$ remains crystalline at the irradiation depth of $1.11 \mu \mathrm{m}(\sim 240 \mathrm{dpa})$.

(a)

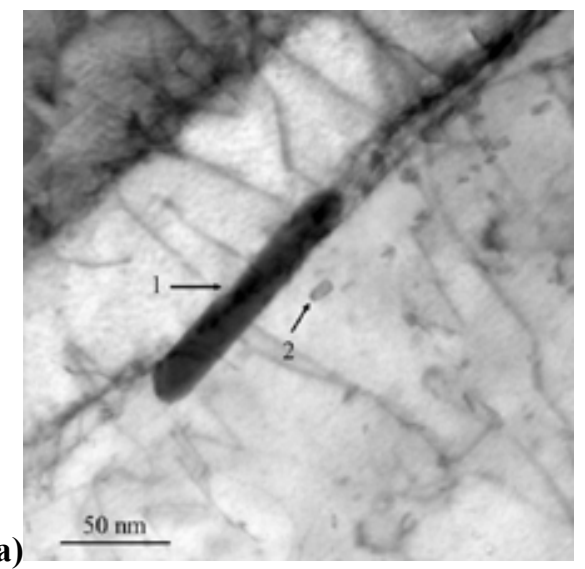

(b)

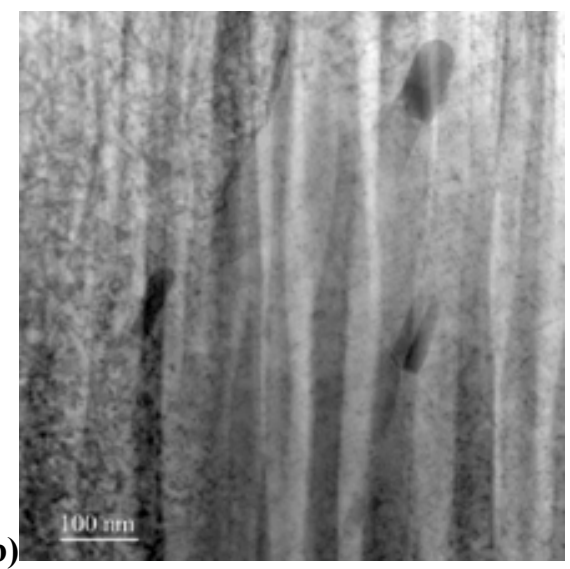

Figure 37. Precipitates in FTN1 (NA): (a) Undamaged region with the arrow-pointed 1 as $(\mathrm{Cr}, \mathrm{W})_{23} \mathrm{C}_{6}$ and 2 as a Ti, W, Nb-rich carbide; (b) Damaged region at $0.54 \mu \mathrm{m}$ showing the particles of $M_{23} C_{6}$.

In summary, the FTN1 (NA) sample has lath grain boundaries, dislocations, $\mathrm{Cr}$-rich $\mathrm{M}_{23} \mathrm{C}_{6}$ and fine Ti, Wrich carbides. Irradiation up to $250 \mathrm{dpa}$ at $350^{\circ} \mathrm{C}$ created dislocation loop sizes of $3.0 \pm 1.5 \mathrm{~nm}$ with a 
dislocation loop density of $9 \times 10^{22} \mathrm{~m}^{-3}$ at 0.54 irradiation depth $(\sim 140 \mathrm{dpa})$. No cavities were found in the irradiated FTN1 (NA).

\subsubsection{FTT1 (TA) irradiated up to 250 dpa at $350^{\circ} \mathrm{C}$}

Figure 38 shows the cross-sectional ABF images of FTT1 (TA) irradiated up to 250 dpa at $350^{\circ} \mathrm{C}$. Irradiation generated a damaged zone about $1.1 \mu \mathrm{m}$ and beyond from surface as indicated by the brighter horizontal band in Figure 38a. Tempered martensite structure retained well after the irradiation. Few dislocation loops, primarily shown as tiny black dots are shown in Figure 38b, which are noticeably less dense than that in Figure 37b for FTN1 (NA). Higher magnification characterization is needed to have statistical loop size and density.
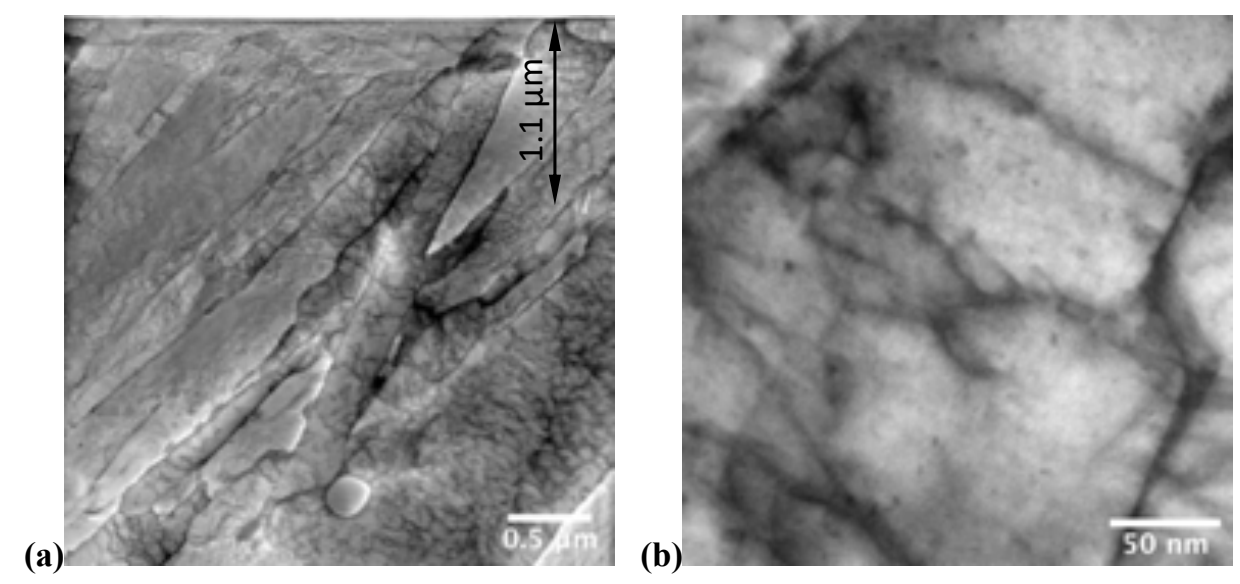

Figure 38. Cross-sectional ABF images of FTT1 (TA) after $350^{\circ} \mathrm{C}$ ion irradiation: (a) Overview and (b) Damaged region at $0.5 \mu \mathrm{m}$ depth with normal direction parallel to [100].

Precipitates in FTT1 (TA) have Cr-rich $\mathrm{M}_{23} \mathrm{C}_{6}$ and Ti-rich MX. Figure 39 shows a DF image using the weak reflection between the (200) two-beam near the [001] zone as shown in the inset, which exhibits ultrafine precipitates with sizes $<5 \mathrm{~nm}$ and a density of $4.2 \times 10^{21} \mathrm{~m}^{-3}$ in this condition, which are believed to be the Ti-rich MX.

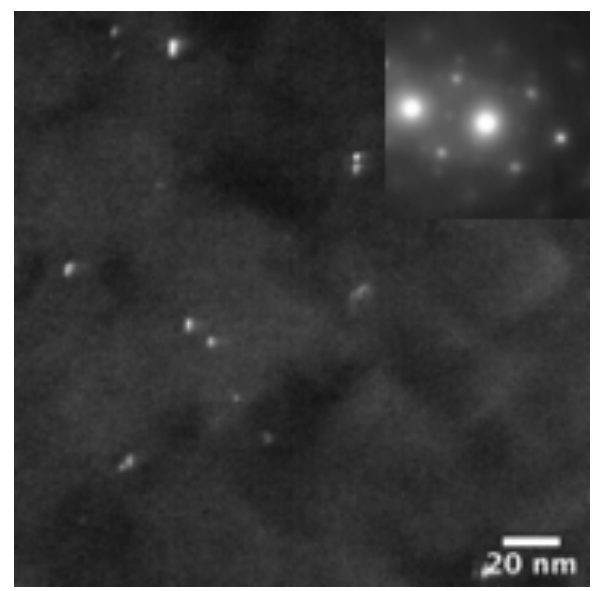

Figure 39. DF image showing MX type precipitates in FTT1 (TA) after $350^{\circ} \mathrm{C}$ ion irradiation at $0.6 \mu \mathrm{m}$ depth. 
In summary, the FTT1 (TA) sample retained lath sub-boundaries as the FTN1 (NA) sample after the irradiation. Dislocation loops were generated by the irradiation but appears not as dense as that generated in the FTN1 (NA) sample. The precipitates of Cr-rich $\mathrm{M}_{23} \mathrm{C}_{6}$ and Ti-rich MX retained after the irradiation without noticeable changes. The Ti-rich MX precipitates have ultrafine sizes $<5 \mathrm{~nm}$ with a density of 4.2 $\times 10^{21} \mathrm{~m}^{-3}$ in one of the four imaging conditions of $\{200\}$ two-beam near the [100] zone axis.

\subsubsection{T91 irradiated up to 250 dpa at $350^{\circ} \mathrm{C}$}

Figure 40 shows the cross-sectional ABF images of T91 irradiated up to 250 dpa at $350^{\circ} \mathrm{C}$. Irradiation damaged the $\sim 1.5 \mu \mathrm{m}$ deep surface region and created dislocation loops, which eliminated nearly all the lath/block/packet sub-boundaries. Figure 40b shows an image of dislocation loops along $<111>$ zone. The size of loops that are visible along $<111>$ is $5.5 \pm 2.6 \mathrm{~nm}$, which have a density of $4.0 \times 10^{22} \mathrm{~m}^{-3}$.
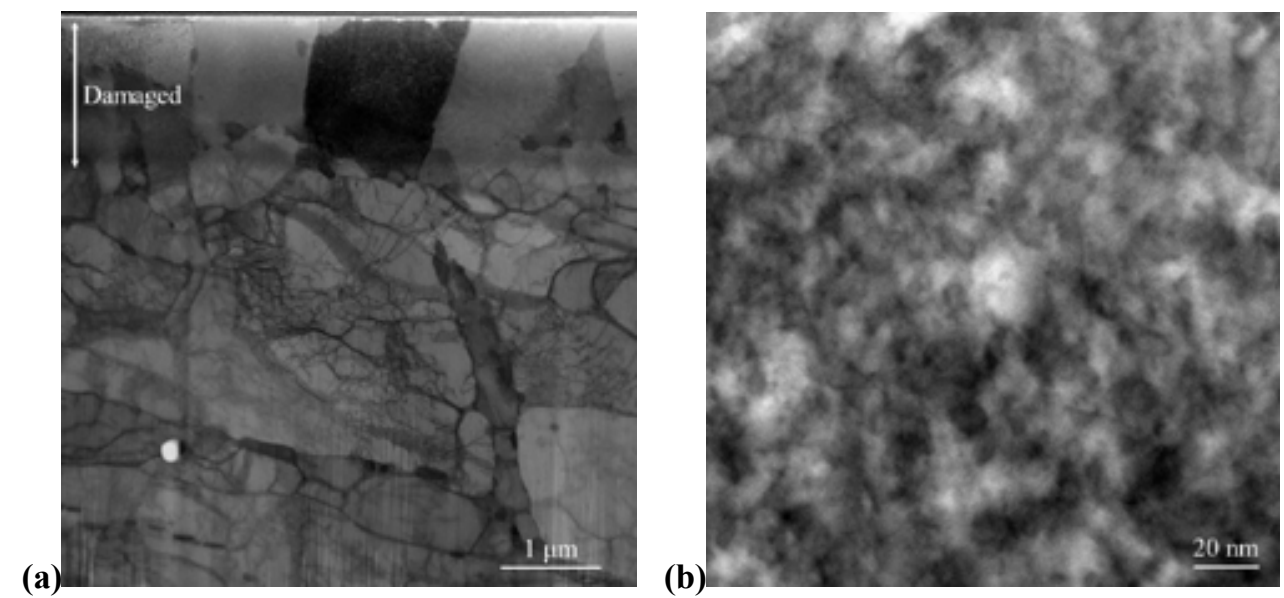

Figure 40. Cross-sectional ABF images of $\mathrm{T} 91$ after irradiation up to $250 \mathrm{dpa}$ at $350^{\circ} \mathrm{C}$ : (a) Overview and (b) Dislocation loops under $<111>$ zone at an irradiation depth of $0.55 \mu \mathrm{m}$.

Precipitates in T91 are shown in Figure 41. Three types of precipitates were observed in the undamaged T91: Cr-rich $\mathrm{M}_{23} \mathrm{C}_{6}$ (about 97Cr-2.8Mo-0.2V metal components, at. \%), V-rich $\mathrm{M}(\mathrm{C}, \mathrm{N})$ (about 97V-3Nb metal components, at. \%), and $\mathrm{Nb}$-rich $\mathrm{M}(\mathrm{C}, \mathrm{N})$ (about $80 \mathrm{Nb}-20 \mathrm{~V}$ metal components, at. \%). In the damaged region, $(\mathrm{V}, \mathrm{Cr}, \mathrm{Nb})(\mathrm{C}, \mathrm{N})$ precipitates were found: one about $69 \mathrm{~V}-29 \mathrm{Cr}-2 \mathrm{Nb}$ metal components at $0.84 \mu \mathrm{m}$ depth, one $26 \mathrm{~V}-60 \mathrm{Cr}-14 \mathrm{Nb}$ at $0.67 \mu \mathrm{m}$ depth, and one $18.6 \mathrm{Nb}-80 \mathrm{Cr}-1.4 \mathrm{~V}$ at $0.97 \mu \mathrm{m}$. The significant $\mathrm{Cr}$ partition in the $\mathrm{M}(\mathrm{C}, \mathrm{N})$ type precipitates suggest the occurrence of phase transformation from MX to Zphase, e.g., simple phase of $\mathrm{CrVN}$ and/or $\mathrm{CrNbN}$. 

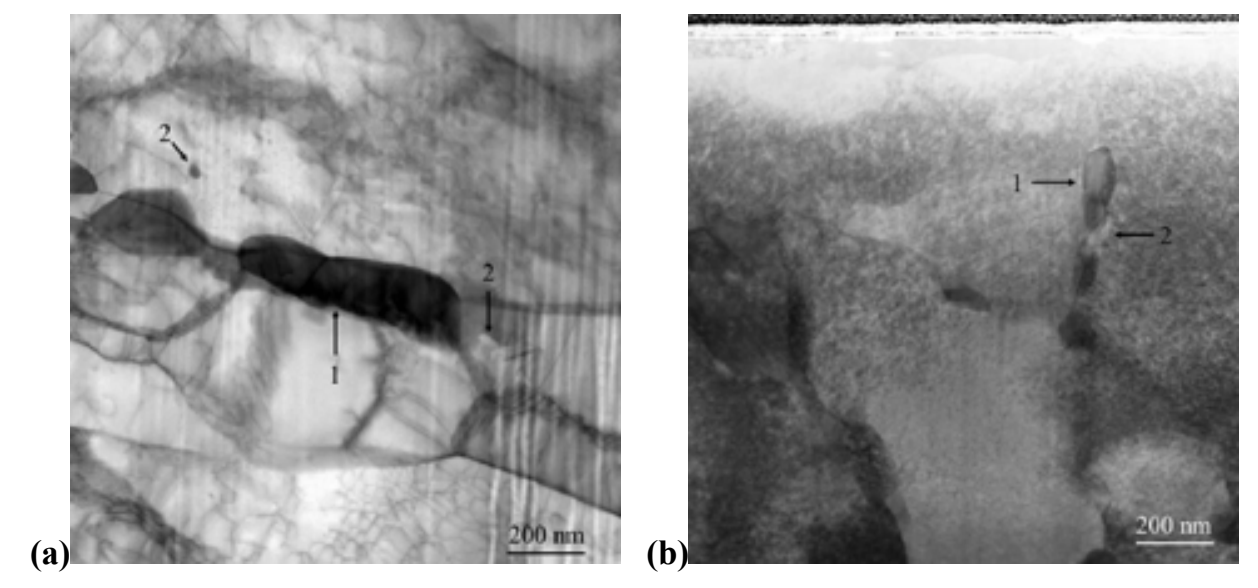

Figure 41. Precipitates in T91. (a) Undamaged. (b) $350{ }^{\circ} \mathrm{C}$ irradiation damaged region. 1 is $\mathrm{M}_{23} \mathrm{C}_{6} .2$ is $\mathrm{V}$, Nbrich MX.

In summary, irradiation up to $250 \mathrm{dpa}$ at $350^{\circ} \mathrm{C}$ generated dislocation loops in T91. The loops have sizes of $5.5 \pm 2.6 \mathrm{~nm}$ at $0.55 \mu \mathrm{m}$ depth under $<111>$ zone with a density of $4.0 \times 10^{22} \mathrm{~m}^{-3}$. T91 has larger dislocation loops and a smaller density than FTN1 (NA). There are Cr-rich $\mathrm{M}_{23} \mathrm{C}_{6}$ and $(\mathrm{V}, \mathrm{Nb})(\mathrm{C}, \mathrm{N})$ in T91. Irradiation appears to attract $\mathrm{Cr}$ into the $\mathrm{MX}$ particles $(\mathrm{V}, \mathrm{Nb})(\mathrm{C}, \mathrm{N})$ to $30-80$ at. $\% \mathrm{Cr}$ in the metal component of the particles, suggesting phase transformation into Z-phase. No cavities were found in the irradiated T91.

\subsubsection{FTN1 (NA) irradiated up to 250 dpa at $475^{\circ} \mathrm{C}$}

Figure 42 shows cross-sectional ABF images of ion-irradiated FTN1 (NA) up to $250 \mathrm{dpa}$ at $475^{\circ} \mathrm{C}$. The dark dispersed features near the end of the irradiation zone are $\mathrm{Cu}$ precipitates, with a higher magnification image shown in Figure 32a. Type $<100>$ dislocation loops were present in the damaged region (Figure 42b, $0.55 \mu \mathrm{m}$ depth). The loops have sizes of $4.0 \pm 2.7 \mathrm{~nm}$ with a density of $4.1 \times 10^{22} \mathrm{~m}^{-3}$. No cavities were found in the $475^{\circ} \mathrm{C}$ irradiated FTN1 (NA) sample.
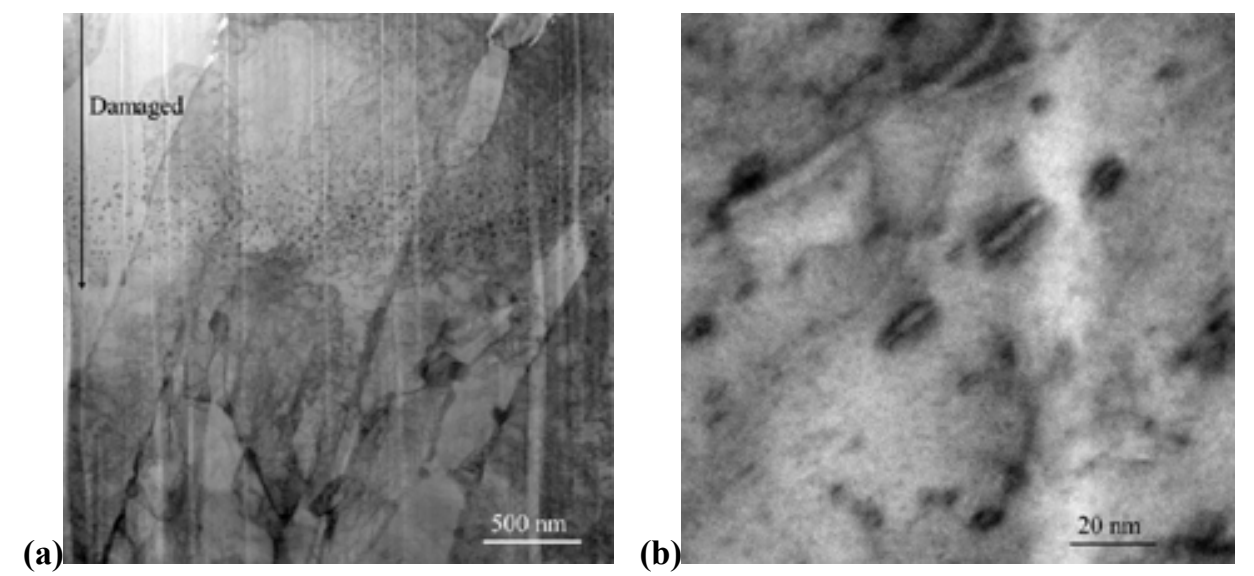

Figure 42. Cross-sectional ABF images of FTN1 (NA) irradiated up to 250 dpa at $475^{\circ} \mathrm{C}$ : (a) Overview of damaged (top part) and undamaged structure; (b) $<100>$ dislocation loops at $0.55 \mu \mathrm{m}$ depth. 


\subsubsection{FTT1 (TA) irradiated up to $250 \mathrm{dpa}$ at $475^{\circ} \mathrm{C}$}

Figure 43 shows cross-sectional ABF images of ion-irradiated FTT1 (TA) up to 250 dpa at $475^{\circ} \mathrm{C}$. Similar to FTN1 (NA) in Figure 42a, $\mathrm{Cu}$ precipitates are dispersed at $\sim 1.1 \mu \mathrm{m}$ depth in Figure 43a. A dense dislocation loops are shown in Figure $43 \mathrm{~b}$ at $0.7 \mu \mathrm{m}$ depth. Precipitates are also believed to be present in Figure $43 \mathrm{~b}$ as suggested by the satellite secondary reflections in Figure $43 \mathrm{c}$ taken from the same area of Figure $43 \mathrm{~b}$. The layout of the secondary reflections from precipitates in Figure $43 \mathrm{c}$ is different from that in the inset of Figure 39, which may suggest different types of precipitates. The precipitates are generally difficult to be distinguished because of the presence of dislocation loops. Therefore, conclusive statistical analysis for the sizes and densities of dislocation loops and precipitates are not achievable. Further investigations are needed to clarify the features. No cavities were found in the sample.

(a)

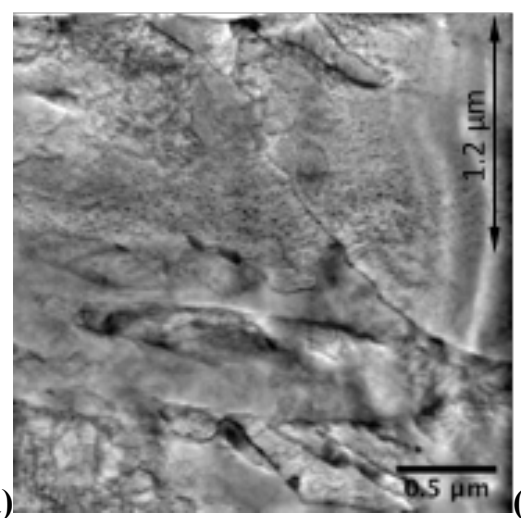

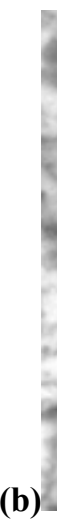
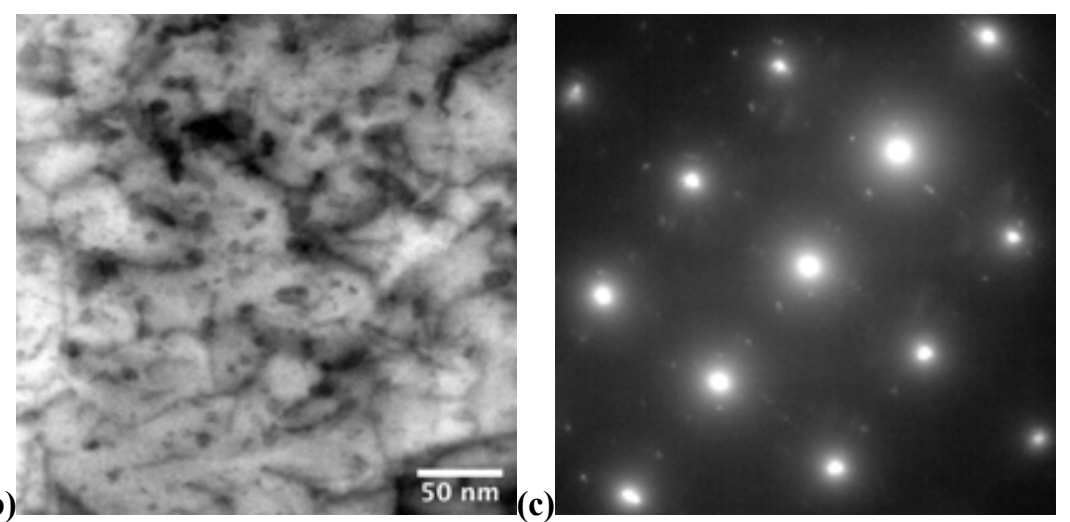

Figure 43. Cross-sectional ABF images of FTT1 (TA) irradiated up to 250 dpa at $475^{\circ} \mathrm{C}$ : (a) Overview of damaged (top part) and undamaged structure; (b) Dislocation loops at $0.7 \mu \mathrm{m}$ depth and (c) corresponding selected area diffraction pattern.

\subsubsection{T91 irradiated up to 250 dpa at $475^{\circ} \mathrm{C}$}

Figure 44 shows a cross-sectional HAADF image of T91 irradiated up to $250 \mathrm{dpa}$ at $475^{\circ} \mathrm{C}$ under the $<111>$ zone axis. Dislocations are shown in the damaged region, but no cavities were found.

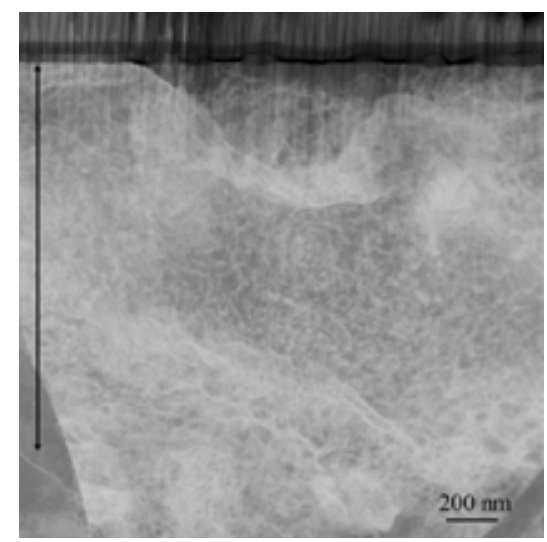

Figure 44. Cross-sectional HAADF image of $\mathrm{T} 91$ irradiated up to $250 \mathrm{dpa}$ at $475^{\circ} \mathrm{C}$ along the $<111>$ zone. Arrow indicates damage depth. 


\subsubsection{TTZ2M irradiated up to 220 dpa at $475^{\circ} \mathrm{C}$ (rastering beam)}

Figure 45 shows the microstructures of TTZ2M irradiated up to 220 pda at $475^{\circ} \mathrm{C}$ using a rastering beam. The irradiated generated $\sim 1.7 \mu \mathrm{m}$ depth of damage layer as shown in Figure $45 \mathrm{a}$. At $\sim 0.6 \mu \mathrm{m}$ depth, corresponding to $\sim 120 \mathrm{dpa}$, a high-density dislocation loops are shown in Figure $45 \mathrm{~b}$, together with ultrafine $(11.5 \pm 7.3 \mathrm{~nm})$ precipitates with a density of $3 \times 10^{21} \mathrm{~m}^{-3}$ as shown in Figure $45 \mathrm{c}$.
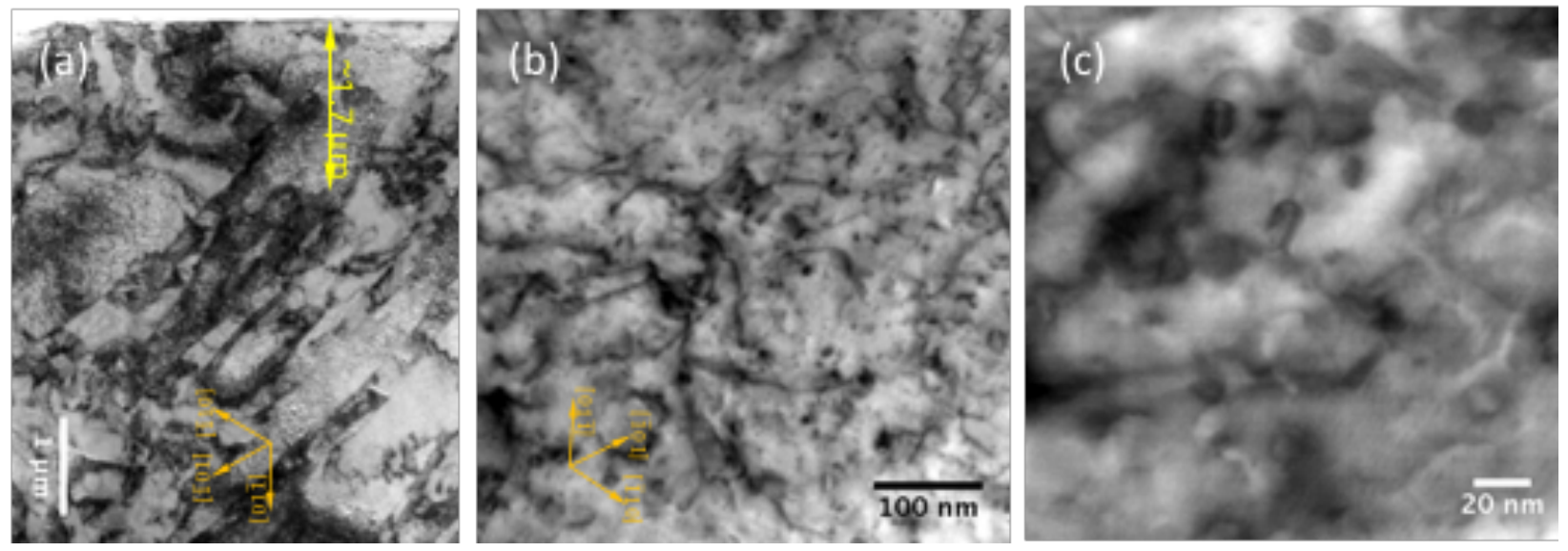

Figure 45. TTZ2M irradiated up to 250 dpa at $475^{\circ} \mathrm{C}$ along the $<111>$ zone: (a) BF-TEM overview image and (b-c) ABF-STEM images at $\sim 0.6 \mu \mathrm{m}$ depth.

\subsubsection{BL-Nb irradiated up to 220 dpa at $475^{\circ} \mathrm{C}$ (rastering beam)}

Figure 46 shows B2 precipitates in the unirradiated region of the sample. The DF TEM image in Figure 46a was taken from a [100] zone axis as shown in the inset, which reveals the B2 phase as bright particles with sizes $<20 \mathrm{~nm}$ uniformly dispersed in the matrix. The diffraction pattern indicates the coherency between the B2 phase (simple cubic with one element on the corner and the other element in the body center) and the bcc matrix. The high magnification HAADF image in Figure 46b shows the B2 particles in dark shade with a white peripheral halo. The HAADF contrast suggests low-Z (mass) nature of the $\mathrm{B} 2$ particles, which is confirmed by its $\mathrm{Ni}$ and $\mathrm{Al}$ enrichment from the EDS line scan (Figure 46c) across a representative B2 particle pointed by an arrow in Figure 46b. Compositional values of $\mathrm{Fe}, \mathrm{Cr}, \mathrm{W}$ fluctuate around zero inside the particle possibly due to small particle size compared to the sample thickness. Averaging the concentration of seven B2 particles yielded $\mathrm{Ni}(53 \pm 4)-\mathrm{Al}(47 \pm 4)$ in atomic percent. Scattered minor enrichment in $\mathrm{Nb}$ was observed at particles' center, which is consistent with the thermodynamically calculated composition of $\mathrm{Ni}(\mathrm{A} 1, \mathrm{Nb})$ type $\mathrm{B} 2$ phase. $\mathrm{B} 2$ particles show a periphery of white contrast in HAADF images and dark contrast in ABF images (not shown here), indicating strain at the particle/matrix interface. 

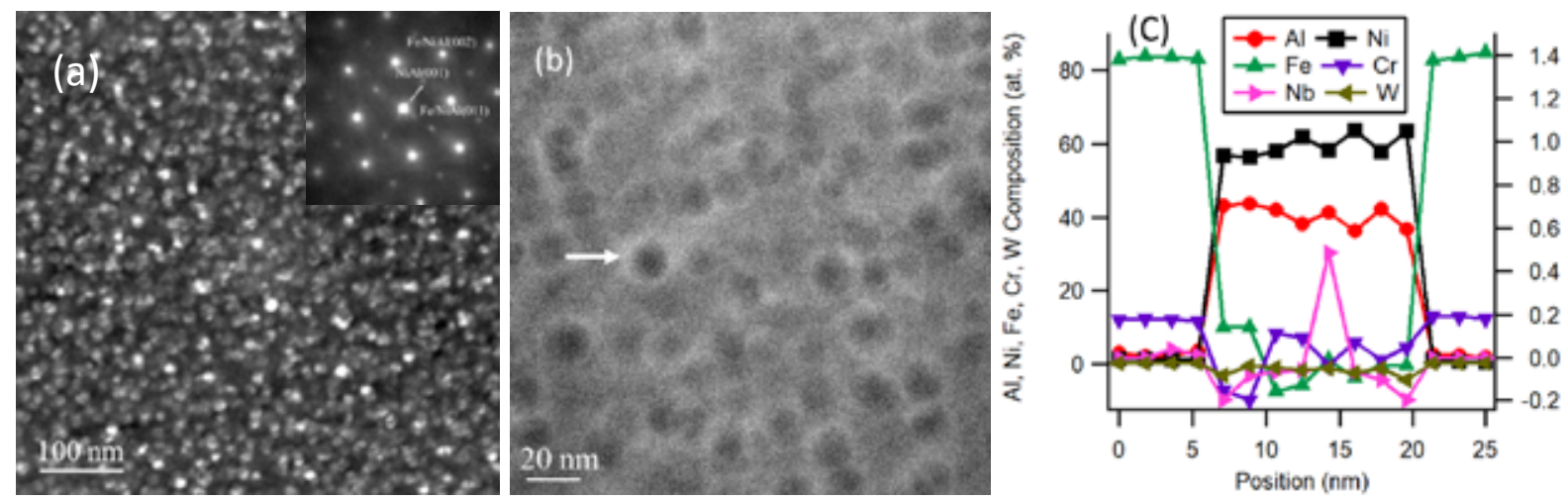

Figure 46. B2-NiAl precipitates in the unirradiated region: (a) DF-TEM image from the [100] zone as indicated in the electron diffraction pattern of the inset, (b) HAADF image, and (c) EDS line scan compositional profiles across the particle pointed by the arrow in (b).

The structure of B2-NiAl particles after $\mathrm{Fe}^{2+}$ ion irradiation at $475{ }^{\circ} \mathrm{C}$ is shown in Figure 47 . The crosssectional regions at depth of $0.15-0.6 \mu \mathrm{m}$ and $1.15-1.6 \mu \mathrm{m}$, corresponding to about 68-115 dpa and 210$10 \mathrm{dpa}$, respectively, are shown in Figure 47a and b. The top side of the images is close to the irradiated surface. The micrographs were imaged using the $(001)_{\mathrm{NiAl}}$ reflection from the [100] zone as shown in the inset of Figure 47a. The irradiation did not alter the crystallinity of the B2 phase particles. Some coarser particles are seen in the top part of Figure $47 \mathrm{a}$ from 0.15 to $\sim 0.3 \mu \mathrm{m}$ depth, which might be influenced by irradiation surface effects $[7,8]$. The average size of B2-NiAl particles in the region encompassing 0.3 to $0.6 \mu \mathrm{m}$ depth was characterized to be $11.3 \pm 0.2 \mathrm{~nm}$ with a number density of $1.5 \times 10^{22} \mathrm{~m}^{-3}$ in Figure $47 \mathrm{a}$ ( 81-115 dpa), which suggests that the particles experienced slight diminution and an increase in number density compared to that in the unirradiated condition (Figure 46a) where the corresponding values were, a size of $12.3 \pm 0.1 \mathrm{~nm}$ and number density of $9.3 \times 10^{21} \mathrm{~m}^{-3}$. In contrast, the B2-NiAl particles appeared with lower contrast at the top part of Figure $47 \mathrm{~b}$ which is taken at a greater depth of 1.15 to $1.3 \mu \mathrm{m}$ approximately corresponding to the range from peak damage to peak implanted Fe. Beyond this, B2-NiAl particle size became $14.0 \pm 0.2 \mathrm{~nm}$, which is larger than that in the unirradiated region, with number density of $7.1 \times 10^{21} \mathrm{~m}^{-3}$. Figure $47 \mathrm{c}$ shows a high-resolution HAADF image of a B2-NiAl particle, taken along the [100] zone illustrated in the inset for a fast Fourie transform (FFT) of the original image, at depth of $0.86 \mu \mathrm{m}$ where the damage level was about $170 \mathrm{dpa}$. The HAADF image was smoothed, together with an applied mask to emphasize atomic columns, which shows Ni columns in a brighter contrast compared to the neighboring Al inside the particle. All the columns of the particle aligned well with the matrix $\{002\}$ planes, verifying full coherency between the irradiated particle and matrix. The wavering contrast in the particle and matrix was induced by local strains.
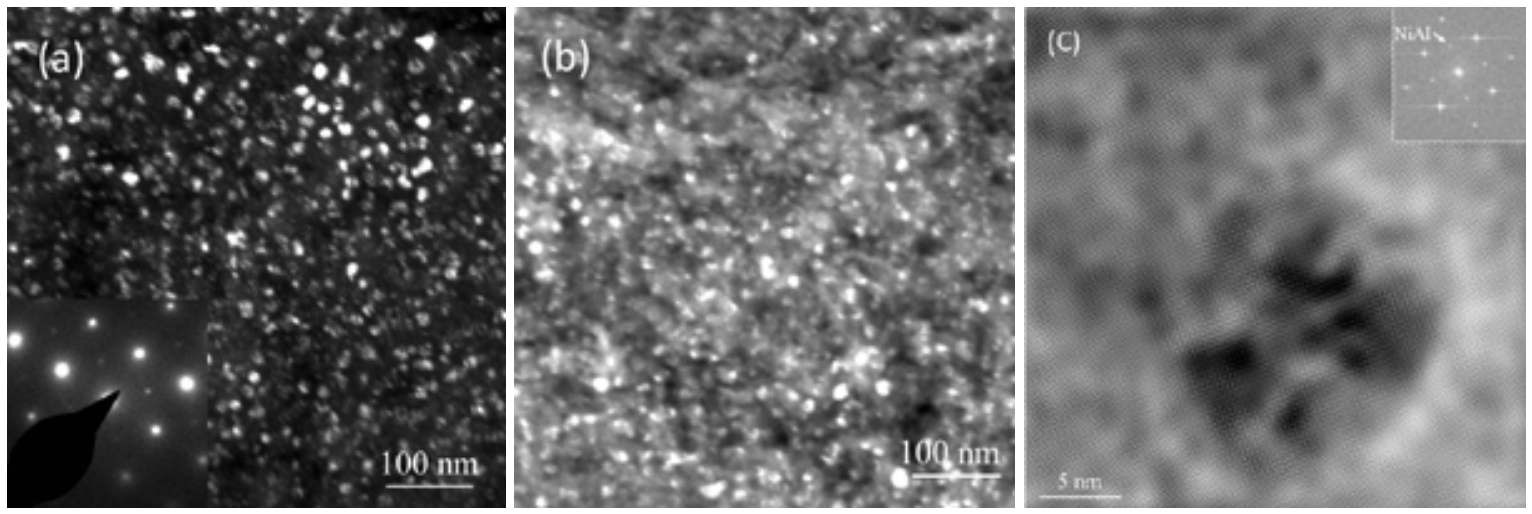
Figure 47. Images of B2-NiAI particles in the irradiated region: DF-TEM images at (a) 0.15-0.6 $\mu \mathrm{m}$ depth and (b) $1.15-1.6 \mu \mathrm{m}$ depth. The images were taken with the (001) $)_{\text {NiAl }}$ diffraction from the [100] zone axis as shown in the inset of (a); (c) HAADF image at $0.86 \mu \mathrm{m}$ from surface with the inset of an FFT of the original image.

Figure 48 shows cross sectional ABF images of BL-Nb irradiated up to 220 dpa at $475^{\circ} \mathrm{C}$. The irradiation generation a damage layer $\sim 1.6 \mu \mathrm{m}$ thick in Figure 48a, close to SRIM calculation result shown in Figure 33. Coarse micron-scale particles and small particles $\sim 100 \mathrm{~nm}$ large are present both inside grains and along grain boundaries. Figure 48b-d show electron diffraction and EDS characterization of undamaged particles. Nanobeam diffraction on particle $\mathrm{A}$ in Figure 48b-c shows a $\mathrm{Fe}_{2} \mathrm{Nb}$-like crystalline phase. The particle is coherent with matrix and is oriented as particle $<011>/ /$ matrix $<100>$, particle (100) // matrix (01 $\overline{1})$, and particle $(\overline{1} 2 \overline{2}) / /$ matrix $(011)$. The composition of particle B in Figure $48 \mathrm{~b}$ is $\mathrm{Fe}(55.4 \pm 3.4)-\mathrm{Cr}(11.9 \pm$ $1.9)-\mathrm{Nb}(21.4 \pm 2.1)-\mathrm{W}(11.3 \pm 1.8)\left(\right.$ at. \%), correspond to a Laves phase $(\mathrm{FeCr})_{2}(\mathrm{NbW})$.
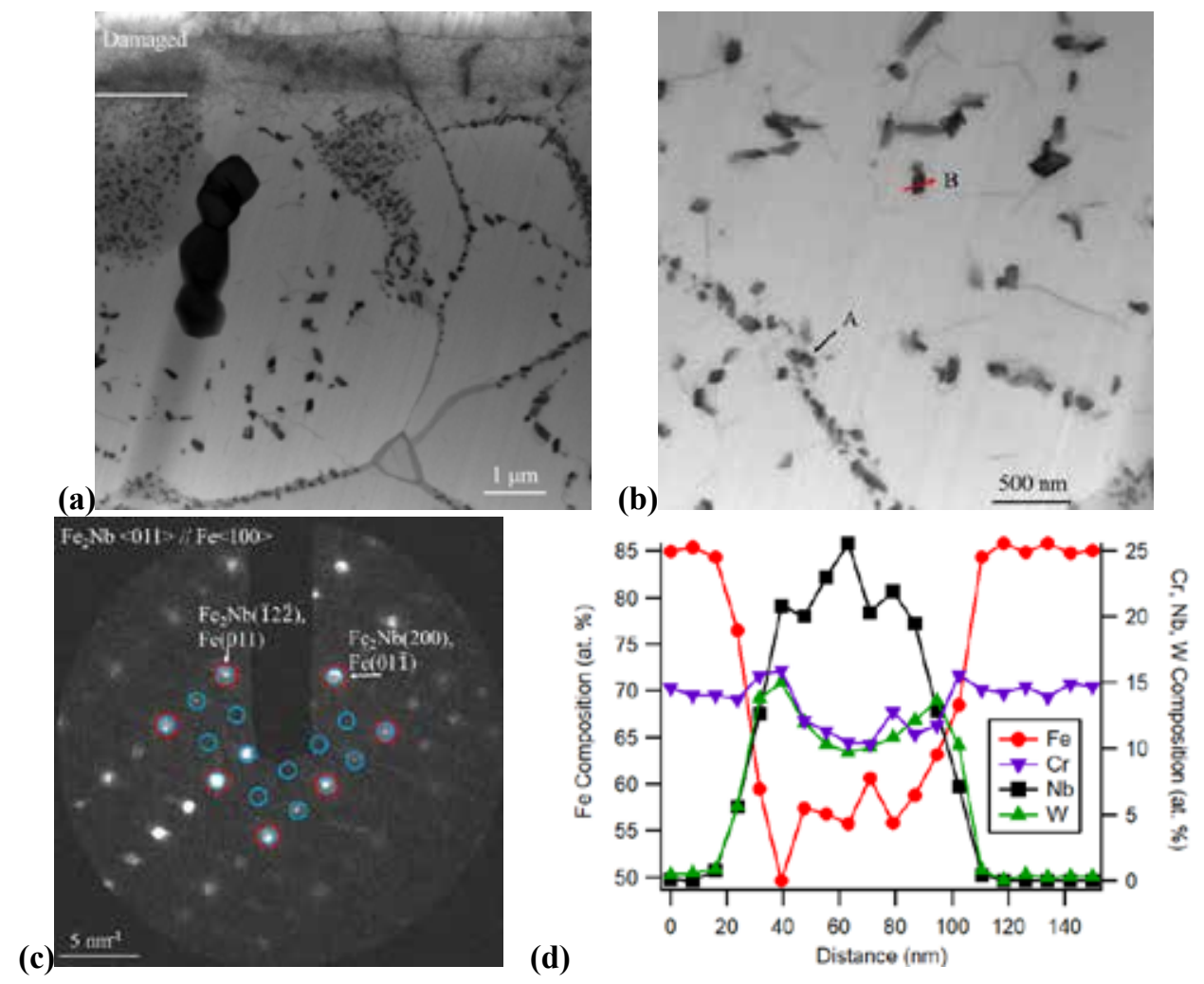

Figure 48. TEM characterization of BL-Nb after $\mathrm{Fe}^{2+}$ ion irradiation up to 220 dpa at $475^{\circ} \mathrm{C}$ : (a-b) Crosssectional ABF images along <100>; (c) Nanobeam electron diffraction of particle $A$ in (b) with red and blue circles indicating matrix and particle diffraction spots, respectively; (d) EDS measured compositional profile along particle $B$ in (b).

Figure 49a shows a cross-sectional image of BL-Nb near the boundary of damaged region. Damage level is $\sim 200 \mathrm{dpa}$ at the image center. Irradiation induced pronounced dislocations and dislocation loops. The three particles pointed by arrows do not have distinctive boundaries, unlike the undamaged particles in lower part of the image. Surrounding the $100 \mathrm{~nm}$-scale damaged particles are nanometer-scale fine precipitates, as shown in Figure $49 \mathrm{~b}$. The damaged particle in Figure $49 \mathrm{~b}$ is $\sim 130 \mathrm{~nm}$ wide. Figure $49 \mathrm{c}-\mathrm{d}$ show that it has a core $\sim 50 \mathrm{~nm}$ wide enriched in $\mathrm{Cr}, \mathrm{Nb}, \mathrm{W}$, and $\mathrm{C}$. It has a remaining core of Laves phase $(\mathrm{FeCr})_{2}(\mathrm{NbW})$. 

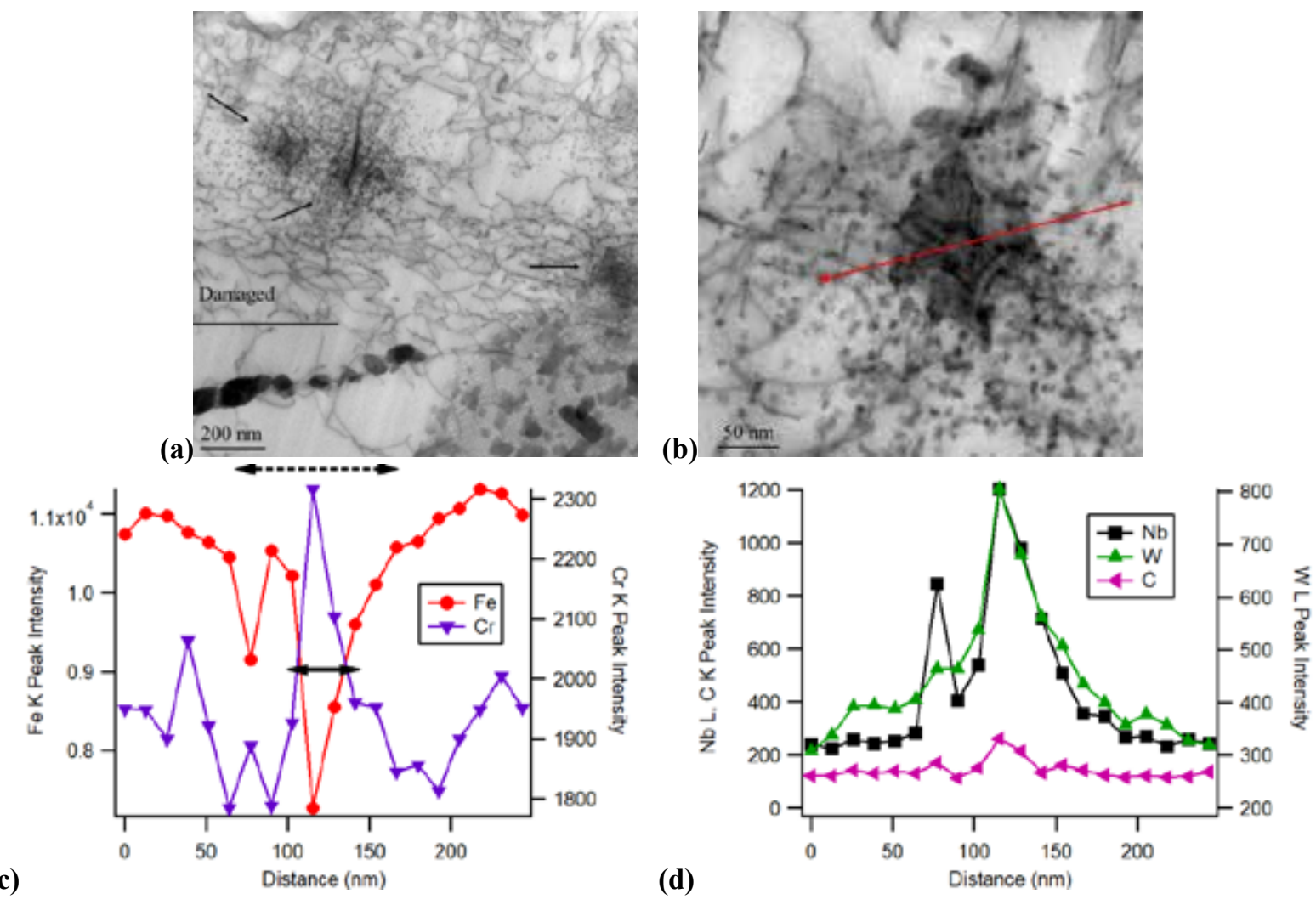

Figure 49. TEM characterization of irradiated particles in $\mathrm{BL}-\mathrm{Nb}$ after $\mathrm{Fe}^{2+}$ ion irradiation up to 220 dpa at $475^{\circ} \mathrm{C}$ : (a) $\mathrm{ABF}$ image along <100> with the image center at $1.2 \mu \mathrm{m}$ depth ( $\left.200 \mathrm{dpa}\right)$; (b) $\mathrm{ABF}$ image along $<100>$ with the image center at $0.83 \mu \mathrm{m}$ depth $(\sim 164 \mathrm{dpa})$; (c-d) EDS peak intensity profile along the arrow line cross the damaged particle in (b). Dashed and solid arrows in (c) indicate widths of particle and core, respectively.

Figure 50 shows nanometer-sized precipitates surrounding damaged Laves phase particles as shown in Figure 49b. Figure 50a-b examine one precipitate $300 \mathrm{~nm}$ away from the damaged Laves phase particle. The damage level at Figure 50a area is $\sim 180 \mathrm{dpa}$. EDS analysis shows the particle is composed of $\mathrm{Nb}, \mathrm{Cr}$, $\mathrm{N}$ and $\mathrm{C}$ (Carbon EDS intensity is not shown here). Figure 50c is a HAADF image of another particle along matrix $<100>$ orientation at $\sim 150 \mathrm{dpa}$. Two major atomic column plane spacings in the particle are $0.30 \mathrm{~nm}$ and $0.26 \mathrm{~nm}$ with $55^{\circ}$ between planes. It matches with $\mathrm{MX}$ phases $\mathrm{NbC}<110>, \mathrm{NbN}<110>$, or Z-phase $\mathrm{CrNbN}<221>$. Combined with the EDS analysis, $\mathrm{CrNbN}$ phase is suggested.

(a)

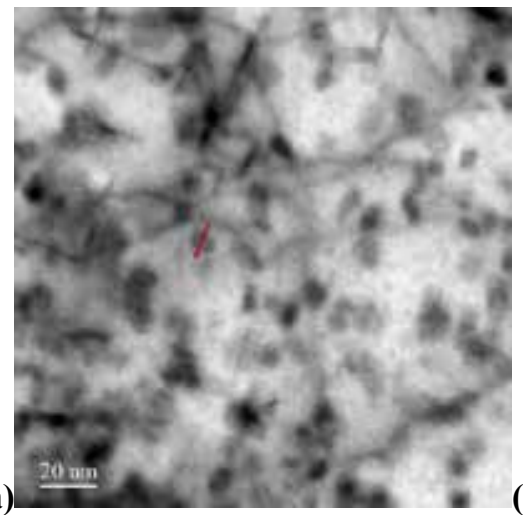

(b)

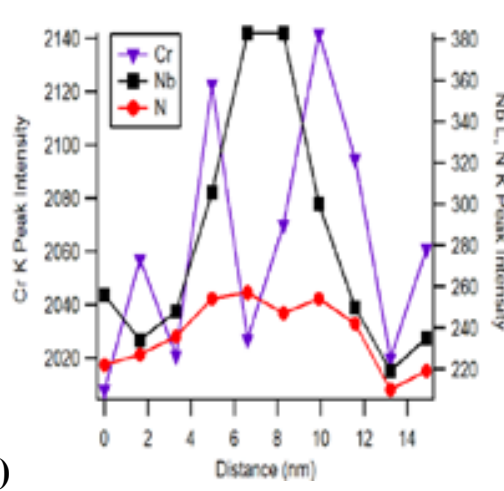

(c)

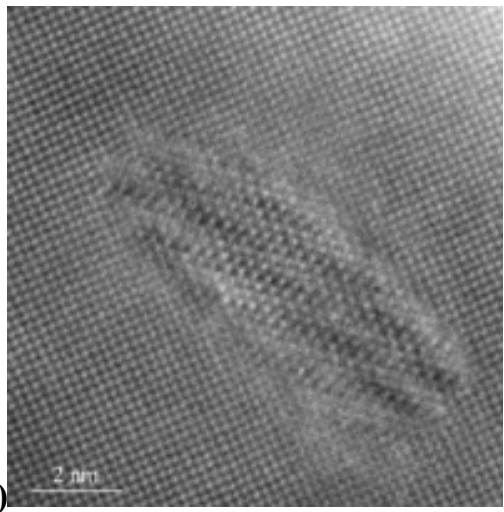


Figure 50. Irradiation induced particles. (a) ABF image at $0.9 \mu \mathrm{m}$ depth, about 180 dpa. (b) EDS peak intensity profile along the arrow in (a). (c) HAADF image of a particle at $0.78 \mu \mathrm{m}$ depth, about $150 \mathrm{dpa}$.

Irradiation damage to big micron-size particles is exemplified in Figure 51. The particle in Figure 51a was partially damaged. A and B are two points, undamaged and damaged, respectively. The undamaged part of the particle shows a $\mathrm{Fe}_{2} \mathrm{Nb}<42 \overline{3}>$ electron diffraction pattern as shown in Figure 51b. EDS verifies the Laves particle to be $(\mathrm{FeCr})_{2}(\mathrm{NbW})$. Irradiated part is amorphous, as shown by the lower diffraction in Figure $51 \mathrm{~b}$. The boundary of crystalline/amorphous regions is at $1.5 \mu \mathrm{m}$ depth where damage level is $\sim 30$ dpa. Composition of the particle is Fe (66.7 \pm 0.9$)-\mathrm{Cr}(8.3 \pm 0.5)-\mathrm{Nb}(20.0 \pm 0.8)-\mathrm{W}(5.0 \pm 0.1)$ (at. \%) for the crystalline phase, and $\mathrm{Fe}(67.5 \pm 0.4)-\mathrm{Cr}(8.5 \pm 0.3)-\mathrm{Nb}(19.0 \pm 0.6)-\mathrm{W}(5.0 \pm 0.2)$ (at. \%) for the amorphous phase.

(a)

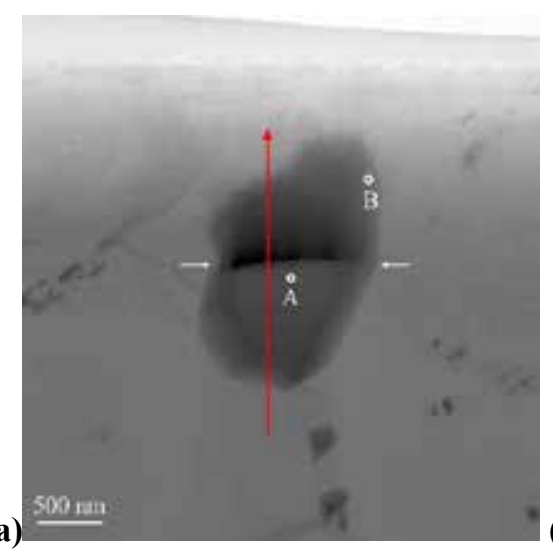

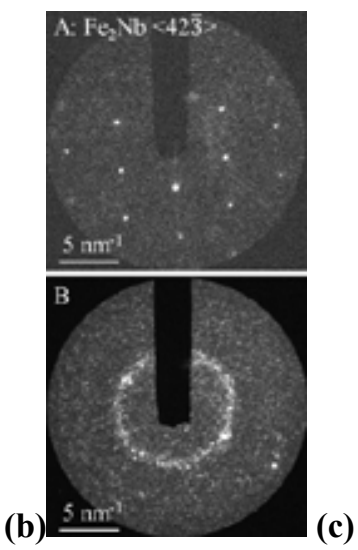

Figure 51. TEM characterization of a partially damaged micron-scale particle: (a) ABF image showing a contrast line inside the particle, as indicated by two short white arrows, at $1.5 \mu \mathrm{m}$ depth $(\sim 30 \mathrm{dpa}$ near the end of damage range); (b) Nanobeam electron diffraction patterns of points $A$ and $B$ labeled in (a); (c) EDS measured compositional profile along red arrow line in (a), with a dashed line indicating the ABF contrast line location.

In summary, rastering-beam $\mathrm{Fe}^{2+}$ ion irradiation of $\mathrm{BL}-\mathrm{Nb}$ up to $220 \mathrm{dpa}$ at $475^{\circ} \mathrm{C}$ induced dislocation loops at lower doses and tangled dislocations at higher doses. B2-NiAl precipitates were relatively stable under the irradiation and had a size of 11-14 nm and a number density of $1.5 \times 10^{22}-7 \times 10^{21} \mathrm{~m}^{-3}$ from the irradiation depth of $0.3-0.6 \mu \mathrm{m}$ to $1.3-1.6 \mu \mathrm{m}$. The alloy contains both coarse micron-scale and fine $(\sim 100 \mathrm{~nm})$ Laves phase particles. The coarse Laves phase particles were amorphized, along with a slight composition change, at irradiation doses greater than $\sim 30 \mathrm{dpa}$. In contrast, disintegration of the finer Laves particles was observed to occur at doses greater than $\sim 70 \mathrm{dpa}(\geq \sim 0.2 \mu \mathrm{m}$ depth). The disintegration resulted in a noticeable composition change and also resulted in the nucleation of many new ultra-fine particles in $\sim 8 \mathrm{~nm}$, identified to be $\mathrm{CrNb}(\mathrm{N}, \mathrm{C})$-type $\mathrm{Z}$-phase, which precipitated within a few hundreds of nanometers from the disintegrated finer Laves phase particles.

\subsection{SUMMARY}

The new ferritic-martensitic steels FTN1 and FTT1 showed comparable radiation resistance, superior to T91 irradiated under the same conditions. Although a direct comparison between the rastered-beam (TTZ2M and BL-Nb) and the defocused-beam (FTN1, FTT1, and T91) irradiated samples is not available, the radiation resistance of TTZ2M and BL-Nb was not significantly different from FTN1 and FTT1. A few points can be concluded below based on the post-irradiation examinations: 
- Grain structures: Martensitic sub-boundaries were noticeably diminished in T91 by ion irradiation at $350^{\circ} \mathrm{C}$ and may also at $475^{\circ} \mathrm{C}$ that needs to be confirmed. In contrast, the grain structures in the other alloys, such as FTN1 (NA), FTT1 (TA), TTZ2M, and BL-Nb, were retained after the irradiations.

- Dislocations: Ion irradiation up to $250 \mathrm{dpa}$ at $350^{\circ} \mathrm{C}$ generated larger dislocation loops in T91 (5.5 $\pm 2.6 \mathrm{~nm})$ than that in FTN1 (NA) $(3.0 \pm 1.5 \mathrm{~nm})$. The loop density in T91 $\left(4.0 \times 10^{22} \mathrm{~m}^{-3}\right)$ is lower than that in FTN1 (NA) $\left(9 \times 10^{22} \mathrm{~m}^{-3}\right)$. Larger but less dislocation loops $\left(4.0 \pm 2.7 \mathrm{~nm}, 4.1 \times 10^{22}\right.$ $\mathrm{m}^{-3}$ ) were created in FTN1 (NA) by irradiation up to 250 dpa at $475^{\circ} \mathrm{C}$. Dislocation loops were also observed in FTT1 (TA) irradiated under the same conditions, which were either comparable to FTN1 (NA) or not able to be statistically quantified. Rastering-beam irradiation up to $220 \mathrm{dpa}$ at $475^{\circ} \mathrm{C}$ generated similar dislocation loops in TTZ2M but more pronounced line dislocations than dislocation loops in BL-Nb.

- Precipitates: $\mathrm{M}_{23} \mathrm{C}_{6}$ and MX types of precipitates exist in the ferritic-martensitic steels FTN1, FTT1, TTZ2M, and T91, which did not show noticeable changes after ion irradiation up to 250 dpa at 350 and $475^{\circ} \mathrm{C}$. However, $\mathrm{Cr}$ incorporation into $(\mathrm{V}, \mathrm{Nb})(\mathrm{C}, \mathrm{N}) \mathrm{MX}$-type precipitates was observed in T91 irradiated up to $250 \mathrm{dpa}$ at $350^{\circ} \mathrm{C}$, suggesting Z-phase formation. In contrast, precipitates of $\mathrm{B} 2-\mathrm{NiAl}$ and Laves phases exist in BL-Nb. The B2-NiAl was relatively stable after irradiation up to $220 \mathrm{dpa}$ at $475^{\circ} \mathrm{C}$. However, amorphization occurred in coarse Laves precipitates at damages $>$ $\sim 30 \mathrm{dpa}$ and disintegration occurred in fine $(\sim 100 \mathrm{~nm})$ Laves precipitates at damages $>\sim 70$ dpa. The disintegration of the fine Laves phase resulted in a noticeable composition change to the Laves phase and the formation of many new ultrafine $(\sim 8 \mathrm{~nm})$ Z-phase type particles within a few hundreds of nanometers from the disintegrated fine Laves phase precipitates.

- Cavities: No cavities were found in all the samples irradiated under a defocused beam, e.g., FTN1 (NA), FTT1 (TA), and T91 irradiated up to 250 dpa at 350 and $475^{\circ} \mathrm{C}$, or under a rastering beam, e.g., TTZ2M and BL-Nb irradiated up to 220 dpa at $475^{\circ} \mathrm{C}$.

- Radiation-hardening: FTN1 (NA) showed better resistance in radiation-hardening at $350^{\circ} \mathrm{C}$. Irradiation up to $250 \mathrm{dpa}$ at $350^{\circ} \mathrm{C}$ increased nanoindentation hardness by $26.4 \pm 7.8 \%$ in FTN1 (NA), which is about half of the hardening by $55.7 \pm 7.5 \%$ in T91 (at indent displacement of 0.5 $\mu \mathrm{m})$. In contrast, irradiation at $475^{\circ} \mathrm{C}$ did not noticeably change the hardness in either FTN1 (NA) or T91 under a defocused beam, while TTZ2M and BL-Nb showed slightly hardening, e.g., $\sim 6 \%$ at $1 \mu \mathrm{m}$, after irradiation up to $220 \mathrm{dpa}$ at $475^{\circ} \mathrm{C}$ using a rastering beam. 


\section{CONCLUSIONS}

Two steels, one ferritic steel BL-Nb and one ferritic-martensitic steel TTZ2M, were down-selected for further investigation. Based on the TTZ2M, two large-scale ferritic-martensitic heats, i.e., FTT1 and FTN1, were produced at industrial steelmaking facilities, which are in contrast to the small laboratory heats BL$\mathrm{Nb}$ and TTZ2M. Other than the standard normalization and tempering condition of the ferritic-martensitic steels, a heat-treated condition was explored for the FTT1 and FTN1, which is named as FTT1-T and FTN1$\mathrm{T}$, respectively. Two-step aging was applied to BL-Nb to favor the precipitation of Laves and B2-NiAl phases. The alloy compositions and heat treatment temperatures were guided by computational thermodynamics and dilatometry. Tensile, Charpy impact, and creep tests were conducted on samples of the steels in air, using a commercial heat of T91 as a reference. Microstructural characterization was primarily using TEM and EDS with occasional uses of optical microscopy.

Tensile of the four steels indicated yield and tensile strength significantly higher than T91, which has up to $\sim 170-350 \mathrm{MPa}$ increases in yield strength at test temperatures from $\sim 23$ to $700^{\circ} \mathrm{C}$. The strength enhancement was compromised by ductility with BL-Nb having the lowest total elongation at room temperature. The heat-treated condition FTT1-T and FTN1-T exhibited comparable tensile properties, with strength lower than the standard condition. The DBTT of TTZ2M, FTT1 and FTN1 are 20 to $60^{\circ} \mathrm{C}$ lower than that of Grade 91 of $-47^{\circ} \mathrm{C}$, while the DBTT of FTT1-T and FTN1-T are way below $-150^{\circ} \mathrm{C}$. The USE of the steels are $23-50 \mathrm{~J}$ higher than that of Grade 91 of $27 \mathrm{~J}$. Ferritic steel BL-Nb exhibited the lowest impact toughness. Creep tests indicated the superior creep resistance of the four steels at $650^{\circ} \mathrm{C}$ compared to T91. The creep-rupture life ratio of the four steels over T91 at $650^{\circ} \mathrm{C}$ was in the range of 2.60 to 7.29 for the creep stress conditions of 100 and $120 \mathrm{MPa}$.

Microstructure characterizations of the creep-ruptured samples indicate noticeable recovery of T91 with diminished lath/block/packet sub-structures and reduced dislocations to the order of $10^{13} \mathrm{~m}^{-2}$. The limited precipitates with a density on the order of $10^{19} \mathrm{~m}^{-3}$ would not effectively help retain the dislocations and the sub-structures at $650^{\circ} \mathrm{C}$. In contrast, the large number of $\mathrm{B} 2-\mathrm{NiAl}$ and Laves $\mathrm{Fe}_{2}(\mathrm{~W}, \mathrm{Nb})$ with about comparable sizes on the order of $100 \mathrm{~nm}$ and a combined density on the order of $10^{20} \mathrm{~m}^{-3}$ after the creep tests helped retain sub-grain structures of BL-Nb, although the size/density and the chemistry of the precipitates evolved during the creep tests. Similarly, the high-density (on the order of $10^{21} \mathrm{~m}^{-3}$ ) of ultrafine $(<\sim 20 \mathrm{~nm})$ Ti-rich precipitates in TTZ2M and FTT1 helped retain the sub-structures and dislocations during the creep tests. The microstructures of the untested condition indicated refined grains $(\sim 10 \mu \mathrm{m})$ for the heat-treated condition FTN1-T and FTT1-T compared to the general $\sim 50 \mu \mathrm{m}$ or larger prior-austenite grains of the standard condition (FTN1 and FTT1) with tempered martensite structures. The refined grains would explain the enhanced Charpy impact toughness of the heat-treated condition with compromised yield/tensile strength and creep resistance.

FTN1 and FTT1 showed comparable radiation resistance, superior to T91 irradiated under the same conditions up to $250 \mathrm{dpa}$ at 350 and $475^{\circ} \mathrm{C}$, in terms of stabilities of grain structures, dislocations, precipitates, and radiation-hardening. For example, noticeably diminished martensitic sub-boundaries, formation of Z-phase by transformation from MX precipitates, and the greatest radiation-hardening were observed in T91. Although a direct comparison between the rastered-beam (TTZ2M and BL-Nb) and defocused-beam (FTN1, FTT1, and T91) irradiated samples is not available, the radiation resistance of TTZ2M and BL-Nb was not significantly different from the FTN1 and FTT1. However, BL-Nb did show instability of Lave phase, e.g., amorphization of coarse Laves precipitates and disintegration of fine $(\sim 100$ $\mathrm{nm})$ Laves precipitates to form ultrafine $(\sim 8 \mathrm{~nm})$ Z-phase particles.

The large-scale industrial heats FTN1 and FTT1 showed comparable or superior mechanical properties compared with the small laboratory heat TTZ2M, which suggest the property sustainability and scale-up 
fabrication feasibility of the developed ferritic-martensitic steels. The systematic study indicates the successful development of the new ferritic-martensitic steels FTN1 and FTT1. 


\section{REFERENCE}

[1] S.J. Zinkle, L.L. Snead, Annual Review of Materials Research 44 (2014) 241.

[2] B. Raj, M. Vijayalakshmi, R.J.M. Konings, T.R. Allen, R.E. Stoller, S. Yamanaka, Comprehensive Nuclear Materials, Elsevier, 2012.

[3] L. Tan, Y. Yang, Metallurgical and Materials Transactions A 46 (2015) 1188.

[4] Y. Yang, T. Chen, L. Tan, Computational thermodynamic aided design of novel ferritic alloys, ORNL/TM-2016/229, June 30, 2016.

[5] NRIM Creep Data Sheet, No. 43, National Research Institute for Metals, Japan, 1996.

[6] W.R. Corwin, A.M. Hougland, Effect of specimen size and material condition on the Charpy impact properties of $9 \mathrm{Cr}-1 \mathrm{Mo}-\mathrm{V}-\mathrm{Nb}$ steel, in: W.R. Corwin, G.E. Lucas (Eds.), The Use of Small-scale Specimens for Testing Irradiated Material, ASTM STP 888, American Society for Testing and Materials, Philadelphia, 1986, p. 325.

[7] G.S. Was, Z. Jiao, E. Getto, K. Sun, A.M. Monterrosa, S.A. Maloy, O. Anderoglu, B.H. Sencer, M. Hackett, Emulation of reactor irradiation damage using ion beams, Scripta Mater. 88 (2014) 33-36.

[8] S.J. Zinkle, L.L. Snead, Opportunities and limitations for ion beams in radiation effects studies: bridging critical gaps between charged particle and neutron irradiations, Scripta Mater. 143 (2018) 154160. 